\title{
Instructional Leadership for Middle School Students with Disabilities in the General Education Classroom: The Role of the Principal
}

Jeremy M. Lynch

West Virginia University

Follow this and additional works at: https://researchrepository.wvu.edu/etd

\section{Recommended Citation}

Lynch, Jeremy M., "Instructional Leadership for Middle School Students with Disabilities in the General Education Classroom: The Role of the Principal" (2012). Graduate Theses, Dissertations, and Problem Reports. 641.

https://researchrepository.wvu.edu/etd/641

This Dissertation is protected by copyright and/or related rights. It has been brought to you by the The Research Repository @ WVU with permission from the rights-holder(s). You are free to use this Dissertation in any way that is permitted by the copyright and related rights legislation that applies to your use. For other uses you must obtain permission from the rights-holder(s) directly, unless additional rights are indicated by a Creative Commons license in the record and/ or on the work itself. This Dissertation has been accepted for inclusion in WVU Graduate Theses, Dissertations, and Problem Reports collection by an authorized administrator of The Research Repository @ WVU.

For more information, please contact researchrepository@mail.wvu.edu. 
Instructional Leadership for Middle School Students with Disabilities in the General Education Classroom: The Role of the Principal

\title{
Jeremy M. Lynch
}

Dissertation submitted to the College of Human Resources and Education at West Virginia University

in partial fulfillment of the requirements for the degree of

\author{
Doctor of Education \\ In \\ Special Education
}

\author{
Barbara Ludlow, Ed. D., Committee Chairperson \\ Ann Richards, Ph. D. \\ Cathy Galyon-Keramidas, Ed. D. \\ Daniel Hursh, Ph. D \\ Toni DeVore, Ed. D \\ Malayna Bernstein, Ph. D.
}

Department of Special Education

\author{
Morgantown, West Virginia \\ 2012
}

Keywords: instructional leadership; principal preparation; students with disabilities Copyright 2012 Jeremy M. Lynch 


\section{ABSTRACT \\ Instructional Leadership for Middle School Students with Disabilities in the General Education Classroom: The Role of the Principal}

\section{Jeremy M. Lynch}

Instructional leadership is the most important responsibility of today's principal, and no other group of students is in need of an effective instructional leader more than students with disabilities. Effective instructional leaders, especially for students with disabilities, create a supportive learning environment and school culture that promotes the education of all students. Furthermore, effective instructional leaders are knowledgeable of effective instructional strategies and promote the use of such strategies by communicating with and supervising educators. The purpose of this multiple case study was to provide a detailed description of instructional leadership for students with disabilities in an average school system in West Virginia. West Virginia was selected because none of the five principal preparation programs certified by the West Virginia Department of Education requires Special Education coursework. Middle schools were selected because they have some of the highest pupil to administrator ratios and the percentage of students with disabilities in grades six through eight who achieved proficient scores on the West Virginia achievement test (WESTEST2) are amongst the lowest of all grades in West Virginia. Results from interviews with three principals and two assistant principals representing three middle schools in the selected school system indicated that principals have a limited understanding of effective instructional leadership practices and a limited understanding of effective instructional strategies for students with disabilities. Implications for principal preparation programs, professional development, and future research are discussed. 


\section{Dedication}

I dedicate this work to my wife and daughter. Without your unconditional support over the past two years, this would not have been possible. Rose, we did it. Even though you beat me, I am so proud of what we have done. To my parents, thank you for instilling in me the desire to constantly challenge myself and prove I can do what others said I could not. 


\section{Acknowledgements}

I would like express my most sincere gratitude to the members of my dissertation committee Dr. Barbara Ludlow, Dr. Ann Richards, Dr. Cathy Galyon-Keramidas, Dr. Malayna Bernstein, Dr. Toni DeVore, and Dr. Dan Hursh for the countless hours they have dedicated to helping me attain this goal. This work would not have been possible without your individual contributions and guidance. 
Table of Contents

Abstract $\quad$ ii

Dedication $\quad$ iii

Acknowledgements $\quad$ iv

Table of Contents $\quad$ v

List of Tables $\quad$ vii

List of Figures $\quad$ viii

CHAPTER ONE: Introduction 1

Statement of the Problem $\quad 1$

Purpose of the Study 4

Areas of Inquiry $\quad 4$

Research Questions $\quad 4$

Significance of the Study $\quad 5$

$\begin{array}{ll}\text { CHAPTER TWO: Review of the Literature } & 7\end{array}$

Evolution of the Principal $\quad 7$

Roles and Responsibilities of Today's Principal $\quad 14$

Instructional Leadership for Students with Disabilities 16

Current State of Instructional Leadership for Students with Disabilities 20

Conclusion $\quad 25$

CHAPTER THREE: Methodology 27

Design $\quad 28$

$\begin{array}{ll}\text { Setting } & 29\end{array}$

Participants $\quad 36$

Data Collection $\quad 43$

Data Analysis $\quad 50$

Social Validity $\quad 55$

CHAPTER FOUR: Results $\quad 56$

Individual Case Results $\quad 57$

Case Study A $\quad 57$

Case Study B $\quad 67$

Case Study C $\quad 84$

$\begin{array}{ll}\text { Cross-Case Synthesis } & 99\end{array}$

Principals' Roles and Responsibilities $\quad 99$

Cross-Case Analysis of Interviews 101

Summary 126

CHAPTER FIVE: Discussion 128

Summary of the Study 128

$\begin{array}{lr}\text { Summary of Findings } & 129\end{array}$

Conclusions 133

$\begin{array}{ll}\text { Limitations } & 150\end{array}$ 
Implications

References

158

Appendices 


\section{List of Tables}

Table 1: Percent of Students Proficient on WESTEST 2 in Grades 6, 7, and $8 \quad 16$

Table 2: County and State Demographic Comparison 31

Table 3: School System and State Demographics Comparison 32

Table 4: Middle School Demographic Comparison 35

Table 5: Principal Demographic Information 37

Table 6: Special Educator Demographic Information 39

Table 7: General Educator Demographic Information $\quad 40$

Table 8: Assistant Principal Demographic Information 42

Table 9: Individual Case Data Analysis Overview 44

Table 10: Principal Interview Codes $\quad 51$

Table 11: Percent of Students Proficient on WESTEST 2, Case A 58

Table 12: Percent of Students Proficient on WESTEST 2, Case B 69

Table 13: Percent of Students Proficient on WESTEST 2, Case C 86

Table 14: Overarching Themes and Themes 103

Table 15: Creating a Supportive Environment 105

Table 16: Supporting Their Educators 106

Table 17: Changing Educators' Mindsets 107

Table 18: Being an Advocate $\quad 108$

Table 19: Attending IEP Meetings $\quad 110$

Table 20: Scheduling $\quad 111$

Table 21: Creating Instructional Support Time 111

Table 22: Managing Discipline $\quad 112$

Table 23: Managing Funds $\quad 113$

Table 24: Providing Resources $\quad 114$

Table 25: Differentiated Instruction $\quad 115$

Table 26: Students Working Together 116

Table 27: Active Engagement 117

Table 28: Reflecting on Instruction $\quad 118$

Table 29: Teaching to the Middle 119

Table 30: Reaching the Last Page in the Textbook 119

Table 31: The Inclusive Classroom $\quad 120$

Table 32: Pull Out Classrooms $\quad 121$

Table 33: Grouping Students by Ability 122

Table 34: Focusing on the Individual Student $\quad 123$

Table 35: The Standard Stuff 124

Table 36: Observing Teachers $\quad 125$

Table 37: Reviewing Lesson Plans $\quad 126$

Table 38: Interpretations of Principals' Understanding 136 


\section{List of Figures}

Figure 1: Principal Interview Analysis

Figure 2: Educator Interview Analysis

Figure 3: Document Analysis 


\section{CHAPTER ONE: Introduction}

The roles and responsibilities of the contemporary U.S. principal evolved over the last century (DiPaola \& Walther-Thomas, 2003; Searby, 2010; Urban \& Wagoner, 2009).

Historically, principals served as disciplinarians and the teachers supervisor (DiPaola \& WaltherThomas, 2003; Mills, 1974). As a result, principals' job security rested on public perception of the school and the accomplishments of the school's highest achieving students (P. F. Brown, 2006; Herrington \& Wills, 2005). In other words, if a school produced reputable students, the principal was doing a good job. Contemporary U.S. principals' roles have evolved to include more complex, diverse, and demanding responsibilities (P. F. Brown, 2006; Cooner, Tochterman, \& Garrison-Wade, 2005; DiPaola \& Walther-Thomas, 2003; Portin, 2004). Today principals must manage not only discipline and teachers but also government and public relations, finance, instruction, academic performance, and cultural and strategic planning (Cruzeiro \& Morgan, 2006; Hess \& Kelly, 2007; Leithwood, Louis, Anderson, \& Wahlstrom, 2004; Portin, 2004). Although principals have a wide range of responsibilities, researchers indicated that the most critical of these roles is that of instructional leader (Bays \& Crockett, 2007; Boscardin, 2005; DiPaola, Tschannen-Moran, \& Walther-Thomas, 2004; Leithwood et al., 2004).

\section{Statement of the Problem}

The role of the instructional leader is critical for students with disabilities because many of these students fail to meet performance standards or achieve desired educational outcomes as outlined in federal educational policy (Wagner, Newman, Cameto, \& Levine, 2006; U.S. Department of Education [USDE], 2011a, 2011b). Specifically, research indicated that students with disabilities continue to underachieve academically compared to their peers without 
disabilities (USDE, 2011a, 2011b). This achievement discrepancy is evident in West Virginia where only $14.4 \%$ of students with disabilities earned proficient scores on WESTEST 2 in Reading/Language Arts and only $18.1 \%$ of students with disabilities earned proficient scores on WESTEST 2 in mathematics (West Virginia Department of Education [WVDE], 2011a). Second, a report from the National Longitudinal Transition Study-2 (Wagner et al., 2006) regarding the post-high school outcomes of youth with disabilities indicates that students with disabilities (a) attended post-secondary school at a lower rate, (b) were employed at a lower rate, (c) held a job for less time, and (d) earned less money per hour than their peers without disabilities.

Research indicated that principals who create a supportive education environment and ensure the use of evidenced-based instructional strategies have the potential to increase the academic performance and proficiency of these students (Delaney, 2001; DiPaola et al., 2004; DiPaola \& Walther-Thomas, 2003; Praisner, 2003). However, principal preparation programs have failed to prepare graduates for the role of instructional leader, especially regarding students with disabilities (Lasky \& Karge, 2006; McHatton, Boyer, Shaunessy, \& Terry, 2010). McHatton et al. (2010) identified the existence of "a disconnect between the activities school administrators [principals] engage in regularly and the emphasis placed on those activities in their preparation programs" (p. 14). Others highlighted the discrepancy between principals' Special Education preparation and their responsibilities as the instructional leader (Angelle \& Bilton, 2009; Davis, 1980; Lasky \& Karge, 2006). Davis's (1980) survey of 345 principals indicated that only 50\% received Special Education coursework during their preparation programs. Thirty years later McHatton et al. (2010) and Angelle and Bilton (2009) reported similar findings, despite principals' reports of frequent involvement in (a) Special Education 
department meetings, (b) individual education plan (IEP) meetings, (c) Special Education teacher observations, and (d) reviewing Special Education lesson plans.

As pressure to meet Adequate Yearly Progress (AYP) mounts, principals face greater challenges, which make their instructional leadership all the more crucial (Acker-Hocevar \& Cruz-Janzen, 2008; Lasky \& Karge, 2006). Several authors suggested reforming principal preparation programs to meet the demands of the contemporary principal related to instructional leadership for students with disabilities (Cooner et al., 2005; DiPaola et al., 2004; Zaretsky, Moreau, \& Faircloth, 2008). However, these recommendations have not influenced principal preparation, as only eight U.S. states currently require Special Education coursework for principal certification.

West Virginia is not one of the eight states, and has thus far has not updated principal preparation to meet the complex, diverse, and demanding responsibilities of instructional leadership for students with disabilities. Currently in West Virginia, five institutions of higher education (IHE) offer principal certification programs: West Virginia University, Marshall University, Salem International University, Wheeling Jesuit College, and Concord University. Despite research indicating principals with Special Education coursework are more likely to support the education of students with disabilities (Praisner, 2003), none of the five programs include Special Education coursework. Additionally, the WVDE does not require Special Education coursework or preparation for principals (WVDE, 2009). This lack of coursework and preparation creates a critical discrepancy between what they are prepared to do and what they need to do in practice. 


\section{Purpose of the Study}

The purpose of this descriptive multiple case study resided in providing a thick and rich description of how participating principals understand and practice instructional leadership for middle school students with disabilities educated in the general education classroom. This description has the potential to contribute to more appropriate preparation of principals. In accordance with the purpose of this research, the intended audience is the IHEs in West Virginia that offer principal certification and the educational policy makers of the WVDE and in the West Virginia Legislature who develop the certification guidelines for West Virginia principal preparation programs.

\section{Areas of Inquiry}

This study included three areas of inquiry. First, I aimed to develop a better understanding of how participating principals define, communicate, and practice their role as the instructional leader for middle school students with disabilities. Second, I aimed to develop a better understanding of participating principals' perceptions of effective instructional strategies for middle school students with disabilities. Finally, I aimed to develop a better understanding of how participating principals ensure educators use evidenced-based instructional strategies for middle school students with disabilities.

\section{Research Questions}

In accordance with the purpose of this study and areas of inquiry, the following five research questions guided this investigation. These research questions addressed how participating principals define and practice instructional leadership.

1. How do participating West Virginia principals define instructional leadership for students with disabilities? 
2. How do participating West Virginia principals communicate their educational role as the instructional leader for students with disabilities?

3. How do participating West Virginia principals practice instructional leadership for students with disabilities?

4. How do participating West Virginia principals define effective instruction for students with disabilities?

5. How do participating West Virginia principals ensure educators use effective instructional strategies for students with disabilities?

\section{Significance of the Study}

No Child Left Behind ([NCLB], 2002) mandated that all students, including students with disabilities, achieve $100 \%$ proficiency on standardized assessments and have access to highly qualified educators, educated on how to use evidence-based instructional strategies. In order to ensure this outcome, NCLB implemented accountability measures to monitor student performance. As a result, principals are now responsible for the academic proficiency of all students and the use of evidence-based instructional strategies by teachers. Research on the implementation of evidenced-based instructional strategies for students with disabilities revealed that principals influence educators' use of instructional strategies (Boardman, Arguelles, Vaughn, Hughes, \& Klingner, 2005; Boscardin, 2005). Other researchers indicated that principals' willingness to advocate for the use of evidenced-based instructional strategies is related to their knowledge of such strategies (Bays \& Crockett, 2007; Crockett, 2002; Praisner, 2003; Wakeman, Browder, Flowers, \& Ahlgrim-Delzell, 2006).

Nowhere is this more critical than in middle school inclusive classrooms. Specifically, in West Virginia middle schools where pupil to administrator ratios are twice as high as other 
schools and the performance of students with disabilities in grades six through eight is amongst the lowest of all grades (WVDE, 2011a). For West Virginia middle school students with disabilities to meet the goals of NCLB, IHEs and educational policy makers at the state level need to understand how principals serve as instructional leaders, define instructional leadership, and create supportive learning environments. Additionally, they need to understand how principals define, implement, and monitor effective instruction for students with disabilities. Such understanding can help IHEs and educational policy makers to improve principal preparation to address the complex, diverse, and demanding responsibilities of contemporary U.S. principals, especially as they relate to students with disabilities. This research will contribute to this body of knowledge and potentially educate IHEs and educational policy makers about the discrepancy between what principals are prepared to do, and what they are required to do. 


\section{CHAPTER TWO: Review of the Literature}

Evolution is "a process of continuous change from a lower, simpler, or worse to a higher, more complex, or better state" (Merriam-Webster, 2011). The roles and responsibilities of U. S. principals evolved during the $20^{\text {th }}$ century (Kavanaugh, 2005). Traditionally, principals served as the head teacher and then the teachers' bosses (Mills, 1974). In this capacity, they ensured that teachers taught according to a school system's policies and students behaved appropriately. Though performance expectations for students existed, principals were not held accountable for the academic proficiency of all students (Urban \& Wagoner, 2009). Today, the roles and responsibilities of U.S. principals are far more complex and demanding and include the most critical role of being the instructional leader (P. F. Brown, 2006; Leithwood et al., 2004; Searby, 2010). As the instructional leader, principals are now responsible for the academic proficiency of all students, including students with disabilities (Leithwood et al., 2004; NCLB, 2002). In this chapter, I summarized the literature regarding (a) the evolution of the principal; (b) the roles and responsibilities of today's principal, including the most critical role of the instructional leader; (c) instructional leadership for students with disabilities; and (d) the current state of instructional leadership for students with disabilities.

\section{Evolution of the Principal}

According to the literature, the evolution of U.S. principal occurred over four evolutionary periods (a) the head teacher, (b) the teaching principal, (c) the building principal, and (d) the supervising principal (Mills, 1974; Urban \& Wagoner, 2009).

The head teacher. In the late $19^{\text {th }}$ century, the title of principal did not exist (Urban \& Wagoner, 2009), instead, a head teacher served as an educator and a school's disciplinarian. She or he was responsible for keeping records on students and staff while attending to his or her own 
students' instructional needs. The head teacher's purpose was to ensure that both students and teachers followed the rules and to discipline those who broke them.

The teaching principal. U.S. schools became the focus of political debate at the start of the $20^{\text {th }}$ century, when politicians and educational reformers claimed schools were no longer efficient educators of students. At this point the role of the head teacher expanded to the role of the teaching principal (Mills, 1974; Urban \& Wagoner, 2009). Teaching principals assumed responsibility for public relations and school improvement in addition to their roles as teachers and the disciplinarians. They served as conduits between the community and school to help maintain the public's image of the school. The role of the teaching principal had several problems. For example, the school's definition of the duties of these principals was often unclear and inconsistent (Bonar, 1937). Bonar's work discovered varying levels of responsibility for curriculum from school to school, as well as, gender discrepancies between teachers and teaching principals. His survey of 203 principals discovered that $98.5 \%$ of participants were male, even though the overwhelming majority of U.S. teachers at the time were female. The lack of clear roles and responsibilities combined with gender discrepancies caused unrest in schools. To address these problems, Bonar recommended decreasing the number of classes principals taught in order to focus on administrative duties. He also suggested separating the teaching principal from the rest of the staff in order to establish a hierarchy within the school. Bonar believed these changes would establish the principal as an authoritative figure, separate from the school's teachers.

Centralization and the building principal. Despite recommendations to evolve the role of the teaching principal to a building level administrator, or principal, it was not until the centralization of public schools (i.e., the shifting of power away from the local school to 
overseeing multiple schools) in the early to mid $20^{\text {th }}$ century that this change occurred (Urban $\&$ Wagoner, 2009). As school systems began the centralization process, the position of superintendent was created and rapidly expanded (Urban \& Wagoner, 2009). Under the new centralized system, the superintendent assumed more control over the operation and performance of schools (Urban \& Wagoner, 2009). As a result, superintendents created administrative positions at the school level that served as liaisons between superintendent and school. This building level administrator was responsible for ensuring that the school operated according to the superintendent's plan.

However, the teaching principal could not perform the new responsibilities of administration and provide quality instruction, so the role of the building principal emerged. A building level principal, responsible only for administrative duties, helped to maintain efficient and orderly instruction (Urban \& Wagoner, 2009). The role of the principal continued to evolve as principals became responsible for providing instructional leadership, which primarily included supervising teachers (Mills, 1974). Teachers were now accountable for what they taught and were evaluated on their performance.

The supervising principal. In the mid- $20^{\text {th }}$ century, U.S. culture changed as a result of the Civil Rights Movement and enrollment in public schools increased, so the role of the principal evolved once again. In delivering the unanimous decision of the Supreme Court regarding Brown v. Board of Education, Justice Warren famously stated, "We conclude that in the field of public education the doctrine of 'separate but equal' has no place. Separate educational facilities are inherently unequal" (as cited in Urban \& Wagoner, 2009, p. 341). This landmark decision began a series of civil rights actions that created a more inclusive U.S. public school culture (Kluger, 1975). By the mid 1960s, Congress had approved the Civil Rights Act of 
1964, the Economic Opportunity Act of 1964, and the Elementary and Secondary Education Act (ESEA) of 1965. Each increased schools' and building principals' responsibilities by mandating that more students have access to public education (Urban \& Wagoner, 2009).

In response to federal policies and increased enrollment, the role of the supervising principal emerged (Urban \& Wagoner, 2009). The supervising principal was responsible for several aspects of a school's operation including (a) instructional supervision, (b) curriculum development, (c) improvement of instructional methods and materials, (d) finance, (e) facility management, (f) personnel manager, (g) district-wide policy making, and (h) planning and directing educational changes (Mills, 1974). Melton (1971) identified seven skills vital for effective school leadership: (a) group leadership, (b) curriculum development and revision, (c) community involvement, (d) understanding the social-psychological environment of the school, (e) self-evaluation, (f) delegation of clerical duties, and (g) planning advanced professional development for teachers. He argued that principals who were trained and knowledgeable in these seven skills created better learning environments for students, which promoted higher academic performance.

However, 20 years after Melton (1971) and Mills (1974) defined the principal's roles and responsibilities, changes in U.S. public education once again clouded the previously clear responsibilities of instructional leadership. Black (1992) stated, "Even though a great deal of focus has been placed on the importance of principals providing instructional leadership, the construct has remained ambiguous" (p. 7). In response to this role ambiguity, U.S. public education defined the responsibilities of instructional leadership by mandating that principals be accountable for the academic proficiency of all students, including students with disabilities 
(NCLB, 2002). As a result, this last evolution of the U.S. principal far exceeded the previous shift from the head teacher to the supervising principal.

\section{The effect of NCLB on the evolution of the principal.}

Why would anyone want the job of principal? Many school principals we know have the look these days of the proverbial deer caught in the headlights. Almost overnight, it seems, they have been caught in the high beams of the burgeoning accountability movement (Tucker \& Codding, 2002, p. 1).

The current reauthorization of the ESEA, commonly known as NCLB (2002), created a profound impact on the instructional leadership responsibilities of contemporary U.S. principals (Lyons \& Algozzine, 2006). Today's principals are responsible for the academic proficiency of all students, regardless of disability, socio-economic status, or racial/ethnic group, or cultural/linguistic backgrounds. The federal government implemented accountability measures and required schools to make Adequate Yearly Progress (AYP) and to hold principals accountable for the achievement of students (NCLB, 2002).

The aim of NCLB, and its AYP measures, was to raise the academic standards in U.S public schools (Taylor, Stecher, O'Day, Naftel, \& Le Floch, 2010). NCLB was developed with the idea that higher academic standards would increase the academic performance of the lowest performing students (A. B. Brown \& Clift, 2010). Essentially, if schools became more academically rigorous, students, teachers, principals, schools, and states will increase their efforts to meet the higher expectations. To ensure this would happen, NCLB required states to measure the proficiency of all students using standardized tests (NCLB, 2002). Each state was responsible for adopting rigorous academic standards and aligning standardized tests to assess students' knowledge of those standards (NCLB, 2002).

While these policies continue to receive scrutiny from the professional community for failing to increase the proficiency of all students (A. B. Brown \& Clift, 2010; Foley \& Nelson, 
2011), supporters claim the increased accountability ensures that all students receive the same high quality education (Linn, Baker, \& Betebenner, 2002). One point of agreement between both sides is the inadequacy of using standardized tests as the sole measure of performance (A. B. Brown \& Clift, 2010; Foley \& Nelson, 2011; Linn et al., 2002; Reeves, 2003). By allowing each state to develop its own academic standards and standardized tests, NCLB created an unequal system of rewards and punishments (Foley \& Nelson, 2011). For instance, states that created high academic standards risk having higher percentages of schools failing to make AYP, while states that created less rigorous academic standards may have lower percentages of schools failing to make AYP.

This is a critical issue because schools that fail to make AYP benchmarks are subject to corrective action under NCLB and are at risk for losing federal funding (NCLB, 2002). Punitive policies, ranging from implementation of support teams to replacing the school's staff, drive the accountability movement, and place greater demands on the instructional leadership responsibilities of principals (Foley \& Nelson, 2011). As a result of the increase in pressure to make AYP, principals reported higher levels of job dissatisfaction (Foley \& Nelson, 2011) and a growing disconnect between the preparation they receive in their administrator preparation programs and the actual demands of the job (Styron Jr. \& LeMire, 2009).

As more schools failed to meet AYP, more states elected to use corrective action measures that affect the principal's role as the instructional leader. Taylor and colleagues (2010) confirmed principals' concerns about AYP in their report on state and local accountability under NCLB. They found that during the 2004-2005 school year, 54\% of the states that had schools in the corrective action phase replaced school staff in low performing content areas. During the 2006-2007 school year, that percentage increased to 66\%. Similarly, during the 2004-2005 
school year, $46 \%$ of states used the corrective action strategy of significantly decreasing principals' management authority (Taylor et al., 2010). By the end of the 2006-2007 school year, that percentage increased to $62 \%$. During the 2004-2005 school year, 24\% of states used the restructuring strategy of replacing all school staff, including principals. In 2006-2007, the percentage of states using this replacement strategy increased to $46 \%$ (Taylor et al., 2010). In West Virginia, 20\% of schools failed to make AYP at the end of the 2008-2009 school year and by $2009-2010,3 \%$ were identified as in need of improvement and $1 \%$ were in restructuring (USDE, 2010a).

In order to comply with NLCB (2002) mandates, the West Virginia Department of Education (WVDE) developed Policy 2320, A Process for Improving Education: Performance Based Accreditation System (2007) and in it defined the corrective action measures to reform under performing schools. Specifically, if a school continually fails to meet AYP, the WVDE can implement a replacement strategy by "Declaring the position of the principal as vacant, and assigning a principal for the school who shall serve at the will and pleasure of and, under the sole supervision of, the West Virginia Board of Education" (WVDE, 2007, p. 23).

The roles and responsibilities of the U.S. principal have changed drastically from when they were the disciplinarians and the teacher's boss. The most significant changes resulted from NCLB (2002) and state policies such as WVDE Policy 2320 (2007) that required principals to serve as the instructional leader, responsible for the academic proficiency of all students, including students with disabilities. Now a principal's job performance is measured by students' test scores and repeatedly low scores can result in corrective action. 


\section{Role and Responsibilities of Today's Principal}

Principals are no longer just the disciplinarian and the teacher's boss. They now assume broader and more complex responsibilities and are accountable for the academic proficiency of all students, including students with disabilities (DiPaola \& Walther-Thomas, 2003; Leithwood et al., 2004). Educational theorists identified six major responsibilities of today's U.S. principal. First, as managers of personnel, principals ensure the hiring of qualified professionals, which directly affects hiring and mentoring practices. The principal also directly influences educator retention through the development and maintenance of effective mentoring programs (Portin, 2004). Second, as managers of students, principals influence the moral character of students by implementing discipline procedures, and effective discipline procedures create environments fostering the learning of all students (Colvin, 2007). Third, as managers of public relations, principals influence both state and community perceptions associated with the school (Hess \& Kelly, 2007) and serve as liaisons between schools and communities (Portin, 2004). Fourth, as managers of finance, principals are now responsible for tasks once assumed by central office staff such as balancing budgets and fundraising (Portin, 2004). Fifth, as managers of strategic planning, principals develop long-term plans that tend "to the symbolic resources of the school" and promote the school's "vision, mission, and goals" (Portin, 2004, p. 17). Finally, as managers of instruction and academic performance, principals heavily influence the development of learning environments contributing to improved academic performance (Leithwood et al., 2004).

Among all their roles and responsibilities, educational theorists believed instructional leadership is the most critical responsibility of today's principal (Boscardin, 2005; DiPaola \& Walther-Thomas, 2003; Leithwood et al., 2004). Leithwood and colleagues (2004, p. 5) asserted, "Leadership is second only to classroom instruction among all school-related factors 
that contribute to what students learn at school." They defined effective instructional leadership as (a) setting directions and developing a shared vision of the purpose and goals of the school, (b) developing people by promoting best practices and providing educators with support to use those practices, and (c) redesigning the school to create the most effective learning environment using effective instructional practices.

Effective instructional leaders have the ability to influence educators' mindsets about instructional practices (Supovitz, Sirinides, \& May, 2010; Waters, Marzano, \& McNulty, 2003). Waters and colleagues (2003) reported that instructional leaders who had an understanding of effective instructional practices and communicated the importance of using such practices changed educators' attitudes about instruction. Supovitz and colleagues (2010) expanded upon these findings. They confirmed principals' ability to change educators' mindsets and reported that the resulting change in instructional practices led to increased student performance (Supovitz et al., 2010). Furthermore, Quinn (2002) reported a significant correlation between instructional leadership practices and active teaching and learning. Specifically, he reported a significant positive correlation between principals who were perceived as an effective instructional leader by teachers and students and reports of active learning environments. Quinn also reported a significant negative correlation between principals perceived as less skilled instructional leaders and student disengagement.

Gentilluci and Muto's (2007) research supported educational theorists' beliefs on the importance of instructional leadership by examining its effects from a student's perspective. They interviewed 39 eighth graders and inquired about their perceptions of their principal's impacts on their academic performance. They found that students believed their principals had a direct impact on their academic performance by being actively involved in student-centered 
activities related to instruction. One student stated, "She talks to us...kinda like a teacher. It makes me want to do better, you know, make her proud of my schoolwork and stuff. My other principal, she didn't do that. She just stayed in the office" (Gentilluci \& Muto, 2007, p. 229).

Today's principals are required to fulfill many roles and responsibilities. However, none is more important than the role of the instructional leader. As pressure to make AYP benchmarks mounts, principals must learn to be effective instructional leaders because effective instructional leaders have the ability change educators' mindsets towards instruction (Waters et al., 2003), which influences students' learning (Gentilluci \& Muto, 2007; Supovitz, et al., 2010).

\section{Instructional Leadership for Students with Disabilities.}

No other group is in need of effective instructional leadership more than students with disabilities. Students with disabilities continually fail to meet proficiency standards on standardized assessments (Taylor et al., 2010; USDE, 2011a, 2011b). As a result, schools continually fail to make AYP. This is particularly apparent in West Virginia middle schools where the academic performance of students with disabilities is significantly lower than students without disabilities (WVDE, 2011a).

Table 1

Percent of Students Proficient on WESTEST 2 in Grades 6, 7, and 8

\begin{tabular}{|c|c|c|c|c|c|c|}
\hline \multirow{2}{*}{$\begin{array}{l}\text { Proficient on WESTEST 2, } \\
\text { percent, } 2010\end{array}$} & \multicolumn{2}{|c|}{ Grade 6} & \multicolumn{2}{|c|}{ Grade 7} & \multicolumn{2}{|c|}{ Grade 8} \\
\hline & Sw/oD & SwD & Sw/oD & SwD & Sw/oD & SwD \\
\hline Mathematics & 45 & 10 & 44 & 11 & 40 & 8 \\
\hline $\mathrm{R} / \mathrm{LA}$ & 50 & 9 & 51 & 11 & 48 & 8 \\
\hline Science & 41 & 13 & 42 & 12 & 42 & 12 \\
\hline
\end{tabular}


Educational theorists suggested that in order to increase the performance of students with disabilities, especially those students who are included in the general education classroom and participate in standardized assessments, principals must understand and practice effective instructional leadership for these students (Boscardin, 2005; DiPaola et al., 2004; MurtadhaWatts \& Stoughton, 2004).

As part of their role as the instructional leader for students with disabilities, principals must now manage some Special Education responsibilities once managed by directors of Special Education (Boscardin, 2005; Patterson, Marshall, \& Bowling, 2000) such as communicating with parents of students with disabilities, attending individualized education plan (IEP) meetings, and disciplining students with disabilities (Lasky \& Karge, 2006). Results from Lasky and Karge's (2006) survey of 205 principals revealed that $75 \%$ of principals stated that they spent more time involved in Special Education tasks than in previous years.

However, despite the time spent on the managerial tasks of a Special Education program, educational theorists believed effective instructional leaders should be more concerned about creating and maintaining a supportive learning environment for all students and ensuring educators use effective instructional practices. DiPaola and Walther-Thomas (2003) identified five responsibilities of effective instructional leadership for students with disabilities. First, through defining and communicating the school's educational mission, the effective instructional leader emphasizes the importance of educating all students. Second, through managing curriculum and instruction, the effective instructional leader supports teachers use evidencedbased practices. Third, by supporting and supervising teachers, the effective instructional leader demonstrates the school's commitment to teachers, which increases teachers' sense of belonging and self-worth, a critical factor in retaining Special Education teachers. Fourth, through 
monitoring student progress, the effective instructional leader demonstrates the school's commitment to students, which enhances student self-worth and promotes higher academic performance. Finally, the effective instructional leader establishes the same high expectations for all students, including students with disabilities.

Much attention has been placed on the principals responsibility for creating a school's learning environment (DiPaola et al., 2004). The learning environment is not merely physical in nature, but also includes the school's emotional atmosphere, culture, and learning expectations for all students (Billingsley, 2005; Furney, Aiken, Hasazi, \& Clark/Keefe, 2005; Guzman, 1997). A school's culture is not defined by the race, gender, or ethnicity of its students. It is defined by the beliefs and values that the staff and students model. The effective instructional leader for students with disabilities creates a culture that embodies the belief that all students can learn and values every child's right to an education in the least restrictive environment (DiPaola et al., 2004). Furthermore, as effective instructional leaders, principals need to supervise and support the use of evidenced-based instructional strategies for all students by ensuring students with disabilities are in appropriate educational settings and are provided with appropriate accommodations and modifications (DiPaola et al., 2004). They must also monitor instruction (observe educators) and provide educators with opportunities for professional growth regarding evidenced-based instructional strategies (DiPaola et al., 2004; Leithwood et al., 2004).

As part of this responsibility, principals must emphasize how evidenced-based strategies affect the performance of students with disabilities (Praisner, 2003). To be effective instructional leaders, principals must be knowledgeable of, and advocate for, the use of evidenced-based methods of delivery, effective inclusive practices, and the use of appropriate accommodations and modifications (Burns \& Ysseldyke, 2009). 
Two methods of delivery that principals should have knowledge of, due to their proven ability to increase the academic performance of students with disabilities in Reading/Language Arts, Mathematics, and Science, are peer-tutoring (Allsopp, 1997; Mastropieri et al., 2001; Mastropieri et al., 2006) and cognitive strategies (Bakken, Mastropieri, \& Scruggs, 1997; Berkeley, Mastropieri, \& Scruggs, 2011; Witzel, 2005). Researchers reported significantly greater academic performance when students with disabilities were exposed to these instructional strategies instead direct instruction alone.

Principals should also be knowledgeable of effective inclusive practices because researchers highlighted the effectiveness of including students with disabilities in the general education Reading/Language Arts, Mathematics, and Science classrooms (Bowers, 2009; Emery, 2009; Rea, McLaughlin, \& Walther-Thomas, 2002; Warner, 2009). They concluded that students with disabilities who are appropriately educated in general education classroom perform higher on standardized assessments (Warner, 2009) and earn significantly higher grades (Rea et al., 2002).

In addition to understanding and advocating for the use of peer-tutoring, cognitive strategies, and inclusive education, principals also need to understand and ensure the use of appropriate accommodations and modifications because researchers demonstrated the effects of appropriate assessment accommodations on the standardized test scores of students with disabilities (Fletcher et al., 2006; Meloy, Deville, \& Frisbie, 2002; Schulte, Elliott, \& Kratochwill, 2001). They concluded that the use of appropriate assessment accommodations for students with disabilities resulted in significantly higher scores on standardized assessments compared to the scores of those students who were not provided with appropriate accommodations. 
However, despite strong empirical support for various instructional strategies, researchers reported limited use of evidence-based strategies in the classroom (Burns \& Ysseldyke, 2009; Lynch, 2011). To advance the education of students with disabilities, all stakeholders, especially principals, must be knowledgeable advocates for the use of evidenced-based instructional strategies (DiPaola \& Walther-Thomas, 2003). By promoting the use of effective instructional practices, principals have the ability to influence classroom practices and potentially increase the academic performance of students with disabilities (Supovitz et al., 2010). To accomplish this, principals must shift their focus from the managerial aspects of Special Education to the task of ensuring the school's atmosphere, culture, and student expectations creates a supportive learning environment for students with disabilities in the general education classroom (DiPaola et al., 2004).

\section{The Current State of Instructional Leadership for Students with Disabilities}

Certification programs for principals have existed since the role of the building principal emerged in the mid $20^{\text {th }}$ century and have undergone several reforms to meet the changing demands of the job (Kavanaugh, 2005). In the mid 1990s, the Council for Chief State School Officers' (CCSSO) Interstate School Leaders Licensure Consortium (ISLLC) developed standards for school leaders, which emphasize the principals role as the instructional leader (Kavanaugh, 2005). Today over 40 states, including West Virginia, have adopted the ISLLC standards for principal preparation programs (CCSSO, 2008).

However, despite the importance of being effective instructional leaders for students with disabilities (DiPaola \& Walther-Thomas, 2003), many principals received no Special Education instruction during their preparatory programs (Angelle \& Bilton, 2009; McHatton et al., 2010; Styron Jr. \& LeMire, 2009). McHatton et al. (2010) surveyed 159 principals about the formal 
Special Education instruction they received during their principal preparation programs. They reported that only $49 \%$ of principals received formal Special Education instruction, and only $25 \%$ of those principals received instruction on topics other than Special Education law. Angelle and Bilton (2009) found that 53\% of their principals received no formal Special Education instruction during their preparatory program. Rascoe (2007) reported that $77 \%$ of principals from Virginia indicated no formal Special Education preparation.

Lasky and Karge (2006) indicated that $72 \%$ of their principals had little or no direct experience with students with disabilities during their preparation program. One principal responded:

I did not have any classes in Special Education and just one lecture in my administration program ... boy, was I in for some quick learnings. I have four Special Education teachers on my site. Just to show you how naïve I was I did not realize I was required by law to attend the IEP meetings (Lasky \& Karge, 2006, p. 25).

Davidson and Algozzine (2002) and Styron Jr. and LeMire (2009) examined principals' perceptions of their principal preparation programs and the quality of Special Education instruction they received. They reported that only $53 \%$ of their sample rated their programs as satisfactory. Styron Jr. and LeMire (2009) found that only 56\% of their principals reported that their programs adequately prepared them to manage a Special Education program. Wakeman et al. (2006) focused exclusively on principals in secondary settings and reported that $46 \%$ of a sample of 362 indicated no Special Education coursework in their preparatory program. They then asked principals if any course covered Special Education topics (e.g. Special Education law, characteristics of students with disabilities, and IEPs) and reported that $48 \%$ indicated limited exposure (Wakeman et al., 2006). 
Praisner (2003) found the highest percentage of principals with Special Education coursework; $84 \%$ of 408 elementary principals reported Special Education law instruction and $78 \%$ reported instruction on the characteristics of students with disabilities. While these findings are promising, only $50 \%$ of principals received instruction on supporting and preparing teachers for inclusion, and only $45 \%$ received instruction on academic programming for students with disabilities (Praisner, 2003).

Principals' knowledge of evidenced-based instructional strategies. Researchers have found that principals have a limited understanding of evidenced-based instructional strategies for students with disabilities as a result of limited exposure to Special Education content (Barnett \& Monda-Amaya, 1998; Rascoe, 2007). Barnett and Monday-Amaya (1998) found that principals have widely varying definitions of inclusion and how instruction in inclusive settings should occur. They found only $30 \%$ of their sample selected the statement representing effective leadership for inclusive schools, which they defined as creating a supportive school culture and fostering a collaborative environment. In their study assessing principals' abilities to serve as the instructional leader for students with disabilities, Garrison-Wade et al. (2007) conducted focus groups with 25 special educators and asked them to discuss their principal's ability to serve as the instructional leader for students with disabilities in an inclusive setting. Respondents indicated, "My principal says...we're inclusionary, we're inclusionary, but there's no coteaching, kids are pulled and gone from the general ed classroom" and "The administrator has no idea what is going on in the special ed room" (Garrison-Wade et al., 2007, p. 126).

Using case study methodology, Patterson and colleagues (2000) examined a school district's inclusive strategies. They reported that inclusive strategies varied from school to school and determined that one cause of the varied inclusive practices was on principals' 
knowledge of inclusion. At one school, the principal took a less active role as the instructional leader for students with disabilities due to a lack of knowledge regarding effective inclusive strategies, which left teachers to develop and implement their own inclusive program.

Heckert (2009) completed the most comprehensive study addressing principals' knowledge of evidenced-based instruction, using a multiple case study of five elementary principals to describe their understanding of evidenced-based instructional strategies for elementary students with disabilities. Results indicated that four of the five principals expressed at least a moderate level of understanding in regards to the setting, accommodations and modifications, and delivery methods proven to increase positive academic outcomes for elementary students with disabilities. Heckert (2009) defined a moderate level of understanding as the ability to recognize and articulate, "Several practices associated with improved outcomes for students with LD" (p. 126). She also identified a relationship between principals' level of understanding and the amount of Special Education experience. However, principals were purposefully selected based upon referral from the district Special Education director as effective leaders for students with disabilities. Therefore, the five cases selected may not represent the “typical” principal (Yin, 2009).

McHatton et al. (2010) and Rascoe (2008) investigated principals' knowledge of Special Education topics including the use of accommodations and modifications. McHatton et al. (2010) surveyed 159 principals regarding their knowledge of accommodations and modifications and reported that less than $30 \%$ received instruction on accommodations and modifications. Rascoe (2007) described principals knowledge of accommodations and modifications as limited based on principals' responses to scenarios in which they were to identify appropriate accommodations and modifications. 
Principals self-reported abilities. Despite their limited exposure to Special Education content during their preparation programs and resulting limited understanding of effective instructional strategies, research on principals' self-reported abilities to be an instructional leader for students with disabilities produced mixed results. Some researchers found that principals reported a limited understanding of Special Education competencies (Davidson \& Algozzine, 2002; Lasky \& Karge, 2006; Wigle \& Wilcox, 1999). Wigle and Wilcox (1999) reported principals' desire for additional preparation in several aspects of instructional leadership for students with disabilities including (a) developing and implementing flexible service delivery programs, (b) implementing assessment programs for students with disabilities, (c) ensuring that outcomes for individuals with exceptionalities are addressed in the general education curriculum, and (d) developing and implementing programs responsive to individual and family characteristics. Davidson and Algozzine (2002) reported that 53\% of principals surveyed indicated a limited or basic understanding of Special Education policies and procedures and 82\% indicated a need for additional Special Education preparation. Lasky and Karge (2006) reported that $78 \%$ of principals surveyed believed they were not able to support their Special Education teachers and when asked about the need for Special Education preparation, 87\% stated it was important for instructional leadership.

Other researchers found that principals had a high self-reported understanding of Special Education competencies (Garrison-Wade et al., 2007; McHatton et al., 2010). Despite contradictory data from the focus groups with special educators, Garrison-Wade et al. (2007) found that $82 \%$ of principals agreed they were capable of managing an inclusive program, $90 \%$ indicated being able to implement differentiated learning strategies for students with disabilities, and $87 \%$ felt they were capable of creating a collaborative environment between Special 
Education teachers and general education teachers. McHatton et al. (2010) reported that over $70 \%$ of their sample of principals agreed or strongly agreed that they were well prepared to handle issues related to accommodations and modifications, despite the low percentage of principals (less than 30\%) who reported receiving instruction on accommodations and modifications during their preparation program.

\section{Conclusion}

The roles and responsibilities of today's U.S. principal evolved from the head teacher to the instructional leader over the last several years as a result of U.S. educational reforms and most importantly NCLB. Educational theorists and researchers recognized the importance of effective instructional leadership, especially for students with disabilities. Unfortunately, they also identified a less than desirable state of instructional leadership for students with disabilities due to principals' limited knowledge of evidence-based instructional strategies, low self-reported ability to serve as the instructional leader, and limited exposure to Special Education coursework.

In response to the current state of instructional leadership for students with disabilities, educational theorists suggested ways to reform principal preparation programs to better prepare principals for this most critical role (Cooner et al., 2005; DiPaola et al., 2004; Patterson et al., 2000; Zaretsky et al., 2008). They recommended that principal preparation programs incorporate examples and case studies into courses and address Special Education topics through problembased learning, or student-centered discovery learning (Zaretsky et al., 2008). They also recommended adding ISLLC standards specifically for students with disabilities (Cooner et al., 2005; DiPaola et al., 2004) and incorporating Special Education core competencies in preparation programs (Patterson et al., 2000). 
However, in spite of these recommendations, preparation programs have remained relatively unchanged regarding how they prepare principals to serve as the instructional leader (Kavanaugh, 2005), especially for students with disabilities (DiPaola \& Walther-Thomas, 2003. In fact, research indicates that some of today's principals received the same amount of Special Education preparation as principals 30 years ago (Davis, 1980; McHatton et al., 2010). Some researchers suggested that in order to make meaningful changes to principal preparation programs future research should develop an understanding of principals' perceptions and practices of instructional leadership for students with disabilities (DiPaola et al., 2004; DiPaola \& Walther-Thomas, 2003; Heckert, 2009).

This description is needed in West Virginia where none of the five IHEs offering principals certification require Special Education coursework. Furthermore, the most critical place for understanding instructional leadership practices is in West Virginia middle schools, where pupil to administrator ratios are over twice as high as other schools and the academic proficiency of students with disabilities in grades six through eight is significantly lower than students without disabilities, and amongst the lowest in all grades. 


\section{CHAPTER THREE: Methodology}

The principal's role as instructional leader is crucial to the academic achievement of middle school students with LD (Bays \& Crockett, 2007; DiPaola \& Walther-Thomas, 2003; Praisner, 2003). However, principals may have minimal coursework in Special Education during preparatory programs (McHatton et al., 2010) that provides them with only limited knowledge of evidence-based instructional strategies (Garrison-Wade et al., 2007). This leaves schools with instructional leaders ill prepared to create supportive environments and ensure the use of evidence-based instructional strategies for middle school students with disabilities. The purpose of this research is to describe, in-detail, how participating principals practice instructional leadership for middle school students with disabilities. This description may contribute to the more appropriate preparation of future principals by educating educational policy makers in West Virginia about the current state of instructional leadership for middle school students with disabilities. The following five research questions guided this investigation:

1. How do participating West Virginia principals define instructional leadership for students with disabilities?

2. How do participating West Virginia principals communicate their educational role as the instructional leader for students with disabilities?

3. How do participating West Virginia principals practice instructional leadership for students with disabilities?

4. How do participating West Virginia principals define effective instruction for students with disabilities?

5. How do participating West Virginia principals ensure teachers use effective instructional strategies for students with disabilities? 
I organized this chapter into four sections. I open with the Design, where I discuss the research design used to address research questions. Next, I include Recruitment Procedures, where I detail sampling and recruitment procedures. Third, I include Data Collection to detail data collection efforts. Finally, I include Data Analysis, where I detail systematic processes used to analyze data.

\section{Design}

Three factors determine an investigator's choice of research design (Yin, 2009). First and foremost, research questions dictate the selection of the research design as they determine the type of data needed (Crotty, 2003; Johnson \& Christensen, 2012; Yin, 2009). Second, the researcher's ability, or inability, to control extraneous variables (e.g. variables affecting the phenomenon other than the independent variable) further dictates the research design selection (Crotty, 2003; Flyvbjerg, 2011; Yin, 2009). Finally, the context of the phenomenon under investigation (e.g. historical analysis, contemporary phenomenon, etc.) identifies the most appropriate research design (Crotty, 2003; Gerring, 2007; Yin, 2009). Considering all this, I chose the case study as the most appropriate methodology, because it enabled me to describe how or why a contemporary phenomenon (instructional leadership for middle school students with disabilities) occurs in its natural setting (public schools) without controlling for certain extraneous variables (e.g. instructional settings, methods of delivery, etc.) (Flyvbjerg, 2011; Gerring, 2007; Yin, 2009).

Based on the 3 factors described above, I chose a multiple case design because it enabled me to provide an in-depth description of instructional leadership for middle school students with disabilities in a typical West Virginia school system (Stake, 2006; Yin, 2009). The multiple case design investigates two or more cases while using several sources of embedded evidence (e.g., 
interviews, document analysis, etc.) (Scholz \& Tietje, 2002; Stake, 2006; Yin, 2009, 2012). Data collection and analysis for each case occurred independently, while maintaining procedural integrity across all cases (Scholz \& Tietje, 2002). Cross-case synthesis occurred after analysis of the individual cases and allowed me to provide a more robust description of the phenomenon investigated than a single case study design (Johnson \& Christensen, 2012; Swanborn, 2010; Yin, 2009).

Cases. For this investigation, a case consisted of a middle school in the selected school system and included (a) the principal as the primary unit of analysis (Yin, 2009), (b) a special and general educator as the secondary units of analysis when available (Yin, 2009), and (d) the assistant principal, if the principal stated that the assistant principal is responsible for Special Education programming or instruction. For this investigation, I utilized multiple embedded sources of evidence including (a) interviews with principals, (b) interviews with special and general educators, (c) document analysis, and (c) archived records analysis to address my research questions and provide a detailed description of each case.

\section{Setting}

The purpose of this investigation is to provide a thick and rich description of how principals practice instructional leadership for middle school students with disabilities. In accordance with this purpose, I conducted this investigation in three middle schools in West Virginia that educate students with disabilities in grades six through eight.

State sampling procedures. I purposefully chose West Virginia as the setting for this investigation for two reasons: (a) a review of WVDE Policy 5100 regarding Special Education preparation for principals and (b) my convenient access to West Virginia public schools. First and foremost, I purposefully selected West Virginia using critical case sampling (Johnson \& 
Christensen, 2012; Patton, 2002) based on a review of WVDE Policy 5100 (WVDE, 2009). Critical case sampling refers to the selection of a case based the unique nature of the sample that distinguishes it as "particularly important" (Patton, 2002, p. 236), WVDE Policy 5100 provides the legislative rule regarding the approval of educational personnel preparation programs. In it, the WVDE outlines the requirements for principal preparation programs and the preparation each IHE must provide to pre-service principals. Despite evidence that principals with Special Education coursework serve more effectively as instructional leaders for students with disabilities (Lasky \& Karge, 2006; Praisner, 2003) WVDE Policy 5100 does not mandate that principals receive Special Education coursework as a condition of certification (WVDE, 2009). As a result, none of the five IHE's in West Virginia that grant principal certification (i.e., West Virginia University, Marshall University, Salem-International University, Wheeling-Jesuit College, and Concord University) includes Special Education coursework in their certification programs. This represents a critical case that is particularly important to the phenomenon of instructional leadership for students with disabilities.

Second, I purposefully selected West Virginia based on convenience sampling. Convenience sampling refers to the selection of cases based on ease of accessibility (Flick, 2009; Patton, 2002). I lived in West Virginia, which makes these public schools accessible.

School system sampling procedures. As is commonly done in case study research (Bays \& Crockett, 2007; DeMik, 2008; Gerring, 2007; Heckert, 2009; Welch, 2009; Yin, 2009, 2012), I purposefully selected the school system for this investigation using (a) typical case sampling (Patton, 2002). Typical case sampling refers to the selection of cases based on data that "provide(s) a normal distribution of characteristics from which to identify average-like cases" (Patton, 2002, p. 236). This sampling technique aligns with the purpose and audience of 
this investigation by providing a thick and rich description of how principals serve as the instructional leader for middle school students with disabilities in 3 average-like middle schools in West Virginia (Yin, 2009, 2012). First, I purposefully selected the school system for this investigation because it is located in an average-like county in West Virginia based on (a) percent of persons under age 18, (b) percent of females and males, (c) percent of white persons, (d) percent of black persons, (e) percent of Hispanic or Latino persons, (f) median household income, (g) percent of persons below poverty level, (h) persons per household, and (i) percent of person age 25 and over who graduated high school (U.S. Census Bureau, 2012). Table 2 provides a detailed comparison of the county and state demographics.

Table 2

County and State Demographics Comparison

\begin{tabular}{lcc}
\hline & County & WV \\
\hline Persons under 18 years, percent, 2010 & 21.8 & 20.9 \\
Female persons, percent, 2010 & 51.8 & 50.7 \\
Male persons, percent, 2010 & 48.2 & 49.3 \\
White persons, percent, 2010 & 96.4 & 93.9 \\
Black persons, percent, 2010 & 1.1 & 3.4 \\
Persons of Hispanic or Latino origin, percent, 2010 & 0.9 & 1.2 \\
Median household income, 2009 & $\$ 39,229$ & $\$ 37,423$ \\
$\begin{array}{l}\text { Persons below poverty level, percent, 2009 } \\
\text { Persons per household, 2005-2009 }\end{array}$ & 16.5 & 17.8 \\
$\begin{array}{l}\text { High school graduates, percent of persons age 25+, } \\
\text { 2005-2009 }\end{array}$ & 2.31 & 2.37 \\
\hline $\begin{array}{l}\text { Note. Adapted from “State \& County QuickFacts" by U.S. Census Bureau, 2012, retrieved from } \\
\text { http//quickfacts.census.gov/qfd/states/54/54107.html. }\end{array}$ &
\end{tabular}

Second, I purposefully selected the school system because it represents an average-like school system in West Virginia based on (a) percent of students proficient on WESTEST 2 in 
reading and math, (b) percent of students with disabilities proficient on WESTEST 2 in reading and Mathematics, (c) pupil to administrator ratio, (d) pupil to teacher ratio, (e) years of professional experience of school staff, (f) percent of classes not taught by highly qualified teachers, (g) percent of teachers on permit, (h) poverty rate, (i) average class size, (j) dropout rate, (k) attendance rate, and (l) graduation rate (WVDE, 2011b). Table 3 provides a detailed comparison of the school system and state demographics.

Table 3

School System and State Demographic Comparison

\begin{tabular}{lcc}
\hline & School System & WV \\
\hline $\begin{array}{l}\text { SwD enrollment, percent of total enrollment, } \\
\text { 2009-2010 }\end{array}$ & 13.5 & 15.7 \\
Per pupil expenditure, 2009-2010 & $\$ 10,212.2$ & $\$ 10,699.9$ \\
$\begin{array}{l}\text { Proficient on WESTEST2, percent, 2010 } \\
\quad \text { R/LA }\end{array}$ & 44.5 & 41.9 \\
$\quad$ Math & 43.9 & 42.0 \\
SwD proficient on WESTEST 2, percent, 2010 & & 14.4 \\
$\quad$ R/LA & 15.4 & 18.1 \\
$\quad$ Math & 18.1 & $151: 1$ \\
Pupil to administrator ratio, 2009-2010 & $145.1: 1$ & $13.9: 1$ \\
Pupil to teacher ratio, 2009-2010 & $14.4: 1$ & 17.0 \\
Professional experience of staff (average in yrs), & & 84.3 \\
2009-2010 & 17.8 & 5.8 \\
Classes not taught by highly qualified teachers, \\
percent, 2009-2010 \\
Teachers on permit, percent, 2009-2010
\end{tabular}

Note. $\mathrm{SwD}=$ students with disabilities and includes all disability categories recognized by the WVDE (i.e. autism, blindness and low vision, deafblindness, deafness, developmental delay, emotional/behavioral disorder, hard of hearing, mental impairment, orthopedic impairment, other health impairment, specific learning disability, speech/language impairment, and traumatic brain injury. Adapted from "2009-2010 NCLB Report Card" by WVDE, 2011b, retrieved from http://wveis.k12.wv.us/nclb/pub/rpt0910/rptcardC/test2.cfm?sy=10\&cn=096. 
School system recruitment procedures. To recruit the school system for this investigation, I emailed the superintendent a cover letter explaining the purpose of the investigation and requested permission to conduct research activities (see Appendix A for cover letter). The superintendent agreed to participate by printing, signing, and mailing a permission letter that was submitted to West Virginia University's (WVU) Institutional Review Board (IRB) (see Appendix B for permission letter). I mailed a copy of the IRB approval letter to the superintendent for his record.

Middle school sampling procedures. I purposefully selected middle schools using critical case and criterion sampling (Johnson \& Christensen, 2012; Patton, 2002). First, using critical case sampling, I purposefully selected middle schools because the pupil to administrator ratio in middle schools is over twice the school system average (WVDE, 2011b). This large ratio indicates that there are fewer principals in the building, which requires the principal to be skilled in all aspects of instructional leadership. For instance, in a high school with three principals and low pupil to administrator ratio, the principal can delegate some instructional leadership responsibilities to his or her assistant principals. In middle schools with higher ratios, the principal may not have that opportunity. Additionally, I selected middle schools because the percent of students with disabilities who were proficient on WESTEST 2 was lower than the percent of students without disabilities in grades six through eight (see table 1).

Second, using criterion sampling, I purposefully selected all five middle schools in the school system to provide a thick and rich description (Gerring, 2007; Yin, 2012). Criterion sampling refers to the selection of cases based on a set of predetermined criteria (Patton, 2002). The criteria for middle schools included (a) educating students with disabilities in grades six through eight and (b) being accountable for AYP under NCLB and WVDE Policy 2320. I 
selected the criterion of grades six through eight because it represents the grade levels commonly associated with middle school (Emery, 2009; Thurlow, Christenson, Sinclair, Evelo, \& Thronton, 1995; Weidenthal \& Kochhar-Bryant, 2007). All middle schools selected for this investigation educated students in grades six through eight.

I selected the criterion of being accountable for AYP under NCLB and WVDE Policy 2320 because accountability for student proficiency on state standardized tests is of critical importance to instructional leaders (Foley \& Nelson, 2011; Lyons \& Algozzine, 2006). All middle schools selected were accountable under NCLB and WVDE Policy 2320. However, only three principals agreed to participate and allow their schools to be represented in this investigation. Table 4 provides a detailed description of the three middle schools used in this investigation. 
Table 4

Middle School Demographics Comparison

\begin{tabular}{|c|c|c|c|}
\hline & $\begin{array}{l}\text { Middle } \\
\text { School } \\
\text { A }\end{array}$ & $\begin{array}{c}\text { Middle } \\
\text { School } \\
\text { B }\end{array}$ & $\begin{array}{c}\text { Middle } \\
\text { School } \\
\text { C }\end{array}$ \\
\hline Grades & $6-8$ & $6-8$ & $6-8$ \\
\hline Enrollment, FAY, 2010-2011 & 495 & 577 & 328 \\
\hline SwD enrollment, FAY, 2010-2011 & 67 & 54 & 47 \\
\hline $\begin{array}{l}\text { SwD enrollment, percent of total } \\
\text { enrollment, 2010-2011 }\end{array}$ & 13.5 & 9.3 & 14.3 \\
\hline AYP Status, 2010-2011 & NI & NI & NI \\
\hline AYP Status for SwD, 2010-2011 & $\mathrm{F}$ & $\mathrm{F}$ & N/A \\
\hline \multicolumn{4}{|l|}{$\begin{array}{l}\text { Proficient on WESTEST 2, percent, } \\
2010-2011\end{array}$} \\
\hline $\mathrm{R} / \mathrm{LA}$ & 47.7 & 61.9 & 41.0 \\
\hline Math & 44.2 & 50.6 & 45.3 \\
\hline \multicolumn{4}{|l|}{$\begin{array}{l}\text { SwD proficient on WESTEST 2, } \\
\text { percent, 2010-2011 }\end{array}$} \\
\hline $\mathrm{R} / \mathrm{LA}$ & 13.4 & 20.4 & 12.8 \\
\hline Math & 19.4 & 22.2 & 17.0 \\
\hline $\begin{array}{l}\text { Pupil to administrator ratio, 2009- } \\
2010\end{array}$ & $266.5: 1$ & $284.0: 1$ & $100.3: 1$ \\
\hline Pupil to teacher ratio, 2009-2010 & $14.0: 1$ & $15.4: 1$ & $11.5: 1$ \\
\hline $\begin{array}{l}\text { Professional experience of staff } \\
\text { (average in yrs), 2009-2010 }\end{array}$ & 14.6 & 16.5 & 15.9 \\
\hline $\begin{array}{l}\text { Classes not taught by highly } \\
\text { qualified teachers, percent, 2009- } \\
2010\end{array}$ & 10.8 & 9.2 & 6.1 \\
\hline Teachers on permit, 2009-2010 & 1 & 1 & 1 \\
\hline $\begin{array}{l}\text { Low income students, percent, 2009- } \\
2010\end{array}$ & 42.4 & 36.4 & 72.3 \\
\hline Average class size, $2009-2010$ & 21.5 & 22.0 & 17.4 \\
\hline Attendance rate, percent, 2009-2010 & 97.2 & 98.4 & 97.3 \\
\hline
\end{tabular}




\section{Participants}

As is common in research investigating instructional leadership for students with disabilities (Bays \& Crockett, 2007; Garrison-Wade et al., 2007; Heckert, 2009), participants for this investigation included principals, special educators, and general educators who provide direct instruction to students with disabilities in the selected middle schools. I used principals (and assistant principals as needed) as the primary unit of embedded analysis (Heckert, 2009; Yin, 2009) for this investigation because they provide the most direct information regarding instructional leadership at the school level. I used special and general educators as secondary units of embedded analysis (Heckert, 2009; Yin, 2009) to confirm, refute, or expand upon information gleaned from principals.

Principal sampling procedures. I purposefully selected principals (one from each middle school) using criterion sampling. The criterion for principals included serving as the principal of a middle school that educates students with disabilities in the selected school system. Table 5 provides a detailed description of participating principals. Although demographic was collected and reported in the results, I did not include other demographic variables (e.g. gender, age, years of experience, and preparation program) in the selection criteria for principals because I wanted to be able to discuss how instructional leadership varied from school to school based on individual differences between principal (e.g., where they completed their principal preparation program or what subjects they taught prior to entering administration). 
Table 5

Principal Demographic Information

\begin{tabular}{|c|c|c|c|}
\hline & $\begin{array}{l}\text { Principal } \\
\text { A }\end{array}$ & $\begin{array}{l}\text { Principal } \\
\text { B }\end{array}$ & $\begin{array}{l}\text { Principal } \\
\mathrm{C} \\
\end{array}$ \\
\hline Gender & M & M & M \\
\hline Year Certified as a Principal & 2003 & 1990 & 1993 \\
\hline Certification Program & Marshall & University of Dayton & $\begin{array}{l}\text { WV College of } \\
\text { Graduate Studies } \\
\text { (Marshall) }\end{array}$ \\
\hline Years as Principal & 9 & 12 & 13 \\
\hline $\begin{array}{l}\text { Public Education Experience } \\
\text { Years teaching }\end{array}$ & 13 & 18 & 14 \\
\hline Content Areas & Math/Science/Gifted & Health/PE & Math/Soc. St. \\
\hline Experience Instructing SwLD & Yes/Inclusive & $\begin{array}{c}\text { Yes/Dropout } \\
\text { Prevention/Alt. } \\
\text { School Principal }\end{array}$ & No \\
\hline SPED Certification & No & No & No \\
\hline $\begin{array}{c}\text { SPED Courses Taken } \\
\text { Undergraduate }\end{array}$ & 2 & 2 & 0 \\
\hline $\begin{array}{l}\text { Graduate (Unrelated to } \\
\text { Prep Program) }\end{array}$ & 0 & 0 & 1 \\
\hline Preparation Program & 1 & 1 & 1 \\
\hline
\end{tabular}

Principal recruitment procedures. To recruit principals, I first emailed the principals of all five middle schools via professional email addresses publicly available through the state department of education. The email contained a cover letter detailing the purpose of the investigation, the requirements for participation and a demographic questionnaire (see Appendix $\mathrm{C}$ for cover letter). To increase response rates, I informed the principals that by completing and returning the questionnaire they would be entered in a drawing for a chance to win one of three $\$ 50$ gift cards from Amazon.com. Only one of the five principals responded to the initial email 
and he stated he did not think he could help. One week following the initial email, I sent a follow-up email to all five principals. Following the second email, only one principal agreed to participate. I then called the four remaining schools and asked to speak to each principal. Following the phone conversations, two additional principals agreed to participate (including the principal who initial believed he could not help). Finally, I scheduled interviews with participating principals via email (see Appendix F for selection email).

Educator sampling procedures. I purposefully selected general and special educators using confirming and disconfirming sampling (Patton, 2002; Popper, 1959). Confirming and disconfirming sampling refers to the selection of cases based on the important function of "testing ideas, confirming the importance and meaning of possible patterns, and check out the viability of emergent findings with new data and additional cases" (Patton, 2002, p. 239). In order for a special educator and general educator to confirm or disconfirm the information gleaned from principals, they had to provide direct educational services to students with disabilities in the selected middle schools. Table 6 provides a detailed description of each special educator who agreed to participate in this investigation. Table 7 provides a detailed description of each general educator who agreed to participate in this investigation. 
Table 6

Special Educator (SpEd) Demographic Information

\begin{tabular}{lc}
\hline & SpEd \\
Gender & F \\
Year Certified as SpEd & N/A Working on Permit \\
Certification Program & \\
Other Certifications & Elementary Education \\
GenEd Certification & Ohio University \\
Program & \\
Years as SpEd & 2 \\
SPED Courses Taken & \\
Undergraduate & \\
$\quad$ Graduate & 0 \\
Public Education & \\
Experience & \\
Years teaching & \\
Content Areas & English, Science, Social \\
Experience Instructing \\
SwLD \\
$\begin{array}{l}\text { Content Area Instruction } \\
\text { for SwLD }\end{array}$
\end{tabular}


Table 7

General Educator (GenEd) Demographic Information

\begin{tabular}{lc}
\hline & $\begin{array}{c}\text { GenEd } \\
\text { B }\end{array}$ \\
\hline Gender & F \\
Year Certified as GenEd & 2005 \\
Certification Program & WVU Parkersburg \\
SPED Courses Taken & \\
Undergraduate & \\
$\quad$ Graduate & 1 \\
SPED Certification & 0 \\
$\begin{array}{l}\text { Public Education } \\
\text { Experience } \\
\text { Years teaching } \\
\text { Content Areas }\end{array}$ & No \\
& \\
Experience Instructing & 6 \\
SwLD & Elementary/ \\
Note. SwLD = Students with LD; SPED = Special Education.
\end{tabular}

Educator recruitment procedures. Once principals agreed to participate in the investigation, I began recruiting special and general educators from their school. To recruit special and general educators, I first asked the principal which special educators and general educators provide direct instruction to students with disabilities. I then emailed each educator a cover letter detailing the purpose of the investigation, the requirements for participation, and a demographic questionnaire (see Appendix G for cover letter). To increase response rates, I informed the educators that by completing and returning the questionnaire they would be entered in a drawing for a chance to win one of three $\$ 50$ gift cards from Amazon.com. Following the initial email, I received no responses. One week later, I sent a follow-up email to all the educators (see Appendix I for follow-up email). Two educators (one general and special) from 
Middle School B responded to the follow-up email and agreed to participate in the investigation. I then contacted the principals from the other two schools and asked them to talk to their educators about participating. I then attempted to contact the educators again via email. Only one educator responded and he declined to participate. Finally, I attempted to schedule the faceto-face interviews with the educators who agreed to participate. However, the educators stated they did not have the time for a face-to-face interview and asked if it could be completed over the phone.

Assistant principal sampling procedures. During data collection, I encountered that three assistant principals had responsibilities for the instructional leadership of students with disabilities and therefore should be included in this investigation. This is referred to as opportunistic or emergent sampling (Johnson \& Christensen, 2012; Patton, 2002) and is a strength of qualitative research (Flick, 2009; Johnson \& Christensen, 2012; Patton, 2002). However, only two of the three assistant principals agreed to participate. Table 8 provides a detailed description of the two assistant principals. 
Table 8

Assistant Principal (AsstPrin) Demographic Information

\begin{tabular}{|c|c|c|}
\hline & $\begin{array}{c}\text { AsstPrin } \\
\text { B }\end{array}$ & $\begin{array}{l}\text { AsstPrin } \\
\text { C }\end{array}$ \\
\hline Gender & $\mathrm{F}$ & M \\
\hline Year Certified & 2005 & \\
\hline Certification Program & $\begin{array}{l}\text { Salem Int. } \\
\text { University }\end{array}$ & \\
\hline Years as AsstPrin & 3 & $>1$ \\
\hline $\begin{array}{l}\text { Public Education } \\
\text { Experience } \\
\quad \text { Years teaching }\end{array}$ & 16 & \\
\hline Content Areas & $\begin{array}{c}\text { Elementary/ } \\
\text { Middle School } \\
\text { Math }\end{array}$ & $\begin{array}{c}\text { Science/ } \\
\text { Physical } \\
\text { Education }\end{array}$ \\
\hline $\begin{array}{l}\text { Experience Instructing } \\
\text { SwLD }\end{array}$ & Yes/Inclusive & \\
\hline SPED Certification & No & No \\
\hline $\begin{array}{c}\text { SPED Courses Taken } \\
\text { Undergraduate }\end{array}$ & Don't Know & \\
\hline Graduate & Several & \\
\hline Preparation Program & Several & \\
\hline
\end{tabular}

Assistant principal recruitment procedures. I was directed to the assistant principals

by their respective principal. In School B and School C, the principal informed the assistant principal of the interview prior to my arrival at the school. At school B, the assistant principal was asked by the principal to attend the interview with Principal B. The assistant principal completed the demographic questionnaire after the interview was completed. At school $\mathrm{C}$, the principal directed me to one of the assistant principals prior to the interview. The assistant principal agreed to participate on site and completed the demographic questionnaire after the interview. During the interview with Principal C, he mentioned that his other assistant principal 
is responsible for curriculum and instruction. Following the interview, I attempted to recruit the assistant principal by emailing her a cover letter detailing the purpose of the investigation, the requirements for participation, and a demographic questionnaire. One week following the initial email, I sent her a follow-up email (see Appendix I for follow-up email). She declined to participate in the investigation.

\section{Data Collection}

To increase the validity and reliability of multiple case designs, data collection procedures must include multiple sources evidence to the triangulate data (Scholz \& Tietje, 2002; Swanborn, 2010; Yin, 2009). To obtain the thickest and richest description of instructional leadership within the confines of this investigation, I interviewed principals, special educators, and general educators. In addition to participant interviews, I analyzed various documents and use archived records to provide a detailed description of each case. Table 9 displays the research questions each triangulated source of data addresses, the corresponding method of analysis, and purpose of each source. 
Table 9

Individual Case Data Analysis Overview

Research Question

Data Source

Method of Analysis/Purpose

How do participating West Virginia principals define instructional leadership for students with disabilities?

Principal Interviews Coding/Theme development

Educator Interviews Coding/CRE

How do participating West Virginia principals communicate their educational role as the instructional leader for secondary students with disabilities?

Principal Interviews Coding/Theme development

Educator Interviews Coding/CRE

How do participating West Virginia principals practice instructional leadership for students with disabilities?

$\begin{array}{ll}\text { Principal Interviews } & \text { Coding/Theme development } \\ \text { Educator Interviews } & \text { Coding/CRE } \\ \text { Job Descriptions } & \text { Content analysis/CRE } \\ \text { Programming Forms } & \text { Content analysis/CRE }\end{array}$

Principal Interviews Coding/Theme development

Educator Interviews Coding/CRE define effective instruction for students with disabilities?

Principal Interviews Coding/Theme development

How do participating West Virginia principals ensure teachers use effective instructional strategies for students with disabilities?

Educator Interviews

Coding/CRE

Evaluation Forms

Content analysis/CRE

Note. CRE = Confirm, refute, or elaborate Coding = Line-by-line coding (Patton, 2002).

Primary data collection instrument. I used face-to-face interviews as the primary data collection instrument. A predetermined set of open-ended questions guided the interviews (see Appendix $\mathrm{K}$ for principal interview questions and Appendix L for educator interview questions). The interview questions for this investigation were derived from the existing literature on instructional leadership (Boscardin, 2005; DiPaola et al., 2004) and the Special Education knowledge principals should possess (Angelle \& Bilton, 2009; Cooner et al., 2005; GarrisonWade et al., 2007). For principal interviews, I used open-ended interviews with a combination of narrative and standardized open-ended formats. Narrative interviewing techniques allow 
participants to construct his or her understanding of a phenomenon based on life experiences (Rosenthal, 2004). For example, question 1 of the principal interview protocol used the narrative technique and allowed principals to define their role without added influence from the interviewer. Standardized open-ended interviews increase the comparability of responses, and facilitate data organization and analysis (Patton, 2002). The remaining principal interview questions employed the standardized technique to obtain detailed information that addressed the research questions. Educator interviews only used the standardized open-ended format to obtain detailed information that addressed the research questions and confirmed, refuted, or elaborated on information gleaned from principal interviews. This interview technique ensured that all principals and educators were asked the same questions, to facilitate cross-case synthesis (Swanborn, 2010; Yin, 2009). In addition to the predetermined set of questions, I also asked questions to request clarification of topics that emerged during the interview.

Educator interview modifications. Because of poor response rates from educators, I modified the interview format for the educator interviews. Instead of conducting face-to-face interviews, I conducted telephone interviews. The questions for the educator interviews did not change.

Content validity. The primary data collection instrument's content validity and reliability was established by (a) a review of the existing literature on instructional leadership for students with LD, (b) an independent analysis of the principal interview by two principals and one university faculty member with expertise in instructional leadership, (c) an independent analysis of the educator interview by two special educators, two general educators and one university faculty member with expertise in instructional strategies for students with disabilities, and (d) revisions based on the results of a pilot study conducted in April 2011 in a different West 
Virginia school system. The analysis of the interviews by principals, educators, and faculty, along with the results of the pilot study, resulted in changes to the current interview questions. Specifically, based on the results from the pilot study, I chose a more standardized open-ended questions and included only one narrative question in the principal interview. Based on the analysis of the interviews by principals and educators, I reduced the number of questions asked by combining questions and changed the order of the principal interview questions. Based on the analysis of the interview questions by faculty with expertise in interviewing and educational leadership, I restructured the interviews to reflect a more conversational tone and less intimidating terminology. Specifically, in both interview protocols, I replaced the term evidence-based instructional strategies with effective instruction.

Interview procedures: Principals. To conduct each interview with principals, I first contacted each individual via email and scheduled a date and time to conduct the interview in his or her office. Second, at the beginning of the interview, I reminded the principal of the interview's purpose, that participation is voluntary, and that he or she may quit at any time without penalty. I asked permission to audio record the interview for transcription and reviewed confidentiality procedures. Third, once the principal agreed to continue, I asked the first question. I ended the interview when the principal asked to stop or when I finished asking all questions, including questions that emerged during the interview. Fourth, I informed the principal that he or she would receive a transcribed copy of the interview, via email, for review. Finally, using member checking, I gave the principal a week to review the transcription for accuracy and completeness and to make any necessary adjustments. This technique increases the validity and reliability of the findings (Stoner, 2010). The principal returned his or her revised interview transcript to me via email. 
Interview procedures: Educators. To conduct educator interviews, I first contacted each educator via email and scheduled a date and time to conduct the interview via phone. Second, at the beginning of the interview, I reminded the educator of the study's purpose, that participation is voluntary, and that he or she may quit at any time without penalty. I asked permission to audio record interviews for transcription and reviewed confidentiality procedures. Third, once the educator agreed to continue, I asked the first question. I ended the interview when the educator asked to stop or when I finished asking all questions, including questions that emerged during the interview. Fourth, I informed the educator that he or she would receive a copy of the interview transcription via email for review. Finally, using member checking, I gave the educator a week to review the transcription for accuracy and completeness and to make any necessary adjustments. The educator returned his or her revised interview transcript to me via email.

Additional embedded evidence collection. To further triangulate data gleaned from principal interviews, I collected various sources of embedded evidence. This additional embedded evidence refers to any documentation, archival records, observations, or artifacts confirming, refuting, or expanding upon information regarding the primary unit of analysis (Scholz \& Tietje, 2002; Swanborn, 2010; Yin, 2009). For this investigation, I collected and analyzed various documents and collect archived records as embedded evidence that are commonly used when investigating instructional leadership (Heckert, 2009; McHatton et al., 2010; Welch, 2009).

Documentation. I used course catalogs, principal job descriptions, educator evaluation forms, Special Education programming forms, and other documents identified by principals during the interview as documentation. First, I collected course catalogs from the principal 
preparation program coinciding with the year(s) principals were enrolled in the program to determine what, if any, Special Education preparation was included. I used this information to expand upon the information obtained from principals' demographic questionnaires. Second, I collected principals' job descriptions to understand (a) required instructional leadership responsibilities and (b) responsibilities that include language specific to students with disabilities. I used this information to determine the emphasis placed on instructional leadership by the school system. Third, I collected educator evaluations (blank forms) to determine the performance criteria principals used to evaluate educators' use of instructional strategies. I used this information to confirm or refute what principals stated they are supposed to do to ensure the use of evidenced-based instructional strategies. Finally, I collected Special Education programming documentation, including student referral and identification protocols, IEP development forms, and IEP meeting procedures to determine principals' responsibilities for the education planning of students with disabilities if principals mentioned involvement in these activities during the interview. I used this information to provide a thicker and richer description of how principals serve as instructional leaders for students with LD.

Archived records. Archival records differ from documentation in that they involve quantified data regarding the case or phenomenon (Yin, 2009). For this investigation, I included U.S. census data, school enrollment data, NCLB report cards, and WESTEST scores as archived records. First, I collected U.S. Census data to select the county and school system for this investigation. Second, I collected participating schools' enrollment data to provide a detailed description of each school's population and demographics. Finally, I included NCLB report card data and WESTEST 2 proficiency scores to understand the performance of students with 
disabilities in each school as well as information regarding AYP status. I used this information to enhance the in-depth description of each case and the setting of the investigation.

Case Study Protocol. A case study protocol guided this investigation. The case study protocol is similar to an experimental protocol where the researcher follows a pre-determined set of procedures for each phase of the investigation and includes a systematic data analysis process (Scholz \& Tietje, 2002; Swanborn, 2010; Yin, 2009). This protocol is essential for investigations using a multiple case embedded design because it facilitates data analysis procedures for each individual case study and strengthens the results of the cross-case synthesis (Stake, 2006; Swanborn, 2010; Yin, 2009). The data collection protocol for this investigation included several steps.

1. Collect all documents and archived records for Case A

2. Interview principal A using principal interview procedures

3. Interview assistant principal A, if necessary, using principal interview procedures

4. Interview special educator A using educator interview procedures

5. Interview general educator A using educator interview procedures

6. Repeat process for Cases B.

The function of the case study protocol is to assure that the same data collection techniques and procedures are used for all cases, thereby increasing the validity and reliability of the results (Scholz \& Tietje, 2002).

Confidentiality. To ensure confidentiality, I entered all identifiable markers (e.g., names, email addresses, phone numbers) into password-protected database that only I could access. I used email as the primary method of communication prior to conducting the face-toface interviews. All emails went to a password-protected account that only I could access. I 
locked all printed materials, such as demographic questionnaires and audio recordings of interviews in a desk draw in my home office. I assigned each school, principal, special educator, and general educator a letter that replaced names and other identifiable information. The independent observer for this investigation only had access to the data once I removed identifiable markers. I will keep all data until I have exhausted all publication opportunities (approximately three to five years) and then destroy the data.

\section{Data Analysis}

Following the recommended procedures for analyzing data collected during a multiplecase embedded case study, I used cross-case synthesis to describe how participating principals serve as instructional leaders for middle school students with disabilities (Scholz \& Tietje, 2002; Stake, 2006; Yin, 2009). Cross-case synthesis dictates that I analyze each case as a separate study before making any cross-case comparisons or generalizations (Stake, 2006; Yin, 2009). Therefore, I initially focused on analyzing individual cases. After analyzing all cases independently, I compared the results of each individual case to the findings from other cases and synthesized findings from both cases into a description of how participating principals serve as instructional leaders for middle school students with disabilities.

Individual case analysis. I analyzed data from a realist approach, which emphasizes participants' responses and interpretations of the phenomenon they experienced (Crotty, 2003; Flick, 2009). To the maximum extent possible, I removed my interpretations and subjective viewpoints from findings by using multiple sources of evidence to address the research questions. This approach differed from traditional qualitative data analysis where a researcher's interpretations and phenomenological constructs become embedded within the data analysis (Crotty, 2003). 
Principal interview analysis. To analyze principal interview data, I used Patton's (2002)

process for analyzing qualitative data. Through this systematic process, I first coded then classified the data from each interview response line-by-line based upon the topics discussed and the research question the response addresses. Codes emerged from the data as it related to the relevant literature and the purpose of this investigation. Table 10 presents a list of the codes developed from the analysis of the principal interviews.

Table 10

Principal Interview Codes

\begin{tabular}{ll}
\hline Definition of Instructional Leadership & DIL \\
Instructional Leadership: Role-Definition & IL-RD \\
Instructional Leadership: Role-Communicate & IL-RC \\
Instructional Leadership: Practice & IL-P \\
Instructional Leadership: Environment & IL-Env \\
Instructional Leadership: Ensuring & IL-Ens \\
Effective Instruction: Method of Delivery Setting & EI-M \\
Effective Instruction: Setting & EI-M \\
Effective Instruction: Accommodations/Modifications & EI-A/M \\
Ensures Effective Instruction & EEI \\
\hline
\end{tabular}

For example, when asked to describe their role as the instructional leader for students with disabilities, Principal B stated that Assistant Principal B attends IEP meetings. This response was coded Instructional Leadership: Practice. Once the transcripts were initially coded, I reviewed the codes for accuracy and recoded responses as necessary. Following the second coding, I developed words or phrases that represented the overall context of each 
response. I then placed each word or phrase into the corresponding case's word table (see Appendices M, N, and $\mathrm{O}$ for the word tables). Once I created the word tables for each case, I applied the concept of convergence (e.g., how the data agree) (Patton, 2002) to the words or phrases to develop and then strengthen an overarching theme, or pattern in the data. For instance, in their discussions of how they practice instructional leadership, all three principals, and both assistant principals, listed several managerial practices. Based on this convergence I developed the overarching theme of managing the Special Education program. I developed the title for each overarching theme based on what I believed were the underlying meaning of the responses. The words or phrases from the word tables that were used to developed the overarching themes became the themes under each overarching theme If a word or phrase appeared in at least 2 cases, a subtheme was developed. Figure 1 is a visual representation of this process using a response from Principal B.

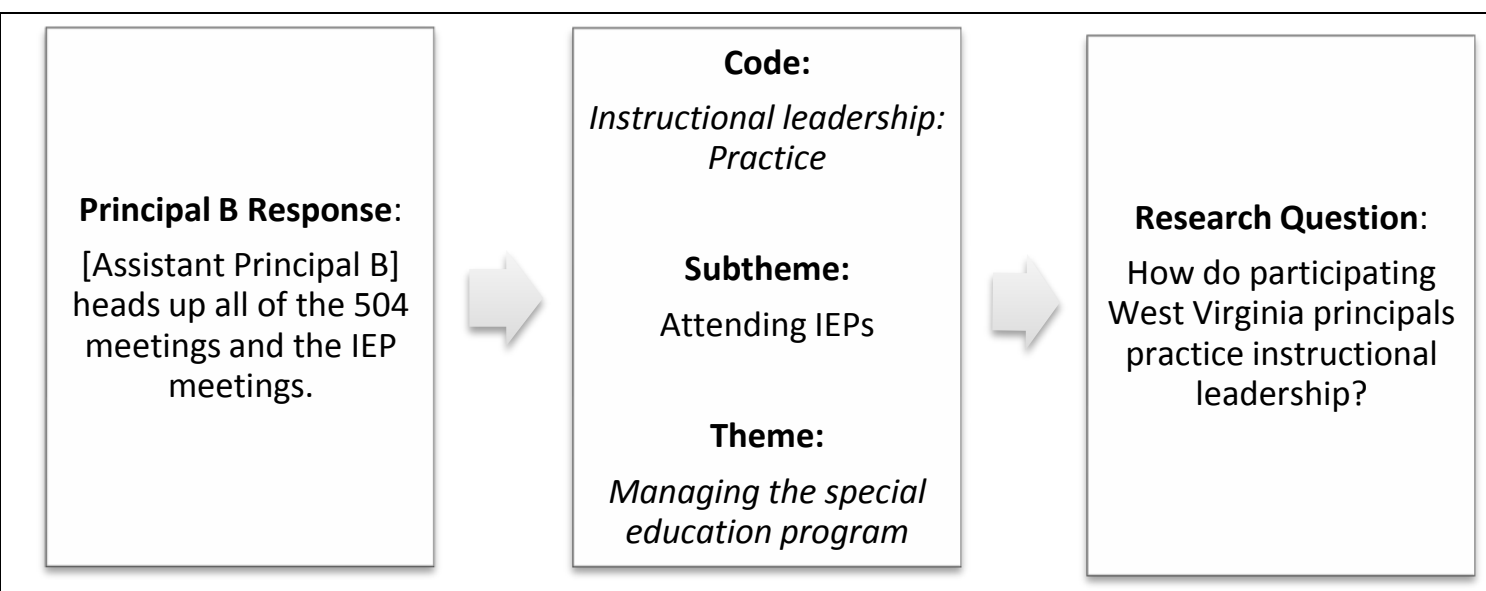

Figure 1. The purpose of this example is to provide a visual representation of the principal interview analysis process that was used in this investigation.

Educator interview analysis. I analyzed educator interviews separately from principal interviews. Once I analyzed a principal's interview, developed themes, and populated a word table, I used the responses from corresponding educators' interviews to confirm, refute, or elaborate on the themes. I did not conduct cross-case synthesis between educators or between an 
educator and another principal. For example, I only used the data gleaned from the interview with Special Educator B and General Educator B to support the data gleaned from Principal B and Assistant Principal B. Figure 2 is a visual representation of how I will use responses from the educator interviews to strengthen the responses from the principals.

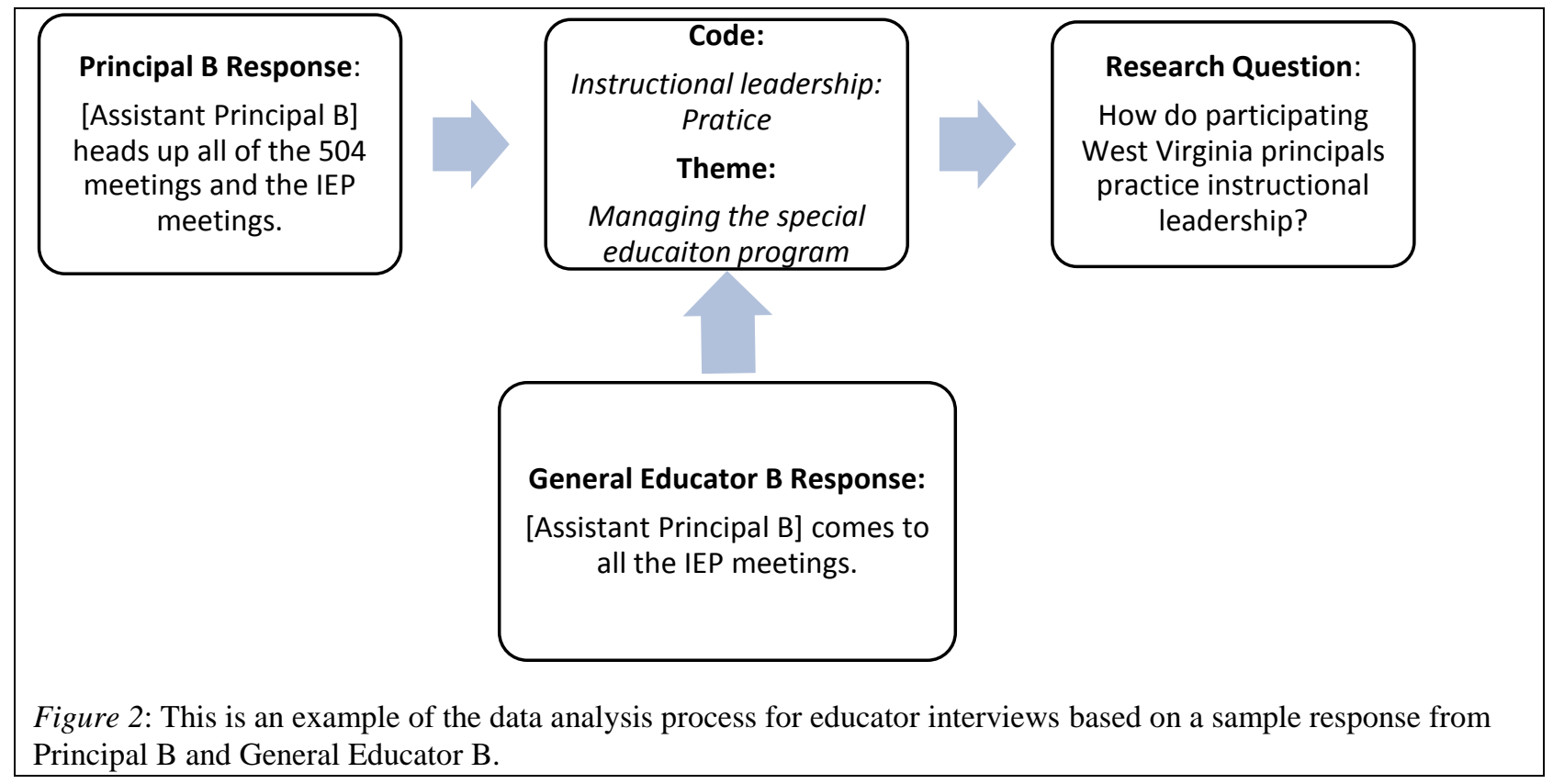

Documentation analysis. I used content analysis (Patton, 2002) to analyze documents to confirm, refute, or expand upon the themes developed from principal interview analysis. I used each document to support a theme and subtheme. For example, I used the principals' job description and the WVDE policy on the education of exceptional children to confirm the principals' role as the IEP chairperson. Figure 3 is a visual representation of this process. 


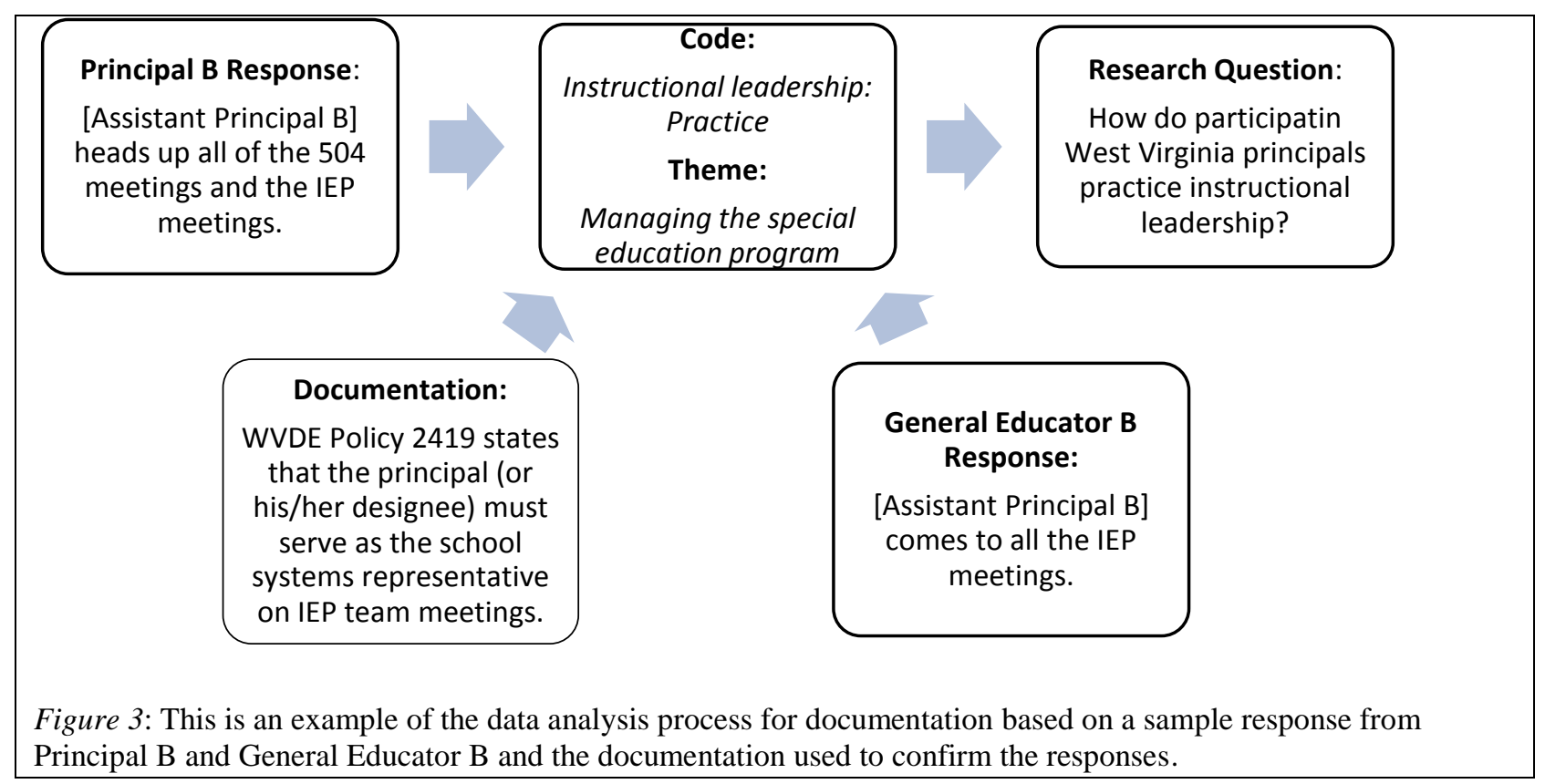

Case Study Database. I used a case study database to record and store all information, organized by themes, in a central location. This practice permitted an independent observer to access all data to confirm or refute the results of the investigation (Irvine, Lupart, Loreman, \& McGhie-Richmond, 2010). The database was provided to the independent observer to verify preliminary results and document inter-observer agreement once the initial coding of the data and the development of propositions was complete

Coding reliability An independent professional with a terminal degree in curriculum and instruction who was trained in qualitative data analysis coded $10 \%$ of the principal transcriptions to establish coding reliability. This is the minimum percentage of the sample that should be used to calculate reliability (Neuendor, 2002). An acceptable level of agreement for this investigation was $90 \%$. Reliability was calculated by dividing the number of agreements with the sum of the total number of agreements and disagreements (Neuendorf, 2002). Initial results produced a coding reliability of $85 \%$. Disagreements in coding were resolved through discussion until $90 \%$ agreement was obtained. Final coding reliability was $95 \%$. 


\section{Social Validity}

Social validity refers to how "applicable and useful" an investigation is to the stakeholders involved (Mertens, 2009, p. 212). I established social validity via two methods. First, the data I gathered from this investigation is applicable to providing a thick and rich description of how principals serve as instructional leaders for middle school students with disabilities. Second, by purposefully selecting a school system that represents an average-like school system in an average-like county in West Virginia and focusing on the critical case of middle school students with disabilities, the data gleaned from this investigation will be useful to my intended audience, educational policy makers in West Virginia. 


\section{CHAPTER FOUR: Results}

The purpose of this multiple case study was to provide a thick and rich description of how participating principals understand and practice instructional leadership for middle school students with disabilities. I used interviews with principals and educators, principals' job description, the WVDE Policy 5310 (Performance Evaluation of School Personnel), WVDE Policy 2419 (Education of Students with Exceptionalities), IEP documents, and archived records to describe instructional leadership in 3 middle schools in an average-like school system in West Virginia based on 13 demographic characteristics (see Table 4 for the School System and WV demographic comparison). The following research questions guided this investigation:

1. How do participating West Virginia principals define instructional leadership for students with disabilities?

2. How do participating West Virginia principals communicate their educational role as the instructional leader for students with disabilities?

3. How do participating West Virginia principals practice instructional leadership for students with disabilities?

4. How do participating West Virginia principals define effective instruction for students with disabilities?

5. How do participating West Virginia principals ensure teachers use effective instructional strategies for students with disabilities?

I organized this chapter in two sections. Section 1 provides a description of the three individual cases. I organized the cases to address the five research questions in a question and answer format. Section 2 includes the cross-case synthesis, which I developed based on my analysis of the principals' job descriptions, teacher observation documents, IEP documents, and 
the common themes from interviews. Because this is a descriptive case study, I did not include my subjective interpretations of the results in this chapter.

\section{Individual Case Results}

\section{Case Study A}

Case Study A focused on a middle school in the selected county and the principal of the school. I obtained the descriptive information for School A from annual report cards available to the public and the descriptive information for Principal A from the demographic questionnaire. I obtained the information used to address the research questions from the interview with Principal A. Despite recruitment efforts, no educators from the school agreed to participate in the investigation.

Description of School A. School A is a middle school in the selected school system that educated 495 students in grades six through eight during the 2010-2011 school year. Of those students, $13.5 \%(\mathrm{~N}=67)$ were students with an identified disability and received services under an IEP, which equaled the school system average and ranked second among middle schools used in the investigation. Additionally, $42.4 \%$ of the students in School A were identified as economically disadvantaged (i.e. qualified for free/reduced meals), which was second lowest among included middle schools (school system average was 49.9\%). School A had the lowest attendance rate of included middle schools at $97.2 \%$ (school system average was $97.5 \%$ ).

Results from the 2010-2011 WESTEST placed the School A in need of improvement because the subgroup of students with disabilities failed to make AYP. Specifically, only $13.4 \%$ of students with disabilities achieved mastery or above in Reading/Language Arts, compared to $47.7 \%$ of general education students and only $19.4 \%$ of students with disabilities achieved mastery or above in Mathematics, compared to $44.2 \%$ of general education students. Compared 
to the other middle schools in the school system, students with disabilities in School A scored second highest in both Reading/Language Arts and Mathematics (Table 11 displays the percent of students with disabilities who earned proficient scores on WESTEST 2 for all 3 schools) Table 11

Percent of Students with Disabilities Proficient on WESTEST2, Case A

School A $\quad$ School B $\quad$ School C

SwD proficient on WESTEST 2, percent, 2010-2011

R/LA $13.4 \quad 20.4 \quad 12.8$

$\begin{array}{llll}\text { Math } & \mathbf{1 9 . 4} & 22.2 & 17.0\end{array}$

Note. $\mathrm{SwD}=$ Students with disabilities; $\mathrm{R} / \mathrm{LA}=$ Reading/Language Arts.

With a pupil to administrator ratio of 266.5:1, School A had one of the highest pupil to administrator ratios in the school system, which had an average pupil to administrator ratio of 145.1:1 and the second highest pupil to administrator ratios among the middle schools used in this investigation. The pupil to teacher ratio of 14.0:1 in School A was lower than the school system average of 14.6:1 and second lowest among included middle schools. School A had the second highest average class size (21.5 students per class) among included middle schools. The average years of experience of the staff at School A was 14.6, the lowest among included middle schools and lower than the school system average of 17.8 years. School A had a higher percentage of classes not taught by highly qualified teachers $(10.8 \%)$ than the school system average of 5.4\%, and ranked School A highest among included middle schools. See Table 5 for a comparison of the three middle schools included in this investigation.

Description of Principal A. Principal A is a male with 9 years of experience as a school principal. He received his principal certification from Marshall University in 2003. Prior to entering administration, Principal A taught Mathematics, Science, and Gifted Education for 13 
years. Principal A indicated that he had experience instructing students with disabilities in his inclusive Mathematics and Science classes. He is not certified as a special educator and has taken three Special Education courses. Two courses were required during his undergraduate teacher preparation program and one course was during his principal preparation program. I reviewed the graduate handbook from Marshall University for principal certification and was unable to confirm the Special Education course. The program guide did not indicate that a Special Education course was required for certification. However, because I could not review Principal A's official transcript or individual course syllabi, I cannot refute his report.

\section{How does Principal A define instructional leadership for students with disabilities?}

Principal A defined instructional leadership for students with disabilities as creating an environment that supports the education of all students, ensuring the use of differentiated instruction, developing the "whole child," and using data to make instructional decisions.

Principal A discussed the importance of creating a supportive environment for students with disabilities because "a student doesn't care how much you know until they know how much you care." He also discussed the importance of promoting the use of differentiated instruction as the instructional leader. He stated,

A lot of teachers just teach to the middle. That's terrible. As principal, I need to make sure that's not happening. We have to find ways to teach all kids. And it's not always the same way for all of them.

Along with differentiating instruction to meet the needs of all students, Principal A believed that instructional leadership is, "Focusing on our kids by developing the whole child." He elaborated on this statement by discussing the need to understand not only how each student performs in the classroom but also the background from which they come.

We have $42 \%$ of students on free/reduced lunch. Well that's a problem. Because when you're giving those kids homework you're sending them with a job to a house where the 
parents don't have a job. Well they don't have a point of reference to go to. They see "Well I don't need to work hard because we I get a check and my dad doesn't work. Why do I need this?"

Principal A stated that this knowledge about a student's home life is crucial for the instructional leader because:

I want the kids to know that we care about them and we value them becoming productive members of society, not just good Social Studies students, or good English students. Because a well-rounded kid is, better off in the long run than a straight A student that doesn't have the caring aspect.

In addition to creating a supportive environment and developing the whole child,

Principal A defined instructional leadership as using data to make instructional decisions and plan for future programming. He believed that data should drive instruction and it is the principal's job to "make sense of it all." He elaborated on this belief by expressing his frustration with the current WESTEST system.

If the state of West Virginia would allow us to take the WESTEST online and get the scores immediately, I'd do it. Just to get the immediate results count me in. We take it May and we don't get the results until August. So we can't use those scores to adjust a kids schedule because we don't get them until after school starts. We don't have all the data analyzed and aggregated and we can't use it as well as we could.

He expressed that receiving the information sooner is necessary because "We have a belief that all kids can and will learn if the circumstances are right, and we just have to figure out what's right and that's an important piece."

\section{How does Principal A communicate his educational role as the instructional leader}

for students with disabilities? Principal A communicates his educational role as the instructional leader for students with disabilities by supporting creative instruction, challenging traditional approaches to instruction, and developing a schedule that allows for specific instructional time he believes is necessary to increase student performance. Principal A discussed how he communicates the importance of creative instruction to his educators. 
I try to be supportive of teachers who are doing outside the traditional box instructional methods by encouraging the teachers to try new things. I can't think of an instance where a teacher came to me and says "I'd really like to try this" and I say no I don't think so. Because if it fails, why did it fail, if it worked, why did it work? You have to look at what you're doing and evaluate what you're doing and then tweak it.

He continued by discussing how he communicates to his teachers his dislike of traditional teaching methods when instructing students with disabilities.

Getting teachers out of their comfort zones and out from behind their podiums. I feel like taking teachers seats and podiums out of the classrooms. I've got one teacher, who's a good teacher, who doesn't get up and move around at all. The kids learn, but I tell him, do you know how much more they'd learn if you got up and moved around and came over into their space. Get the kids up and moving around. You can teach history by getting the kids up and moving around and talking a little bit.

He also discussed how he addressed a teacher's ineffective use of instructional time.

I was so mad at a teacher the other day, she was showing a movie in a class for two days. She was doing it so her other classes could catch up. There's no need for that. I told her she could have been doing some enrichment activities or just moving ahead.

Principal A discussed that the most effective way for him to communicate his educational role as the instructional leader is by building time into the schedule and telling teachers what they will be doing during that time. He believes that data should drive educational decisions and communicating those decisions to students, especially students with disabilities, helps motivate them to learn. Principal A communicated this belief to the teachers by creating the opportunity for teachers to discuss each student's WESTEST scores one on one.

We have sustained silent reading three days a week for 30 minutes. I tell them (teachers), they are going to sit down with their kids in that class and print off their test scores and show them how they've done so they'll have a record of what they are doing. I think it's a tool for kids to see what they're doing and where they need to do better. I'm anxious to see how they've been doing.

\section{How does Principal A practice instructional leadership for students with}

disabilities? Throughout the interview, Principal A discussed how he practices instructional leadership for students with disabilities. Specifically, he discussed attending IEP meetings, 
developing the Special Education program, scheduling, and providing teachers with instructional resources.

When asked about his role as the instructional leader for students with disabilities, the first thing Principal A stated was, "I attend most IEPs. The assistant principal and I attend all of them in some fashion or another." However, he discussed that he does not attend the entire meeting and only makes decisions that involve additional staff or anything else that requires approval from the central office. When asked why he does not attend the entire meeting he stated:

Quite honestly, I do not spend the entire time in the IEP meeting because, although I am in charge, I am not the expert on all the kids' exceptionalities. The teachers have done it for a long time and I trust them.

In addition to attending IEP meetings, Principal A practices instructional leadership for students with disabilities by managing the Special Education program. He discussed the Special Education schedule at his school stating:

I have input on the way the classes are run. I decide whether we are doing inclusion or a pull out program. The vast majority of it is handled through multicategorical classrooms. Right now, we have two multicategorical teachers, one in 6th grade, and one in 8th grade. We are operating the 7th grade like it's a multicategorical inclusion program also, but the person serving in that program is only certified in learning disabilities. So, if we have a kid whose minutes are different, what we do is cross team a little bit. But, we are trying to have the 6th grade teacher go into inclusive classes for 4 periods and then one pull out class, which is normally their strong suit class, Social Studies, reading, etc.

In addition to creating the Special Education class schedule, Principal A stated that he practices instructional leadership by managing student schedules.

Our scheduling is very flexible. We're willing to change their [students with disabilities] schedules a little bit to help them with their basic reading. We have extra health classes. We do [health] all three years when we only have to do it once in their time here. So, we're willing to pull them out of those extra health classes to work on their reading or whatever they need. 
Aside from his managerial responsibilities, Principal A practices instructional leadership for students with disabilities by providing his teachers with instructional resources that he believes promotes the use of effective instruction for students with disabilities. During the interview, Principal A discussed that he believes too many teachers "teach to the middle." $\mathrm{He}$ also believed that too many teachers do not even teach the content that is required for students to reach mastery or above mastery, especially to students with disabilities. In order to address this problem, Principal A provides his teachers with an instructional resource that allows them to monitor the performance level of their content:

On the back of the WESTEST score sheet is a very neat, concise plan for a year. If your child is ranked in mastery, you child is able to do the below mastery stuff, the mastery stuff, and the novice stuff. If they are distinguished, they can do all of it. I have a poster for each of the grades with that. That tells you what you need to expose your kids to. If you teach Math and you never touch anything that is in the distinguished no kid in your room is going to get distinguished. If everything you do is mastery or below nobody is getting above mastery or distinguished. The poster has the sixth, seventh, and eighthgrade curriculum for the four major subjects. Teachers each have that in their classroom at all times.

\section{How does Principal A define effective instruction for students with disabilities?}

Principal A discussed what he believes is effective instruction for students with disabilities regarding methods of delivery, setting, and accommodations and modifications.

Methods of delivery. Principal A's definition of effective methods of delivery for students with disabilities focused on peer interaction and active engagement. When asked to describe what he thought was effective instruction for students with disabilities, he stated:

Appropriate interactions with their peers and their instructors. Breaking the idea that the teacher is just the deliverer of the goods. A lot of teachers still like to lecture and that's not the way that kids with disabilities learn. They need hands on stuff and real life examples. Get them working together.

He elaborated on this statement by discussing what some teachers believed was effective instruction: 
Teachers want to start at page 1 and get to page 376 . They think that if I don't get to page 376 it was a bad year and if I get to 390 it's awesome. The kids need more than that out of a teacher.

Setting. Principal A discussed, in detail, what he believes is the most effective

educational setting for students with disabilities. When discussing the inclusion program at his

school, he stated:

I can see both sides of the argument. My own opinion is that I don't think it is the best way to do it. We have kids who have a disabilities, that have average or above IQ that a deficiency, in with kids that have BD and with kids that are low functioning. To put them into one classroom isn't actually addressing their specific needs. The inclusive classroom is not the solution.

He supported this statement by discussing changes he made to the Special Education

program at his school:

We've done a lot of homework and what we learned was flexible ability grouping works. Taking kids' strengths and weaknesses and moving their schedule around so you can address their needs by putting them with people that have the same strengths and weaknesses. We tried to make a group of the top students, a couple groups of the middle [students], and a group of the low [students]. We tried to keep the low student group as small as possible and accelerate the top students in a bigger class because you have less problems. We did that across the board and we were flexible with it.

Principal A believed the program was effective because the inclusive special educators

had a "larger umbrella of influence." In this program, the special educators went with the low-

level classes where they could provide direct support to more students than heterogeneously

grouped classes. However, the Board of Education disagreed with the program and forced him

to change the way he scheduled courses:

When I talked about how good we thought it was going, the board members jumped stiff legged and said, "Well that's leveling." I'm like yeah it is and I know the literature that shows leveling is bad for kids self esteem. But can show you where like ability grouping is good for their academics. But we had go back and rearrange and put more in the blender so it's more homogeneous. 
Accommodations and modifications. Principal A's discussion of accommodations and modifications focused on students with disabilities and students on 504 plans. He explained that his school provides accommodations and modifications based on the individual needs of the students addressed by the IEP team. He expressed his belief that accommodations and modifications should be meaningful and allow the student to have a better chance at success. Although he agrees with providing accommodations and modifications, Principal A stated, "The standard stuff, most of them are crap." When discussing preferential seating he stated, "You shouldn't need an IEP for that. You put the kid in the front if he needs it or you put him in the back if he needs that." He specifically addressed a modification that he believed was too common and not meaningful:

We try to keep them from just saying they [students] only have to do half the work. Some people have hung onto that idea that you have to do 35 homework problems in Math just to prove you can work hard. I don't buy into that. Don't just say he only has to do half of the 35 problems. Just make him show what he can do. If he can do it in a couple of problems that's all you need.

Principal A's discussion of accommodations and modifications for students with disabilities included the use of testing accommodations and modifications, specifically reading tests aloud. He stated, "Our teachers are very good about allowing kids to come to the Special Education class for reading tests aloud."

\section{How does Principal A ensure teachers use effective instructional strategies for} students with disabilities? Principal A ensures teachers use effective instructional strategies for students with disabilities by observing teachers, reviewing lesson plans, and providing feedback on lesson plans. He stated, "I try to be in the classroom and observe what's happening on a routine basis so I know that the subjects that are being covered are educationally appropriate and that we're following the CSO's for the state." Principal A stated that the majority of his efforts to 
ensure the use of effective instructional strategies focused on reviewing lesson plans and providing feedback:

When the teachers turn in their lesson plans I go over them a couple times a month. I'll sort through and make a checklist to see what they are doing. I'm pretty good about not letting teachers turn in last year's lesson plans with new dates.

He discussed how monitoring lesson plans allows him to ensure teachers use instructional time effectively and reinforced how he communicates it to them:

I've worked with teachers that thought they could do six months worth of lesson plans. I told them that's not possible because if you have six months of lesson plans and every class is doing the same thing one class is going to be faster and they're going to have 20 minutes of dead time and one class is going to be slower and they're going to be behind. Do not have stall time built into your teaching. If you have people ahead take them further. Make some flexibility.

Summary. School A was second among the middle schools in this investigation in percent of students with disabilities, percent of economically disadvantaged students, WESTEST performance in Mathematics and Reading/Language Arts, pupil to administrator ratio, pupil to teacher ratio, and class size. It had the lowest attendance rate, the highest percent of classes not taught by a highly qualified teacher, and the lowest average years of experience of school staff.

Principal A defined instructional leadership for students with disabilities in terms of creating a supportive environment for students, ensuring the use of differentiated instruction, developing the "whole child," and using data to make instructional decisions. In order to communicate those roles, he created a school climate where creative thinking and non-traditional approaches to instruction are encouraged. Principal A also emphasized how he communicated the importance of using data to drive instruction and motivate students by creating instructional time dedicated to using WESTEST data. As the instructional leader, Principal A stated he attends IEP meetings, manages the Special Education program, and provides teachers with 
instructional resources. He emphasized the development of content posters to increase student exposure to higher-level skills.

In addition to exposing students to higher-level skills, Principal A stated that effective instruction for students with disabilities should include peer interactions and active engagement with the teacher and curriculum. Although the Special Education program at School A primarily educates students with disabilities through an inclusive model, Principal A expressed his concerns with inclusive education and discussed a failed attempt to make classrooms more homogeneous. When asked about accommodations and modifications, he stated that his school provides meaningful accommodations and modifications that allow students to have a better chance but only directly mentioned the read tests aloud accommodation. To ensure teachers use effective instructional strategies for students with disabilities, Principal A discussed observing teachers, reviewing lesson plans, and providing feedback on lesson plans. He emphasized the importance of providing feedback on lesson plans to ensure teachers use instructional time effectively.

\section{Case Study B}

Case study B focused on a middle school in the selected school system. Participants for this case included the principal, assistant principal, a general educator, and a special educator. I obtained the descriptive information for School B from annual report cards available to the public and the information for Principal B, Assistant Principal B, General Educator B, and Special Educator B from demographic questionnaires. Assistant Principal B was recruited on site at the request of Principal B. Also, at the request of Principal B, the principals were interviewed together. I obtained the information used to address the research questions from the 
interview with Principal B and Assistant Principal B. I confirmed, refuted, and elaborated on the principals' responses with the educator interviews.

Description of School B. School B is a middle school in the selected school system that educated 577 students in grades six through eight during the 2010-2011 school year. Of those students, $9.3 \%(\mathrm{~N}=54)$ of the population, have been identified as a student with a disability and received services under an IEP, which was less than the school system average and lowest among middle schools used in this investigation. Additionally, 36.4\% of the students in School B were identified as economically disadvantaged students during the 2009-2010 school year, which is below the school system average of $49.9 \%$ and lowest among included middle schools. School B had the highest attendance rate of included middle schools during the 2009-2010 school year (98.4\%). The attendance rate at School B was also higher than the school system average of $97.5 \%$.

Results from the 2010-2011 WESTEST indicated that the school was in need of improvement. School B was labeled as in need of improvement because the subgroup of students with disabilities failed to make AYP. Specifically, only $20.4 \%$ of students with disabilities achieved mastery or above in Reading/Language Arts, compared to $61.9 \%$ of general education students, and only $22.2 \%$ of students with disabilities achieved mastery or above in Mathematics, compared to $50.6 \%$ of general education students. Compared to the other middle schools in the school system, students with disabilities in School B scored highest in both Reading/Language Arts and Mathematics (Table 12 displays the percent of students with disabilities who earned proficient scores on WESTEST 2 for all 3 schools) 
Table 12

Percent of Students with Disabilities Proficient on WESTEST2, Case B

\section{School A}

SwD proficient on WESTEST 2, percent,

2010-2011

R/LA

Math
13.4

19.4
School B

20.4

22.2
School C

12.8

17.0

Note. $\mathrm{SwD}=$ Students with disabilities; R/LA = Reading/Language Arts.

With a pupil to administrator ratio of 284.0:1, School B also had one of the highest pupil to administrator ratios in the school system (school system average $=145.1: 1$ ) and the highest pupil to administrator ratios among the middle schools in this investigation. The pupil to teacher ratio of 15.4:1 in School B was higher than the school system average of 14.6:1 and highest among included middle schools. School B had the highest average class size (22.0 students per class) among included middle schools. The average years of experience of the staff at School B was 16.5, the highest among included middle schools and lower than the school system average of 17.8 years. School B had a higher percentage of classes not taught by highly qualified teachers $(9.1 \%)$ than the school system average of 5.4\%, and ranked second highest among included middle schools. See Table 5 for a comparison of the three middle schools included in this investigation.

Description of Principal B. Principal B is a male with 12 years of experience as a school principal. He received his principal certification from the University of Dayton in 1990. Prior to entering administration, Principal B taught Health and Physical Education for 18 years. Principal B indicated that he had experience working with students with disabilities as a dropout prevention specialist and the principal of an alternative school for 4 years. He was never certified as a special educator and has taken three Special Education courses. Two courses were 
required during his undergraduate teacher preparation program and one course was during his principal preparation program. I reviewed the graduate handbook from the University of Dayton for principal certification and was unable to confirm the Special Education course. The program guide did not indicate that a Special Education course was required for certification. However, because I could not review Principal B's official transcript, I cannot refute his report.

Description of Assistant Principal B. Assistant Principal B is a female with 3 years of experience as a school principal. She received her principal certification from Salem International University in 2005. Prior to entering administration, Assistant Principal B taught $4^{\text {th }}$ and $5^{\text {th }}$ grade for 3 years and middle school Mathematics for 13 years. She indicated that she had experience working with students with disabilities in both an inclusive elementary and an inclusive Mathematics classroom but was never certified as a special educator. Assistant Principal B reported taking several Special Education courses. She reported that she could not remember if she took any Special Education courses during her teacher education program but reported taking several during her principal preparation program and several others unrelated to a degree or certification. I reviewed the graduate handbook from Salem International University and was unable to confirm the Special Education courses. However, because I could not review Assistant Principal B's official transcript, I cannot refute her report. Assistant Principal B reported that she has taken several Special Education courses unrelated to a degree or certification because she has a family member with a disability.

Description of Special Educator B. Special Educator B is a female with 2 years experience as a special educator. She received elementary teaching certification from Ohio University in 2000. She was working as a special educator on an Emergency Permit from the WVDE while attending West Virginia University for her Special Education certification. She 
anticipated completing her degree in two or three years. She educated students with disabilities in the inclusive and pull-out settings and provided content instruction in English, Science, and Social Studies. Special Educator B reported that she has taken four Special Education courses at the graduate level as a requirement of her Special Education certification. She reported no Special Education courses during her undergraduate teacher education program.

Description of General Educator B. General Educator B is a female with 6 years of teaching experience. She received her undergraduate teaching certification from West Virginia University at Parkersburg in Elementary Education in 2005. She is certified to teach middle school Reading/Language Arts. She reported working with students with disabilities in an inclusive Reading/Language Arts classroom. General Educator B reported that she is not certified in Special Education and took one Special Education course during her teacher education program.

\section{How do Principal B and Assistant Principal B define instructional leadership for}

students with disabilities? Principal B and Assistant Principal B defined instructional leadership for students with disabilities as supporting teachers and advocating for students with disabilities. Throughout the interview, Principal B discussed the importance of supporting teachers and the role he has in creating a supportive environment for teachers.

I think the impact that we can have on Special Education is that we need to make sure that teachers understand we're here to provide support for them. It's a difficult job being out there in that classroom and dealing with all the things that they have to do. So they have to feel like we've got their back.

Special Educator B confirmed the support that the principals discussed. She stated, "He's our motivator. He's kind of like our little pep squad. He tells us the difference we make in the environment." 
Assistant Principal B echoed the need to support teachers stating, "They've got to know that we support them and what they are doing. We'll take it from the parents or the Central Office so they don't have to."

In addition to supporting teachers, Principal B also defined the role of the instructional leader for students with disabilities as being an advocate:

It's also important that the administration be advocates for kids. Because they [teachers] tend to forget and they need reminded that we're in the business to help kids, all kids. Not just the ones that are going to Harvard and Princeton and not just the ones that are going to college. They're here to help kids, all of them. If the faculty senses that we don't care, for sure they're not going to care.

In discussing the role of Assistant Principal B, Principal B stated:

[Assistant Principal B] is a huge advocate for struggling students and I think I've learned a lot from her. In this building, there is a genuine concern of nurturing and understanding. As far as instructional leadership goes that is important.

Assistant Principal B also believed that advocating for students is part of instructional leadership:

You've got to advocate those kids, especially the ones out in the classrooms with the other kids. You've got to give them a chance and you've got to make sure everyone sees that. Without support they'll fall behind or just be forgotten.

Neither General Educator B nor Special Educator B mentioned the principals being advocates for students with disabilities or creating a supportive environment during the interview. When asked what she thought would be effective instructional leadership for students with disabilities, Special Educator B stated:

I don't know if that is a role that they should be stepping into. The teachers are the ones who work closely with the students and are aware of the student's strengths, needs, and they should be the ones doing it. They have access to the CSOs and they should be the ones that weave in the CSOs based on those individual strengths and needs. I don't think that is something the principal can do anything about. 
When asked the same question General Educator B stated, "I don't know that my principals could bring the answer. I think the answer lies way before we get to the principal."

\section{How do Principal B and Assistant Principal B communicate their educational roles}

as the instructional leader for students with disabilities? Throughout the interview, when

Principal B talked about communicating his role as the instructional leader, he discussed

changing the current mindset of the teachers. He explained that the current mindset is a problem

for students with disabilities:

We're still in the process of transitioning to a different mindset. Here's the dilemma that's facing Special Education. You got a lot of people, a lot of veteran teachers in West Virginia that have gone beyond retirement or into their 60 s and they can't retire.

Probably the top 3/4 of the teaching force in WV have gone through as students and then have gone through the early part of their teaching when Special Education kids were pulled out and in many cases weren't even in the same building. Now what you're seeing is all transitioning to inclusion. And inclusion, we're still working on getting acceptance with inclusion.

Principal B and Assistant Principal B discussed how they work to change the current mindset in order to create a supportive environment for students with disabilities. Principal B stated:

We've worked this year just trying to just change the mindset through our vision statement, our philosophy on how we're going to teach these kids. Trying to convince and train teacher to understand that in your classroom you can teach different levels. How do you get beyond the mindset we're doing them a disservice? Well I suppose when they get out in the real world somebody's going to do that. No the idea is to get them out in the real world with some skills.

Assistant Principal B supported repeated attempts to change teachers' mindset:

It's not going to be an overnight thing. We're just chipping away at it and we're making progress. And the way you chip away at is you discuss it with teacher. You try to find teachers who are modeling it and praise them.

Principal B highlighted one strategy that he uses to help change teachers' mindset:

We do things in a roundabout way. For example, we'll get an office referral for a Special Education students and it will say will not work in big letters, insubordinate, "sleeping in 
class and they want us to bust them down here for that. We're stopping that trend because by saying well Mrs. Whoever what are you doing different for this student. This is a low-level kid, we had him in ISS and according to your plans, and you sent the same worksheet for him that you gave the rest of your students in the classroom. He can't even read. Now how are they supposed to be doing it? No wonder he's got his head down. I'd be doing the same thing. No wonder he's acting out. The teachers are starting to figure it out. If you're going to send somebody down there to the office there better be some indication of differentiated instruction or we're going to send them back.

Both General Educator B and Special Educator B confirmed that Principal B communicates to teachers regarding instruction for students with disabilities. General Educator B stated, “[Principal B] has talked to us several times about differentiation.” Special Educator B discussed how Principal B communicates to teachers:

He sends out twice-daily emails about anything that is coming down the line to give us a heads up. Letting us know things that are going on in nearby counties that we need to be aware of. Changes coming forth in education. He's kind of our heads up on all of that.

In addition to communicating with educators, Principal B discussed how he also communicates his role as the instructional leader by changing parents' mindsets while discussing the use of collaborative pairs for students with disabilities:

One thing we're finding with group work... because it's something new and it's a new thing in education, these collaborative pairs and letting kids have hands on stuff. Now we're having to educate the community about the values of that because that didn't happen when they were in school. It was all lectures. We get parents that say, that teacher doesn't do anything but sit up there. Well they don't just sit there, they're monitoring and guiding and the kids are talking.

\section{How do Principal B and Assistant Principal B practice instructional leadership for}

students with disabilities? In addition to communicating their educational roles as the instructional leader to the staff, Principal B and Assistant Principal B practice instructional leadership for students with disabilities by attending IEP meetings, managing discipline, and managing the Special Education program. Specifically, Principal B stated:

[Assistant Principal B] works directly with the Special Education teachers. She heads up all of the 504 meetings and the IEP meetings. She works with staff on creating and 
implementing behavior management plans. At the building level, she deals with a lot of those [behavior] meetings and observations.

Assistant Principal B elaborated on this role:

We have about seven or eight students who because of their discipline issues we picked them out at the beginning of the year and put them on behavior plans because if we didn't their suspensions days would have been much higher. We believe that if you put things in writing for kids and you let them know these are your expectations it tends to nip it a lot faster. They know what their limitations are they've been good. For several of them it's really worked.

Both educators confirmed Assistant Principal B's role regarding students with disabilities. When asked to describe either principal's relationship to instruction for students with disabilities, General Educator B stated, "Well I know that the assistant principal is the person I would go to if I had questions or if I wanted information. She's the person that comes to all the IEP meetings and SAT meetings." Special Educator B stated, "The assistant principal is in charge of attendance, discipline, and she works closely with the SPED team. Doing behavior plans and stuff."

Principal B stated that he practices instructional leadership for students by assisting the assistant principal with discipline issues:

If there are issues that she can't solve that she's dealing with it lands over here when the parent gets upset. Then it's the old saying the buck stops here. I end up saying the same thing but because it came from [my office] its final.

Special Educator B confirmed the principal's role in discipline by stating, "The principal is the go to for discipline if we need to bring him in above what is being done with the assistant principal.

Aside from student discipline and IEP meetings, Assistant Principal B believed the most important managerial practice for the instructional leader is ensuring Special Education compliance. 
You just have to make sure your ducks are in a row in Special Education. Really, I mean if you do the paperwork right and you make sure the kids' needs are met you won't have any issues. We've had plenty of advocates in this building, and we haven't had any issues with them. But it takes a lot of work.

Principal B confirmed the challenges of being the assistant principal who serves as the disciplinarian for the school, manages attendance, and handles Special Education issues.

When I started 12 years ago, we had about 14 to 16 non-gifted Special Education kids. Today we're well over 50. It's gotten to the point where if you look at her duties and job descriptions you could almost say. You're not doing discipline anymore, you're not doing observations anymore. All you're doing is Special Education. In a school this size, you should have a principal, an assistant principal, and a Special Education director in the school.

When discussing how he practices instructional leadership for students with disabilities, Principal B discussed how he manages the Special Education program by managing funds and resources:

We have an autism program now. My role is getting the phone call [from central office] and being told, 'you're getting a new program next year, now find ways to fund it.' Well I don't have any ways to fund it. 'Well find it.' And getting the call saying, 'You're going to have a new program and you're going to need a room.' Well we don't have a room. 'Find it.' So, we try to be flexible, we find ways to get creative with our schedule.

Although General Educator B and Special Educator B confirmed the principals' roles as instructional leaders for students with disabilities regarding discipline and meeting attendance, both educators articulated different perceptions of instructional leadership when asked about their principals' relationship to instruction. When asked about Assistant Principal B's relationship to instruction for students with disabilities, Special Educator B stated, "To instruction, really none. She's more discipline and attendance. Instruction is left to the teachers." She continued by discussing Principal B's role as the instructional leader for students with disabilities. She stated, "He really has no role in that. We go to him in terms of discipline. 
In terms of instruction with Special Education, that's just left to the Special Education teachers."

When asked to describe the principals' roles in the school, General Educator B explained:

I have no idea. They're in charge of meetings. They're in charge of attendance. They're in charge of any kind of severe behavior problems. They deal with parents and work with scheduling. But what they do each and every day besides from attendance I'm really not sure.

When asked about their relationship to instruction General Educator B stated:

[Assistant Principal B] really doesn't discuss anything as far as content and what I'm teaching. [Principal B] has talked to us several times about differentiation but that's about the extent of anything they do in general education.

\section{How do Principal B and Assistant Principal B define effective instruction for}

students with disabilities? Principal B and Assistant Principal B defined effective instruction for students with disabilities regarding methods of delivery, setting, and accommodations and modifications. Specifically, both principals articulated project-based learning, differentiated instruction, and collaborative pairs as effective methods of delivery. They articulated inclusion in the general education classroom as an effective instructional setting. Finally, they articulated testing and classroom modifications as effective instructional strategies.

Methods of Delivery. When asked to describe effective instruction for students with disabilities, Principal B discussed how the changing demographics of students in West Virginia have changed the classroom environment:

I think that I could speak on behalf of most of the principals in West Virginia in saying that as our clientele changes and we get more Special Education [students] and as the demographics in West Virginia change, we've got to revisit and find ways that we can teach all levels in the same classroom. We're not doing a very good job at it.

He used the problem of the changing demographics of students to continue discussing the importance of differentiated instruction:

If we don't start changing how we approach these students, we're going to have more issues with classroom management. So, we try to convince and train teachers to 
understand that in your classroom you can teach different levels. And they've got to get beyond the mindset that these students might have different worksheets, these students might be on the computer, and they can still achieve a $\mathrm{C}$, or a $\mathrm{B}$, or an $\mathrm{A}$ even though they aren't doing the work that the other kids are doing. They've got to get beyond the mindset of how is this kid every going to achieve mastery.

Assistant Principal B supported Principal B's statement about the current state of instruction stating, "We're not [differentiating]. We teach to the average learner. We've got to get more hands on, more project-based learning." She continued discussing a more hands-on approach to instruction for students with disabilities when talking about the new Math curriculum:

When it finally switches over, they're not even getting new textbooks. They're going to be forced to have to develop some of their own things, interactive things. That's going to make a major change. They're going to have to use their brains and pull from different things to meet these objectives. I think that's going to make a big difference in our Math curriculum. It's already happening in our Science curriculum. Our Science curriculum already has a lot of project-based instruction.

Principal B followed the statement by the assistant principal with his own thoughts on effective methods of delivery, stating, "Our teachers have done a great job this year putting our kids in collaborative pairs. We do a lot of group work, which is a great thing." He continued with a discussion of what he looks for when he observes teachers:

We look for things like if teachers are still teaching like how Laura Ingalls was talking about 100 years ago. Are the kids engaged? Is it all just lecture? Some lecture is fine. Are they using technology? How are they getting to all students?

Despite the importance that Principal B and Assistant Principal B placed on differentiated instruction, project-based learning, and collaborative pairs, Special Educator B articulated a different belief regarding effective methods of delivery for students with disabilities. When asked to describe effective instruction for students with disabilities, she stated:

Direct teacher instruction. They need repetition. They need visuals. They need consistency and routines. What I find is that the discovery type learning or the inquirybased stuff doesn't work. If you wait for them to discover something you'll be waiting a 
long time and they are never going to learn. You have to be direct and explicit about what you are teaching and why you are teaching it.

She continued her discussion of effective instruction by describing what she does in one of her pull out classes:

I just find that my students do better with predictability. Each day you come in and you do the same thing. I know the research is all down on worksheets, but that is truly what is more effective with my students. They need to be doing something, they need consistency, and they need it laid out there.

General Educator B, who collaborates with Special Educator B in an inclusive English class, confirmed what Special Educator B expressed. When asked to describe effective instruction for students with disabilities, she stated, "I use a lot of PowerPoints. In that class, it's kind of small and there are two of us so we break into groups and lead small group activities."

However, when asked how she creates a supportive learning environment for students with disabilities, General Educator B discussed how she differentiates instruction for her students:

I try to think of my objectives. What is it I want them to learn? And then I come up with different ways that they might respond to. I have certain students who aren't going to respond to some activities that I do and other students who would really like a different activity. So I try of think of different ways of introducing the material. As many as I can.

She continued to discuss how she actively engages students with the material by making it meaningful to them:

I try to make everything as interesting as I can and think about what they would personally like and plan my objectives around that. How can I make this something that would want? How can I bring this to them in a way that would want to learn it because it's different for each of them.

Setting. Principal B discussed that his school uses an inclusive model with some pull out classes for educating students with disabilities. He stated, "I routinely tell people for us in Special Education they get an inclusion teacher and some of them get pull out minutes." Special 
Educator B confirmed the principal's statement. When asked where students with disabilities are educated she stated, "Some of them are in pull out settings and some of them are in the inclusive setting.”

Although Principal B and Assistant Principal B implemented an inclusive model in the school, Assistant Principal B discussed the problems with this instructional strategy:

I still don't think that teachers and Special Education teachers have learned how to coteach appropriately. There's still that concept of the Special Education teacher coming into the room and working with their kids. They don't like inclusion. We're still working towards that goal of co-teaching. We've come a long way but we still have a long way to go.

Principal B continued discussing the problem with inclusion by stating that special educators lack knowledge due to insufficient preparation:

There aren't a lot of openings in education right now but you go on the state website and look up SPED there's a gazillion openings. Somebody who's young can get those six hours, and you can get them easily, now you're on permit... They go in the classroom and work at the leisure of the classroom teacher. A lot of them aren't doing the coteaching model that you want.

Special Educator B confirmed the problem Principal B highlighted with educator

attitudes towards inclusion:

If you talk to the teachers and you talk to the students you will find that they feel more comfortable in a smaller pullout setting. And their performance will be better because it is tailored to the level they're at. It's not fair to throw them into a general education Geography class when they're reading at a 3rd or 4th grade level despite all the modifications you could do.

In addition to discussing the inclusion program, Principal B also explained how he does

not homogenously group students. While discussing differentiated instruction, Principal B stated that newly trained teachers are trained for heterogeneously grouped classes:

As the younger ones come in, they're being drilled and taught and their lesson plans are immaculate. They're being taught how to differentiate, how to modify. They come in and they don't remember the separate buildings for kids. They don't remember the smart 
class, the average class, and the low class. Like when we used to level. Our older teachers still remember and still want leveled classes.

However, during her discussion of how she provides instruction to students with disabilities in the inclusive setting, Special Educator B mentioned that the principal schedules students in classes based on WESTEST performance:

What typically happens is the inclusion students are all kept together so I can be in the classroom with them. Then they are also lumped based on WESTEST scores so you end up with general education students that struggle in with the inclusion students.

Accommodations and modifications. When asked about accommodations and modifications for students with disabilities, Assistant Principal B discussed testing accommodations. She stated, "It just depends on the student. For IEPs, it varies from extra time and reading tests aloud." When asked if educators provide any other accommodations or modifications she stated, "Our teachers use agenda checks, notes from the teacher, and allowing students to type their work." disabilities:

General Educator B elaborated on some of the accommodations for students with I use a lot of accommodations. Instead of reading stories, we'll listen to them on the disk. I try to pull things I know they'll like. If there's a vocabulary song on something, I want to teach, I break it down into small pieces. We'll take one-step and cut it into three and take it one-step at a time.

She also provided an example of a recent accommodation she used for students in her collaborative English class.

Today, for instance we started a new story so we did a little T-chart. I read a paragraph to them and they to try and find direct characterization. We let them do it at their own pace. We keep working on a skill until it's mastered. We'll have half the class working on the next step while the other half is still working on the first one.

Special Educator B also elaborated on accommodations for students with disabilities:

In Math, I usually try to take them from concrete with manipulatives. Once I get them to the concept that way, the next day I might introduce something representational and that 
could be some kind of a computer application with some kind of a visual that is not tactile. Then I'll take them to the pure calculations and stuff like that. It's very much in stages.

\section{How do Principal B and Assistant Principal B ensure teachers use effective}

instructional strategies for students with disabilities? To ensure teachers use effective

instructional strategies for students with disabilities, Principal B and Assistant Principal B

discussed conducting teacher observations and evaluations, reviewing lesson plans, and

providing written feedback on lesson plans. Principal B stated, "[Assistant Principal B] is the

one in charge of doing evaluations. She works to make sure plans are implemented." However, Special Educator B indicated that the principal conducts observations and evaluations. General Educator B elaborated on the observations from principals stating, "I know that early in the process you are observed and evaluated fairly regularly. But after the three-year period of time, you still see them occasionally but it's not really in the same kind of context."

Principal B also discussed conducting random walk-throughs:

We're required to do walk-throughs. We're supposed to randomly walk through classes to see what's going on. We're looking for any signs of differentiation or anything besides lecturing. I can't say that we do them as often as we should but we're in the halls constantly.

Special Educator B confirmed Principal B's statement. When asked about her principals' roles, Special Educator B stated, “[Principal B] will sometimes pop into the classrooms and observe. He's a constant presence in the building. He's in the halls, popping into the classrooms, at lunch, after school."

In addition to evaluating teachers and conducting walk throughs, Principal B also stated that he reviews lesson plans and provides written feedback:

I'm the one who does the lesson plan checks. I'm the one who gives them the feedback and I do that every week and they get official written feedback at the end of every term. And I look for signs, any signs, of differentiated instruction. 
Special Educator B confirmed Principals B's statements about reviewing lesson plans.

She stated, "The principal is the one who does the lesson plan reviews. We turn those into him each week. He'll make comments on them sometimes."

General Educator B stated that their school system uses modification calendars to ensure teacher provide the necessary modifications for students with disabilities. The modification calendars are used by the Central Office to track the services provided to the students for Medicaid billing purposes. However, neither Principal B nor Assistant Principal B mentioned the calendars. When asked what she thought was effective instructional leadership, General Educator B mentioned the lack of oversight regarding the modification calendars:

Maybe there should be some checks and balances. Maybe in that sense the principals could do something. They could check the modification calendars and make sure teachers are actually doing it. Right now teachers just fill it out and send it in. No one knows if you're actually doing any of them.

Summary. School B had the lowest percent of students with disabilities and percent of economically disadvantaged students among the middle school in this investigation. School B had the highest WESTEST scores in Mathematics and Reading/Language Arts for the Special Education subgroup. It had the highest pupil to administrator ratio, pupil to teacher ratio, attendance rate, years experience of staff, and class size. School B was second highest in percent of classes not taught by a highly qualified teacher.

Principal B and Assistant Principal B defined instructional leadership for students with disabilities as creating a supportive environment for teachers and students. However, neither General Educator B nor Special Educator B mentioned principals being advocates for students with disabilities or creating a supportive environment. To communicate their education roles, both principals discussed changing teachers' mindsets. Principal B provided an example of how the tries to change teachers' mindsets through discipline referrals. As the instructional leader, 
Principal B and Assistant Principal B stated they attend IEP meetings, manage discipline, and manage the Special Education program. However, when asked how their principals serve as instructional leaders, both educators had different views of what that entailed than the principals.

When asked about effective methods of delivery for students with disabilities, Principal B and Assistant Principal B discussed the importance of project-based learning, differentiated instruction, and collaborative pairs. General Educator B supported the use of differentiated instruction. Special Educator B discussed the ineffectiveness of project-based learning and the effectiveness of direct instruction. Special Educator B and General Educator B confirmed the general education classroom as the primary setting for students with disabilities. Special Educator B also confirmed Principal B's concerns over teacher attitudes towards inclusive education. A discrepancy arose when discussing the placement of students in the general education setting. Principal B stated that he no longer groups students by ability. However, Special Educator B stated that all students, including students with disabilities, are grouped by ability. When asked about accommodations and modifications, Assistant Principal B discussed the use of testing accommodations such as reading tests aloud and classroom accommodations such as agenda checks. General Educator B and Special Educator B confirmed the use of testing accommodations and elaborated on the use of classroom accommodations. To ensure teachers use effective instructional strategies, Principal B and Assistant Principal B observe and evaluate teachers, conduct random classroom walk throughs, and review lesson plans. General Educator B and Special Educator B confirmed the use of these strategies.

\section{Case Study C}

Case study $\mathrm{C}$ focused on a middle school in the selected school system. Participants included the principal, and assistant principal. I obtained the descriptive information for School 
$\mathrm{C}$ from annual report cards available to the public and the descriptive information for Principal $\mathrm{C}$ from the demographic questionnaire. Assistant Principal $\mathrm{C}$ was recruited on site and verbally agreed to participate in the study at the request of Principal C. However, I do not have descriptive information for Assistant Principal $\mathrm{C}$ because he did not return a completed demographic questionnaire. I obtained the information used to address the research questions from interviews with Principal C and Assistant Principal C. Despite recruitment efforts, no educators from the school agreed to participate in the investigation.

Description of School C. School C is a middle school in the selected school system that educated 328 students in grades six through eight during the 2010-2011 school year. Of those students, $14.3 \%(\mathrm{~N}=47)$ of the population, have been identified as a student with a disability and received services under an IEP, which was higher than the school system average (13.5\%) and highest among middle schools used in this investigation. Additionally, $72.3 \%$ of the students in School C were identified as economically disadvantaged students during the 20092010 school year, which is above the school system average of $49.9 \%$ and highest among included middle schools. School $\mathrm{C}$ had the second lowest attendance rate of included middle schools during the 2009-2010 school year (97.3\%). The attendance rate at School C was also lower than the school system average of $97.5 \%$.

Results from the 2010-2011 WESTEST indicated that the school was in need of improvement. School C was labeled as in need of improvement because the subgroup of Low SES students failed to make AYP. School C was not accountable for the performance of students with disabilities because fewer than 50 students were tested in that subgroup. However, the performance of students with disabilities in School C was the lowest among the included schools (Table 14 displays the percent of students with disabilities who achieved proficient 
scores on WESTEST 2 for all three schools). Specifically, only $12.8 \%$ of students with disabilities achieved mastery or above in Reading/Language Arts, compared to $41.0 \%$ of general education students and only $17.0 \%$ of students with disabilities achieved mastery or above in Mathematics, compared to $45.3 \%$ of general education students.

Table 13

Percent of Students with Disabilities Proficient on WESTEST2, Case C

School A $\quad$ School B $\quad$ School C

SwD proficient on WESTEST 2, percent, 2010-2011

$\begin{array}{lccc}\text { R/LA } & 13.4 & 20.4 & \mathbf{1 2 . 8} \\ \text { Math } & 19.4 & 22.2 & \mathbf{1 7 . 0}\end{array}$

Note. $\mathrm{SwD}=$ Students with disabilities; $\mathrm{R} / \mathrm{LA}=$ Reading/Language Arts.

With a pupil to administrator ratio of $100.3: 1$, School $\mathrm{C}$ had the one of the lowest pupil to administrator ratios in the school system, which had an average pupil to administrator ratio of 145.1:1, and the lowest pupil to administrator ratios among the middle schools used in this investigation. An additional administrator funded under Title I resulted in the low pupil to administrator ratio in School C. The pupil to teacher ratio of 11.5:1 in School C was lower than the school system average of 14.6:1 and lowest among included middle schools. Again, the reason for the low pupil to teacher ratio was due to additional teachers funded under Title I. School C had the lowest average class size (17.4 students per class) among included middle schools. The average years of experience of the staff at School C was 15.9 years, the second lowest among included middle schools, and lower than the school system average of 17.8 years. School $\mathrm{C}$ had the lowest percentage of classes not taught by highly qualified teachers $(6.1 \%)$ among the three included middle schools. However, it was higher than the school system average of $5.4 \%$. 
Description of Principal C. Principal C is a male with 13 years of experience as a school principal. He received his principal certification from the West Virginia College of Graduate Students (now Marshall University) in 1993. Prior to entering administration, Principal C taught secondary Mathematics and Social Studies for 14 years. Principal C indicated that he had no experience instructing students with disabilities because he taught upper level Mathematics courses such as Calculus and Advanced Placement Calculus. He was never certified as a special educator and has taken two Special Education courses. He reported no Special Education courses during his undergraduate teacher preparation program, one course was during his principal preparation program, and one graduate level course unrelated to a degree or certification. I was unable to obtain a copy of the graduate handbook from the West Virginia College of Graduate Studies because it is no longer an active institution. Therefore, I was unable to confirm or refute the Special Education course.

Description of Assistant Principal C. Assistant Principal C is a male who was in his first year of administration at the time of the interview. I recruited him on site and he verbally agreed to participate. Following the interview, I sent an email with the demographic questionnaire to Assistant Principal C but it was never completed and returned.

\section{How do Principal C and Assistant Principal C define instructional leadership for}

students with disabilities? Principal C defined instructional leadership by describing his philosophy of instructional leadership and discussing what he believes the role of the principal should be. When asked to describe his role, Principal C stated:

I've been doing this now for 12 years and I've never played the you're going to do it because I'm the principal card. I just don't believe that there should be that big of delineation between principal and teacher. I think we're all in this together and I think the teachers need to see that. Teaching today goes above and beyond a job. If they're not seeing you giving it all then they aren't going to be giving it as much as they need to. 
He further defined instructional leadership by discussing what he believes is ineffective leadership:

You've got your principals up there who think... I always like to describe it as if they're on a balcony and they're looking down on everything. I guess for some people that works, but it never did work for me. I just feel like you have to roll up your sleeves and get in there with them or they're not going to do it to the degree they could do it.

When asked about instructional leadership for students with disabilities, Principal C discussed advocating for students, setting expectations for teachers, supporting teachers, and creating a supportive environment. At the first mention of students with disabilities, Principal C stated, "And I am truly an advocate for the Special Education kids. If you're not going to fight for them who will? And the teachers need to see that from me." He continued discussing teachers and his role as the instructional leader in creating expectations for teachers:

I'm not a touchy feely administrator. I give you credit, but I'm not there all the time patting you on the back. I expect people to do their job and when they do it okay, you've done your job. Don't expect me to send you flowers just because you did your job. If you do your job well or if you do something above and beyond I'll thank you for doing that.

He discussed why it is important to set expectations for teachers:

If I had a book to write on education the title would be 'In it for the right reasons.' Because it all comes down to that. Teaching more than anything else... my wife works in an office but it's a job to her. She's not dealing with kids' lives. Teaching can't be like that. You're not producing a widget here. You're producing a kid and that kid has a lot of things going on. Especially the Special Education kids. This isn't for a paycheck. The people that get into it for that are not in it for the right reasons.

He also talked about the importance of supporting teachers:

They've got to know you'll back them. I've told them and I'll continue to tell them that I'll back you no matter what you say out in public. No matter what, I'll find a way to back you. Now behind closed doors, I may tell you that's the craziest damn thing you've ever done in your life. But I'm not going to throw you under the bus to the public.

Principal C articulated why instructional leadership should involve creating a supportive environment for students with disabilities: 
You got to make sure that you have stuff in place for [students with disabilities]. If not you're going to end up with kids who have dropped out of school, they just haven't left the building yet. That happens in the 7th and 8th grade. They dropout and just hang around until they hit 16 and leave. We do what we can. We throw every pitch at them that we can find. It's just trying to find whatever it is that can motivate that individual kid.

Assistant Principal C did not discuss instructional leadership. He stated, “That's not what I do. That's more of what [Principal C] and [assistant principal] do.”

\section{How do Principal $\mathrm{C}$ and Assistant Principal $\mathrm{C}$ communicate their educational role}

as the instructional leader for students with disabilities? Principal $\mathrm{C}$ discussed how he

communicates his educational role as the instructional leader for students with disabilities in

detail. He discussed communicating with parents, communicating his values and beliefs to the

staff, and communicating his goals. When asked about instructional leadership for students with

disabilities, Principal $\mathrm{C}$ discussed the importance of communicating with parents:

If you go to the high school and they tell you they can't do this or they can't do this. Bull you make them do it. You have to be an advocate for those folks. If those parents don't fight for what those kids need and deserve and that sort of thing it ain't going to happen up there. So, you have to enlighten those parents to what their kids are entitled to. What they should have. At least the minimum of what they should have.

He also stated that he believes that it is his responsibility as the instructional leader to communicate with parents about their student(s):

I try to tell kids the way it is, I try to tell parents the way it is, and sometimes I'm not as PC as I should be. But come on. Don't call me on Wednesday and ask me if your son has been in school today because you haven't seen him since Sunday. I mean, don't do that. Because if you do I'm going to call CPS. So, I let them know up front that's what's going to happen.

When discussing how he communicates his educational role as the instructional leader for students with disabilities, Principal $\mathrm{C}$ talked about the importance of the school being a reflection of his values and beliefs: 
I guess I hope the school is a reflection of my beliefs and values. You've got all these people working for you. Hopefully, as principal your beliefs align pretty closely with those folks. Because if it doesn't something has to happen. If not you have to convince those folks that this is the way you want to go. You want them to believe what you believe so you've got to tell them what you believe.

He provided an example of how he communicates his values and beliefs to the staff:

To get everybody in the direction that you want to go you have to be very subtle. You get the right people on board with you and then those people can help the other people get on board. It's knowing the staff and knowing what their strengths and weaknesses are. If you can get three or four or five people in the building who you can get their complete trust and their complete integrity you can get those people and start knocking ideas off of them before you take it to the general public. If you put a bug in someone's ear they'll think about it, then they'll talk about it.

In order to communicate his educational goals as the instructional leader, Principal C

discussed how he gives educators ownership in the decision making process:

You've got your boo birds out there that no matter what you want to do it's 'No, that ain't gonna work' or 'We've tried that 20 years ago and it didn't work.' So, to get everybody on board they have to have ownership in it. So, your best ideas that you want to do, you do it in a way where it's almost like they thought of it themselves. You get them almost where you want to be and then let them figure out the next step. Which is the step you wanted them to take but they think 'Oh man I thought of that.' I sit back and say why didn't I think of that.

He provided an example of how accomplished his goal of getting teachers to use SMART

Boards:

I bought everybody in this building a SMART Board. I have people who used it every day and I had people who hadn't even taken it out of the box. Again, that's part of that process where I got a little group of people to start using their SMART Boards. Then someone not using one would walk through and see it and start asking about it. That's how you kind of get it rolling. You can't cram stuff down these teachers' throats. They have too much coming at them now.

\section{How do Principal C and Assistant Principal C practice instructional leadership for}

students with disabilities? Principal C and Assistant Principal C stated they practice instructional leadership for students with disabilities by attending IEP meetings, scheduling, 
managing Title I funding, providing technology, developing a positive behavior support system, and hiring dedicated staff.

Although Assistant Principal C stated that he has little to do with instruction and did not comment on instructional leadership, he did discuss how he practices instructional leadership for students with disabilities:

I first got this job they told me that I would be working with the Special Education group. So right now, I'm the chairperson on the IEPs. I try to go to as many IEPs as I can go to. I'm not always available to go to them. If I'm not there, [Principal C] goes to the them.

However, Principal C also stated that, although he attends IEP meetings, he does not believe he is knowledgeable about Special Education, stating, "That's one area that I personally feel that I need to improve the most on. Number one, my knowledge of Special Education.

Number two, what my roles and the roles of all of the Special Education teachers in the building are." He continued to discuss that he does not practice instructional leadership for students with disabilities effectively:

We haven't collaborated enough, we haven't met enough this year. With all of the IEP, and we have so many SPED kids at this school. We haven't met enough on them. We missed a lot of our timelines and stuff like that for reviews. In addition, it just bothers me that I've not been more actively involved in that.

When asked about his relationship to classroom instruction for students with disabilities, Principal C stated, "I'm the discipline and attendance guy. That's my job. And that's the busiest job.”

Principal C articulated that he practices instructional leadership for students with disabilities by developing the master schedule and managing Title I funding. He discussed how he creates the master schedule to help students with disabilities:

I do the master schedule. We have quite a high population of Special Education kids so they don't get overlooked. So, when we do the master schedule, there are two ways to do it. You can build a schedule and then you can fit the Special Education kids into the 
schedule where it works best. Or you can look at the Special Education kids and then build the schedule around them. Now I don't do that specifically but it's about 50/50. I don't just build a schedule and say well I got five SPED kids let's put one here and one here and so on. No, I'm not going to do that.

In addition to creating the master schedule with students with disabilities in mind,

Principal $\mathrm{C}$ also discussed how he built time for additional support into the schedule:

We also have some time built into the schedule, which we call learning skills time. It's actually a flextime where Special Education teachers can pull students and help them during that time. That time is built in everyday.

Principal C stated he also practices instructional leadership for students with disabilities

by managing Title I funding. Specifically, he discussed how he manages those funds to provide additional staff:

I'm very fortunate being a Title I school. I've always had an additional administrator who does nothing but curriculum and instruction. The lady I've got now, she develops all the PD. She coordinates all the county coaches that come and work with our teachers. She meets with the teams regularly to talk about instruction.

In addition to funding an additional administrative position, Principal $\mathrm{C}$ discussed how he uses Title I funds to staff a full time social worker in the school:

We have a social worker who is on the premises and she helps us out quite a bit. I pay that through Title I. She will do in home services. She'll pick up kids who were sick, get them to the doctor, and arrange transportation. She'll go pick kids up who get up late and need a ride. We try everything we can to get them here. And we're not judgmental about it either. If a kid calls and says, "I got up late I need a ride" he gets a ride. It's not one of those we told you yesterday you better get here today. It's not like that. If you need a ride, we'll get you a ride. He really try to help all our kids, especially our needy kids because we have so many of them.

Principal $\mathrm{C}$ also discussed how he uses Title I funds to provide his staff with professional development and provide students with access to technology:

I get about half a million dollars a year and $\$ 50,000$ needs to be spent on PD. It gives you a chance to send your Title I teachers and your Special Education teachers to some things or bring in some things that a lot other teachers are kind of envious of sometimes. 
I do a lot of technology with those kids. I've got a special computer lab set up just for Special Education with software that self-assesses students. That needs to happen because you can check very quickly and periodically what gains or losses that you're making.

Aside from managing Title I funding and developing the master schedule, Principal C stated he practices instructional leadership for students with disabilities by implementing a positive behavior support system:

We set up a reward system. It's set up like a barter system. We hand out these [school name] Bucks and every 9 weeks and we have what's called a [school name] store. It's just stuff that we have people bring in. Pens, pencils, notebooks, that kind of stuff. We'll go to the dollar store and buy crazy stuff and they can use their Bucks to buy stuff. They love it because they don't have a lot of stuff. It's crazy what kids will do for these little things. Especially our Special Education kids.

Principal C articulated that one of the most important ways he practices instructional leadership is by hiring teachers who are committed to working with Special Education students and students who are at risk:

You have to be honest when hiring people. I lay it out on the line for people and tell them that if you work in this school this is the hardest job you'll have in [school system]. This is the hardest school to work in. We have most low SES kids, we have twice the discipline issues the other schools have, we have the lowest attendance rate in the county, and almost a third of population is in Special Education.

He believed that for his school to be successful teachers have to be willing to accept the challenges that come with working with at risk and needy students:

I tell them I want you to be here if you want to be here. But please don't take this position just because you want a job because it ain't going to be fun. If you're not here for the right reasons this ain't the place to be.

Principal C discussed that it can be particularly difficult when hiring Special Education teachers:

It seems like there are people who are getting into this business for the wrong reasons. ... A lot of problems with the new Special Education people is they get their Special Education certification just so they can get their foot in the door. That ain't always the best thing in town. Every once in while you find one of those SPED teachers who started 
in Special Education to get their foot in the door and they figure out that's what they really want to do.

\section{How do Principal C and Assistant Principal C define effective instruction for}

students with disabilities? Principal C discussed what he believed was effective instruction for students with disabilities in terms of methods of delivery, setting, and accommodations and modifications.

Method of Delivery. When asked to describe what he believed was effective instruction for students with disabilities, Principal C stated:

Good instruction is the feeling that the teacher has that what they are doing is reaching the kids. When I first started teaching when I got out of college, I stood up there and hell, I was a great teacher. I didn't care if you learned anything or not but I was doing a hell of a job up there teaching at the board. Now good teaching is knowing and being able to determine what the kids know, how much they know, and what else they need to know.

He continued by discussing the need for teachers to be flexible and design their

instruction to meet the needs of all students:

I think that good teaching is being flexible. To me a good teacher would take a textbook and throw it out the window. The old standard of 'I got to get from page 1 to the end of the book at the end of the school year.' No you don't. A good teacher knows what you need to teach. They know how to teach it.

Principal C talked specifically about the need to differentiate instruction for students with disabilities:

[Teachers] just need to be able to reach everybody with what they're doing. You can't teach it one way and expect everybody to get it. You've got auditory learners, kinesthetic learners, all those different people. The Special Education kids in the regular classroom has got to have that.

He also discussed that effective instruction involves the educator or educators reflecting on their lessons and having the confidence in their ability to discern what worked and what did not: 
The advantage of having SPED kids in the class is that you have another teacher in there with you. Hopefully between the two of you that you're seasoned enough and savvy enough to know when you can say, 'Well that didn't work. Let's try something else.' You've got to be comfortable enough to be able to do that. You can plan and have all the greatest things and then all of a sudden you realize 'Well that ain't going to work.' To have enough confidence in yourself to say, 'Well that didn't work. Let's try something else.' So many times teachers want to cop out and say, 'Well I taught it the kids just didn't learn it.' Or, 'They're just not motivated.'

He continued by discussing a characteristics he believed effective educators have:

You have to have confidence as a teacher. That only comes with experience and it comes with a certain demeanor you have as a teacher. Some people will never be confident enough to stand up in front of a group of people and actually fail at something. I don't think we can get better as a teacher, a person, or as a principal until we've been a position to fail at something and analyze 'Well I thought this was going to work. Damn I was wrong about that. Where do I go from here?' Being able to know that. If you're not willing to take the risk of throwing something out there and falling on your face, you're never going to get where you need to be.

Setting. When asked where his students with disabilities are educated, Principal C responded:

The regular education classroom. We do have one pullout Math class and one pullout Reading/Language Arts class per grade level. Those kids will spend maybe 3 days a week in the regular classroom and then they pull them out 2 days a week to help with what they need. Some days they pull out three and stay 2. The SPED and the regular teacher make the decision because they're in there together.

He also discussed the importance of educating students in the general education classroom, stating, "You don't just send these kids someplace else and just lock them up in a room and given them a coloring book and a crayon and say go at it. You can't do that." Furthermore, he discussed the need to support students with disabilities in the general education setting:

We try to get out SPED kids out into the regular education classrooms as much as possible. That way they're not down at the end of some hallway somewhere and never seen by the regular education folks. But, if do that and you don't set up a system of support for those kids in the regular classroom you're just throwing them to the wolves. So, what we try to do is get them out there, as much as we can so they aren't stigmatized, 
so they don't feel like they're dumber than everyone else. But, we don't send them out there alone.

Accommodations and modifications. When asked about accommodations and modifications for students with disabilities, Principal $\mathrm{C}$ discussed tailoring instruction to meet the individual needs of a student and communicating with all stakeholders involved in a student's education. He briefly mentioned some testing and classroom accommodations, stating, "You've got your standard stuff like give more time for tests and redirects from the teacher." However, he discussed what he believed was a problem with standard accommodations:

You can just say, 'Okay we're going to reduce this kids assignments and everything will be okay.' Yeah we're just going to give him half of what everyone else is given. It looks good on paper but in reality are you just going to make him learn half his multiplication tables? Are you just going to make him only capitalize half the first words in half the sentences? It sounds good but it doesn't always work. With the Special Education kids, you have to do things on an individual basis.

He continued expressing his concerns over accommodations as Assistant Principal C entered the room:

I was talking about Special Education and I was saying that I don't care what the IEP says it's all different for Special Education. You can't just label a kid with "he needs extra time." That ain't nothing. It's all about the relationship between the SPED teacher and the kid. If they can get along and understand what each other needs then you're good.

He continued to discuss the relationship between the educator and the students with disabilities:

But, it's almost to the point where we just try to get that kid and teacher to bond. So, it's almost like that teacher knows what that kid needs. It's tough because if you lose a kids confidence it takes a hell of a long time to get it back. Especially with these kids who don't see a lot of loyalty or support at home.

In addition to fostering a positive relationship with students with disabilities, Principal C also discussed the importance of collaboration when developing accommodations and modifications for a student with disabilities: 
We have SAT meetings and we'll sit and talk for 30 minutes on one kid. We'll say what does this kid need and what does this kid need in Math compared to English. And right now what does this kid need. What is most important? Does he need to know Math facts or does he need to know vocabulary. If we decide its Math facts more than vocabulary that's where we'll go with him. Even though he has English and History and Language Arts, right now we're going to concentrate on Math the most. Yeah, he'll go there and he'll do work but maybe we'll reduce his assignments and expectations in those classes to focus on Math right now. And then once we get him where we think he needs to be we'll figure out something else. There is no way you can ask a kid with a 75 IQ to keep up in 7 classes and do what everyone else is doing when they have a 100 IQ. You just can't do it. So you have to decide right now what do we need to be doing for him and then next week what do we think we'll need to be doing.

He continued his discussion of developing accommodations and modifications by

discussing how he encourages IEP development:

You put together an IEP, which is supposed to be for a year, but you're writing an IEP for a month and then you're looking at it again. We may not formally change that IEP, the goals and stuff. But, you're always modifying it whether you're actually doing it on paper or you talk about it and do it without changing it on the paper. It's always something different.

\section{How do Principal C and Assistant Principal C ensure teachers use effective}

instructional strategies for students with disabilities? Principal $\mathrm{C}$ provided limited

information on how he ensures teachers use effective instructional strategies for students with disabilities. The only strategy he discussed related to the assistant principal in charge of curriculum and instruction:

We have it built up so that all of our teams have a common plan every day. That way we get them all in there together and they can say well how's so and so doing in your class and your class. What's working for you? What isn't? Our assistant principal attends those meetings.

Summary. School C had the highest percent of students with disabilities and percent of economically disadvantaged students among the middle schools in this investigation. It had the lowest WESTEST performance for the subgroup of students with disabilities in Mathematics and Reading/Language Arts. School $\mathrm{C}$ had the lowest pupil to administrator ratio, pupil to teacher 
ratio, class size, and percent of classes not taught by a highly qualified teacher. It had the second highest attendance rate and years of experience of the staff.

Principal C defined instructional leadership for students with disabilities as being actively involved with students, advocating for students, setting expectations for teachers, supporting teachers, and creating a supportive environment. In order to communicate those roles, he discussed communicating openly with parents, communicating his values and beliefs to the staff, and openly communicating his goals. Principal $\mathrm{C}$ emphasized how he helps communicate his educational goals by giving educators ownership in the decision making process. As the instructional leader, Principal C stated he develops the master schedule, manages Title I funding, provides technology, implements a positive behavior support program, and hires dedicated staff. He emphasized that he uses Title I funds to help support the education of students with disabilities by providing additional staff and professional development opportunities. Assistant Principal C practiced instructional leadership for students with disabilities by attending and chairing IEP meetings.

Principal C stated that effective instruction for students with disabilities requires educators to reflect on and differentiate instruction. He stated that the primary educational setting for students with disabilities is in the general education classroom. When asked about accommodations and modifications, he stated that his school provides standard accommodations and modifications. However, he believed accommodations and modifications should focus on immediate needs of students and not what is written on an IEP. To ensure teachers use effective instructional strategies for students with disabilities, Principal C stated that the assistant principal in charge of curriculum and instruction attends team meetings. 


\section{Cross-Case Synthesis}

The previous section detailed the results from the three individual case studies. I described each school, principal, and any assistant principals and educators as necessary. I organized the individual case results in a question and answer format using rich narratives to address each research question. The cross-case synthesis presents the common themes found after completing the individual case analysis. This section begins with a description of the principals' roles and responsibilities, based on their job descriptions, and concludes with the cross-case analysis of the interviews.

\section{Principals' Roles and Responsibilities}

Given the fact that this investigation was conducted in one school system, the same documents applied to all three principals and both assistant principals. For this investigation, I collected principals' job descriptions, educator observation forms, and IEP documents. I also reviewed West Virginia Department of Education (WVDE) Policy 2419, Regulations for the Education of Students with Exceptionalities (2010); Policy 5310, Performance Evaluation of School Personnel (2006); and Policy 5500.03, Skills for Principals (1997). All documents for this investigation were available to the public on the school system's website or the West Virginia Department of Education's website. A review of the school system's Board of Education policies related to the purpose of this investigation revealed that the school system follows the WVDE policies for defining principals' job duties, conducting teacher observations, and IEP development.

Principals' job description. A review of the school system's job descriptions for principals and assistant principals revealed seven responsibilities: (1) demonstrates instructional leadership to enhance school effectiveness by improving instruction and augmenting student 
performance; (2) provides purpose and direction for schools/county; (3) demonstrates cognitive skills to gather, analyze, and synthesis information to teacher goals; (4) manages group behaviors to achieve consensus; (5) enhances quality of total school/county organization; (6) organizes and delegates to accomplish goals; and (7) communicates effectively. In addition to the job description, WVDE Policy 5500.03 dictates that principals and assistant principals should: (a) articulate a vision and goals that are shared and supported by the school community; (b) advocate, nurture, and sustain the development of a school culture and instructional program that is conducive to student learning; (c) ensure management of the organization, operations, and resources for a safe, efficient, and effective learning environment; (d) collaborate with families and community members, respond to diverse community interests and needs, and mobilize community resources; (e) act with integrity, fairness and in an ethical manner; and (f) understand, respond to, and influence the large political, social, economical, cultural, and legal context as it relates to the school. However, neither the principals' job descriptions nor WVDE Policy 5500.03 specifically addresses Special Education or students with disabilities.

Educator observations. A review of the school system's policy on educator evaluations confirms that principals are responsible for observing classroom instruction as part of the evaluation process. This evaluation process requires principals to assess educators on seven competencies: (1) programs of study, including whether the educator employs a variety of instructional strategies to augment achievement; (2) classroom climate, including whether the educator creates and maintains an environment that supports learning; (3) instructional management, including whether the educator incorporates higher level thinking skills; (4) monitoring students progress; (5) communication; (6) professional work habits, including whether the educator adheres to established laws, policies, rules, and regulations; and (7) 
technology, including whether the educator implements curriculum plans that include methods and strategies for applying technology to maximize student learning.

IEP documents. IEP documents developed by the West Virginia Department of Education require the signature of a chairperson. A review of WVDE Policy 2419, Education of Exceptional Students, indicated that the chairperson must be a representative of the district and be "Qualified to provide or supervise the provision of Special Education, knowledgeable about the general education curriculum, knowledgeable about the availability of resources of the district, and has the authority to allocate resources." Furthermore, Policy 2419 stated that the principal or assistant principal should serve as the chairperson of the team when available. This policy requires principals to have an understanding of the curriculum provided to students with disabilities and the educational setting where they will be educated. WVDE Policy 2419 mandates that principals serve as instructional leaders for students with disabilities by understanding and managing the Special Education program.

\section{Cross-Case Analysis of Interviews}

The purpose of this section is to present how the data converged into themes regarding how principals define, communicate, and practice instructional leadership for students with disabilities and how they define and ensure effective instructional strategies for students with disabilities. Therefore, I organized this section by research questions and the overarching themes and themes that addressed each question. Seven overarching themes emerged from the crosscase synthesis: (1) developing a school culture, (2) managing the Special Education program, (3) effective instruction is..., (4) effective instruction is not..., (5) where students with disabilities are educated, (6) accommodating and modifying instruction, and (7) checks and balances. 
I developed the overarching themes by examining how the data converged onto a topic. For instance, in their discussions of how they practice instructional leadership, all three principals, and both assistant principals, listed several managerial practices. Based on this convergence I developed the overarching theme of managing the Special Education program. I developed the title for each overarching theme based on what I believed were the underlying meaning of the responses. I developed the themes for the cross-case synthesis from the words or phrases from the word tables (see Appendices $\mathrm{M}, \mathrm{N}$, and $\mathrm{O}$ for the word tables). If a word or phrase appeared in at least two cases, a theme was developed. I arranged the themes according to the number of principals who contributed to the theme. For example, I listed the theme creating a supportive learning environment first because all three principals and Assistant Principal B discussed this throughout the interview. I listed the theme being an advocate last because not all the principals discussed being an advocate for students with disabilities (See Appendix $\mathrm{P}$ for a list of each theme and the cases with responses that contributing to the subtheme).

Due to variability in the coding process, some words or phrases appeared under different codes and addressed different research question. Which code and question a response addressed depended on the overall context of the response. For instance, Principals B and C discussed supporting teachers in their definition of instructional leadership. However, Principal A did not mention supporting teaches until he discussed how he communicates his role as the instructional leader. While I could have coded this as Principal A's definition of instructional leadership, the overall context of the response more closely aligned with how he communicates his educational role. Nonetheless, all three principals discussed supporting teachers, which represented a 
common subtheme. Table 14 presents the seven overarching themes and themes according to the research question(s) the overarching themes addressed.

Table 14

Overarching Themes and Themes

Research Question

(1) How do participating West Virginia principals define instructional leadership for students with disabilities and (2) how do they communicate their educational role as the instructional leader for students with disabilities?

(3) How do participating West Virginia principals practice instructional leadership for students with disabilities?

(4) How do participating West Virginia principals define effective instruction for students with disabilities?

(5) How do participating West Virginia principals ensure educators use effective instructional strategies for students with disabilities?
Overarching Theme and Themes

Developing a school culture

Creating a supportive learning

environment

Supporting their educators

Changing educators' mindsets

Being an advocate

Managing the Special Education program

Attending IEP meetings

Scheduling

Creating instructional support time

Managing discipline

Managing funds

Providing resources

Effective instruction is...

Differentiated instruction

Students working together

Active engagement

Reflecting on instruction

Effective instruction is not...

Teaching to the middle

Reaching the last page in the textbook

Where students with disabilities are educated

The inclusive classroom

Pull out classrooms

Grouping students by ability

Accommodating and modifying instruction

Focus on the individual student

The standard stuff

Checks and balances

Observing teachers

Reviewing lesson plans 


\section{How do participating West Virginia principals define instructional leadership for students}

with disabilities and how do they communicate their educational role as the instructional leader for students with disabilities?

Results from the individual case studies provided varying definitions of instructional leadership for students with disabilities and revealed multiple ways principals communicate this educational role. In the individual case analysis, I presented the data that addresses research questions one and two separately. Upon completion of the cross-case synthesis and further review of the data, I discovered that principals' definitions and methods of communication converged on one overarching theme, developing a school culture.

Developing a school culture. Throughout the interviews, all three principals and Assistant Principal B discussed the importance of creating what I interpreted as a culture within their schools. They discussed how they develop a school culture through creating a supportive learning environment for students with disabilities, supporting their educators, and changing educators' mindsets. Additionally, two principals discussed how being an advocate for students with disabilities helps create their desired educational environments. This aligns with the responsibilities listed under the principals' job description. Specifically WVDE Policy 5500.03 (1997) requires principals have the skills to "advocate, nurture, and sustain the development of a school culture and instructional program that is conducive to student learning." These themes address research questions one and two by describing how participating West Virginia principals define instructional leadership and how they communicate their educational role as the instructional leader for students with disabilities.

Creating a supportive learning environment. A reoccurring theme throughout the interviews was principals' emphasis on the importance of creating a supportive learning 
environment for students with disabilities. They discussed why it is an important role of the instructional leader, how they create it, and how they communicate that belief to their staff. Although they discussed it at different times during the interview and in different contexts, they believed that in order for students with disabilities to be successful, they must feel supported and that support must begin with the administration. Principals B and C discussed this while discussing their role as the instructional leader. According to Principal C, as instructional leaders, principals cannot afford to, "Throw [students with disabilities] to the wolves." Principal A discussed creating a supportive environment during his discussion about changing educators' mindsets, stating, "Students don't care how much you know until they know how much you care." These statements revealed principals' desire to foster a learning environment that promotes the education of all students. However, neither of the educators discussed how their principals create a supportive learning environment for students with disabilities. They did not believe their principal had any role as the instructional leaders. Table 15 provides a sample response from each principal that I used to develop this subtheme.

Table 15

Creating a Supportive Learning Environment

\begin{tabular}{ll}
\hline Principal & Sample Response \\
\hline Principal A & $\begin{array}{l}\text { A student doesn't care how much you know until they know how much you } \\
\text { care. }\end{array}$ \\
Asst. Principal B & $\begin{array}{l}\text { You've got to give them a chance and you've got to make sure everyone sees } \\
\text { that. Without support they'll fall behind or just be forgotten. }\end{array}$ \\
Principal C & $\begin{array}{l}\text { You got to make sure that you have stuff in place for these kids. If not you're } \\
\text { going to end up with kids who have dropped out of school, they just haven't } \\
\text { left the building yet. }\end{array}$ \\
\hline
\end{tabular}

Supporting their educators. All three principals and Assistant Principal B discussed the need to support educators working with students with disabilities, especially students with 
disabilities who are educated in the general education classroom. Principal B, Assistant

Principal B, and Principal C discussed this theme while defining instructional leadership, while

Principal A mentioned it during his discussion on how he communicates his educational role.

Collectively, the principals believed educators must trust the administration "has their back" by supporting them in public, supporting them in the difficult task of educating all students, and supporting their desire to try new instructional techniques. Principal C's statement summarized this belief, "If they're not seeing you giving it all then they aren't going to be giving it as much as they need to." Special Educator B supported this subtheme by discussing how important it is that her principal acts as "out motivator." Table 16 provides a sample response from each principal that I used to develop this subtheme.

Table 16

Supporting Their Educators

\begin{tabular}{ll}
\hline Principal & Sample Response \\
\hline Principal A & $\begin{array}{l}\text { I try to be supportive of teachers who are doing outside the traditional box } \\
\text { instructional methods by encouraging the teachers to try new things. }\end{array}$ \\
Principal B & $\begin{array}{l}\text { I think the impact that we can have on Special Education is that we need to } \\
\text { make sure that teachers understand we're here to provide support for them. }\end{array}$ \\
Principal C & $\begin{array}{l}\text { Ijust don't believe that there should be that big of delineation between } \\
\text { principal and teacher. I think we're all in this together and I think the } \\
\text { teachers need to see that. }\end{array}$ \\
\hline
\end{tabular}

Changing educators' mindsets. Even though the principals discussed the need to support their educators, they all discussed the need to change what they referred to as educators' "mindsets" about educating students with disabilities and expressed that negative mindsets are a barrier to learning. Principal B and Assistant Principal B directly talked about how they work to change educators' mindsets regarding the education of students with disabilities in the general education setting. Principal A discussed changing educators' mindsets by challenging traditional 
approaches to instruction and supporting educators who try innovate ways to reach students. Principal C provided an example of how he changes educators' mindsets by giving them ownership in the decision-making process and working closely with a select group who support his goals. Despite their different approaches, all the principals believed that changing mindsets is necessary for creating an environment conducive to learning. The responses from Special Educator B supported the problem the principals identified when discussing educators' mindsets. Special Educator B held strong opinions that opposed her principals' opinions regarding where and how students with disabilities should be educated. Table 17 provides a sample response from each principal that I used to develop this subtheme.

Table 17

Changing Educators' Mindsets

\begin{tabular}{ll}
\hline Principal & Sample Response \\
\hline Principal A & $\begin{array}{l}\text { Get the kids up and moving around. You can teach history by getting the kids } \\
\text { up and moving around and talking a little bit. }\end{array}$ \\
Principal B & $\begin{array}{l}\text { We're still working on getting acceptance with inclusion... Trying to convince } \\
\text { and train teacher to understand that in your classroom you can teach } \\
\text { different levels. }\end{array}$ \\
Principal C & $\begin{array}{l}\text { Your best ideas that you want to do, you do it in a way where it's almost like } \\
\text { they thought of it themselves. You get them almost where you want to be and } \\
\text { then let them figure out the next step. }\end{array}$ \\
\hline
\end{tabular}

Being an advocate. In addition to creating a supportive environment, Principal B, Assistant Principal B, and Principal C discussed the important role of being an advocate for students with disabilities. They believed that in order for students with disabilities to have a chance to be successful and not "drop out and just hang around until they hit 16," administrators must advocate for them. Principal B and Assistant Principal B expressed the need to advocate for students because they believe that without it, students with disabilities in the general 
education classrooms would fail to meet performance expectations because "[educators] need reminded that we're in the business to help kids, all kids. Principal $\mathrm{C}$ summarized the importance of being an advocate for students with disabilities stating, "If you're not going to fight for them who will?" Despite the emphasis the principals placed on being an advocate for students with disabilities, the educators did not discuss that as a role of the principal. Table 18 presents a sample response from each principal that I used to develop this subtheme.

Table 18

Being an Advocate

\begin{tabular}{ll}
\hline Principal & Sample Response \\
\hline Principal B & $\begin{array}{l}\text { It's also important that the administration be advocates for kids. Because } \\
\text { they (teachers) tend to forget and they need reminded that we're in the } \\
\text { business to help kids, all kids. }\end{array}$ \\
Principal C & $\begin{array}{l}\text { I am truly an advocate for the Special Education kids. If you're not going to } \\
\text { fight for them who will? And the teachers need to see that from me. }\end{array}$ \\
\hline
\end{tabular}

\section{How do participating West Virginia principals practice instructional leadership for students with disabilities?}

In the individual case results section, I described how principals practiced instructional leadership for students with disabilities. Several practices emerged from my analysis. Upon further examination, the data from the individual case studies that addressed research question 3 converged on a common practice, managing the Special Education program.

Managing the Special Education program. Although not every principal mentioned the same instructional leadership practices, all their efforts revolved around the role of being the program manager. They managed their Special Education programs through scheduling, creating instructional support time, attending IEP meetings, managing discipline, and providing resources for educators. The practices discussed by the principals align with some of the 
responsibilities outlined in WVDE Policy 5500.03 and in WVDE Policy 2419. Specifically, WVDE Policy 5500.03 (1997) requires principals to "manage resources and funds appropriately and wisely" and ensure "time is managed to maximize the attainment of organizational goals," which the principals discussed when talking about managing Title I funds and allocating existing funds. Additionally, WVDE Policy 2419 (2010) requires principals (or his/her designee) to serve as the school district representative at all IEP team meetings, which all 3 principals and both assistant principals mentioned as one of their primary roles. These themes address research question 3 by describing how participating principals in West Virginia practice instructional leadership for students with disabilities.

Attending IEP meetings. When discussing how they serve as the instructional leader for students with disabilities, at least one principal from each case stated they attend IEP meetings and was one of the first roles the principals discussed. Even the educators listed this as one of their principals' primary roles regarding Special Education. When asked about Special Education, Assistant Principal C first mentioned he attends all IEP meetings. At the beginning of the interview, when I asked Principal B and Assistant Principal B to describe their roles, Principal B explained that Assistant Principal B attends all IEP meetings and is in charge of all 504 plans. When asked to describe what he does as principal, Principal A stated he and his assistant principal attend all IEP meetings. However, Principal A and Assistant Principal C explained that they do not attend the entire meeting. According to Principal A, "I do not spend the entire time in the IEP meeting when those are being done. Although I am in charge, I am not the expert on all the kids' exceptionalities." Table 19 provides a sample response from each principal that I used to develop this subtheme. 
Table 19

Attending IEP Meetings

\begin{tabular}{ll}
\hline Principal & Sample Response \\
\hline Principal A & $\begin{array}{l}\text { I attend most IEPs. The assistant principal and I attend all of them in some } \\
\text { fashion or another. }\end{array}$ \\
Principal B & [Assistant Principal B] works directly with the Special Education teachers. \\
& She heads up all of the 504 meetings and the IEP meetings. \\
Asst. Principal C & $\begin{array}{l}\text { So right now, I'm the chairperson on the IEPs. I try to go to as many IEPs as } \\
\text { I can go to. I'm not always available to go to them. If I'm not there } \\
\text { [Principal C] goes to the them. }\end{array}$ \\
\hline
\end{tabular}

Scheduling. One of the primary ways all three principals managed the Special Education program was through scheduling. They discussed how they managed the schedule to accommodate students with disabilities. Principal A discussed that he creates flexibility in students' schedules to provide them with additional academic support. Principal B stated that he "finds ways to get creative with [the] schedule" to accommodate directives from the central office regarding new Special Education programs. Principal C discussed scheduling in detail. He explained two ways a principal can schedule students with disabilities: building a schedule for the general education students and then "[fitting] the Special Education kids into [it]" or building the schedule around the students with disabilities in the general education classroom. Table 20 provides a sample response from each principal that I used to develop this subtheme. 
Table 20

Scheduling

\begin{tabular}{ll}
\hline Principal & Sample Response \\
\hline Principal A & $\begin{array}{l}\text { Our scheduling is very flexible. We're willing to change their (students with } \\
\text { disabilities) schedules a little bit to help them with their basic reading. }\end{array}$ \\
Principal B & So, we try to be flexible, we find ways to get creative with our schedule. \\
Principal C & $\begin{array}{l}\text { Ido the master schedule. We have quite a high population of Special } \\
\text { Education kids so they don't get overlooked. }\end{array}$ \\
\hline
\end{tabular}

Creating instructional support time. In addition to developing the master schedule and being flexible with students' schedules, Principal A and Principal C also discussed how they created instructional support time for students with disabilities. Principal A discussed how he used sustained silent reading time to enable teachers to review struggling students' WESTEST performance and their areas of weakness. Principal C explained how he used daily "flex time" as an opportunity for special educators to "pull students and help them during that time." Table 21 provides a sample response from each principal that I used to develop this subtheme.

Table 21

Creating Instructional Support Time

\begin{tabular}{ll}
\hline Principal & Sample Response \\
\hline Principal A & $\begin{array}{l}\text { We have sustained silent reading } 3 \text { days a week for } 30 \text { minutes. I tell them } \\
\text { (teachers), they are going to sit down with their kids in that class and print off } \\
\text { their test scores and show them how they've done so they'll have a record of } \\
\text { what they are doing. }\end{array}$ \\
Principal C & $\begin{array}{l}\text { We also have some time built into the schedule, which we call learning skills } \\
\text { time. It's actually a flextime where Special Education teachers can pull } \\
\text { students and help them during that time. }\end{array}$ \\
\hline
\end{tabular}

Managing discipline. The principals and assistant principals from cases B and C explained how they managed the Special Education program and practiced instructional leadership for students with disabilities by managing discipline. Principal B discussed how he 
and Assistant Principal B handle discipline referrals involving students with disabilities in the general education classroom. He also explained how he uses those opportunities to communicate with educators about the importance of differentiating instruction for all students. Assistant Principal B explained how she uses preventative measures for managing discipline problems in the general education setting. Special Educator B expanded upon her principals' role as the manager of discipline. She believed it was Assistant Principal B's primary role. Assistant Principal C stated during the hiring process he was told he would be "working with the Special Education group." Later he explained that in that role he is the "discipline guy." However, unlike Principal B and Assistant Principal B, Assistant Principal C did not view this role as being a responsibility of the instructional leader. Table 22 provides a sample response from each principal that I used to develop this subtheme.

Table 22

Managing Discipline

\begin{tabular}{ll}
\hline Principal & Sample Response \\
\hline Principal B & $\begin{array}{l}\text { If there are [discipline] issues that [Assistant Principal B] can't solve that } \\
\text { she's dealing with it lands over here when the parent gets upset. }\end{array}$ \\
Asst. Principal C & I'm the discipline and attendance guy. That's my job. \\
\hline
\end{tabular}

Managing funds. Principal B and Principal C stated that one of their roles, as the instructional leader, is to manage funds. While both principals discussed this role, they did so for different reasons. Principal $\mathrm{C}$ discussed several ways he manages Title I funding to support the education of all students, especially students with disabilities and students who are economically disadvantages. He talked about providing his educators with professional development and funding an additional administrative position and a full time social worker. Principal B on the other hand, talked about how he has to be resourceful with existing money in 
order to meet Special Education directives from the central office. He discussed how he has to find ways to fund additional programs and buy required equipment while staying within his current budget. Table 23 provides a sample response from each principal that I used to develop this subtheme

Table 23

Managing Funds

\begin{tabular}{ll}
\hline Principal & Sample Response \\
\hline Principal B & $\begin{array}{l}\text { My role is getting the phone call [from central office] and being told, "you're } \\
\text { getting a new program next year, now find ways to fund it." Well I don't have } \\
\text { any ways to fund it. "Well find it." }\end{array}$ \\
Principal C & $\begin{array}{l}\text { I get about half a million dollars a year and \$50,000 needs to be spent on PD. } \\
\text { It gives you a chance to send your Title I teachers and your Special Education } \\
\text { teachers to some things or bring in some things that a lot other teachers are } \\
\text { kind of envious of sometimes. }\end{array}$ \\
\hline
\end{tabular}

Providing resources. Another way principals practiced instructional leadership for students with disabilities was by providing educators with instructional resources. Principal A explained how he provided all his teachers with posters that broke down the curriculum for each content area (i.e., Math, Reading/Language Arts, Science, and Social Studies) in all 3 grades (i.e., sixth, seventh, and eighth). The posters were broken down by WESTEST2 performance levels. Principal A stated that the goal of the posters was to encourage educators to expose all students to higher-level material. Principal $\mathrm{C}$ discussed how he provided all the educators in his building with SMART Boards. In addition to the SMART Boards, he also explained how he created a computer lab specifically for the Special Education program. Table 24 provides a sample response from each principal that I used to develop this subtheme. 
Table 24

Providing Resources

\begin{tabular}{ll}
\hline Principal & Sample Response \\
\hline Principal A & $\begin{array}{l}\text { The poster has the sixth, seventh, and eighth-grade curriculum for the four } \\
\text { major subjects. Teachers each have that in their classroom at all times. }\end{array}$ \\
Principal C & $\begin{array}{l}\text { I've got a special computer lab set up just for Special Education with software } \\
\text { that self-assesses students. }\end{array}$ \\
\hline
\end{tabular}

\section{How do participating West Virginia principals define effective instruction for students with}

\section{disabilities?}

Although General Educator B and Special Educator B believed principals should have no role in instruction, the principals' job descriptions listed instructional leadership as their first responsibility. As the instructional leader, WVDE Policy 5500.03 (1997) states that principals must demonstrate that their "curriculum decisions are based on research, expertise of teachers, and recognized promising practices.” In order to base curriculum decisions on research, expertise of teachers, and recognized promising practices, principals must be knowledgeable of effective instructional strategies. The purpose of research question four resided in developing an understanding of principals' knowledge of effective instructional strategies for students with disabilities. Data from the individual case studies converged on four overarching themes in relation to how principals defined effective instruction.

Effective instruction is... The only consensus regarding what is effective instruction for a student with disabilities was the use of differentiated instruction. The other themes that included at least two cases were peer tutoring, active engagement, and reflecting on instruction. This theme addresses research question four by describing how participating West Virginia principals define effective methods of delivery for students with disabilities. 
Differentiated instruction. Throughout the interviews, all three principals and Assistant Principal B discussed the importance of differentiating instruction for students with disabilities. In some cases, the principals acknowledge the need to differentiate instruction before the conversation transitioned to effective instruction. For example, Principal B discussed the importance of differentiating instruction while discussing how he communicates his role as the instructional leader. During his discussion on handling discipline referrals for students with disabilities, he expressed his beliefs on adapting instruction to meet the needs of all students. Later in the conversation, he and Assistant Principal B revisited the need to differentiate instruction. The educators from School B supported the emphasis Principal B and Assistant Principal B placed on differentiated instruction. Principal A also discussed differentiating instruction during his definition of instructional leadership. Principal $\mathrm{C}$ also expressed his beliefs on the importance of differentiated instruction stating, "You can't teach it one way and expect everybody to get it." Table 25 provides a sample response from each principal that I used to develop this subtheme.

Table 25

Differentiated Instruction

\begin{tabular}{ll}
\hline Principal & Sample Response \\
\hline Principal A & $\begin{array}{l}\text { We have to find ways to teach all kids. And it's not always the same way for } \\
\text { all of them. }\end{array}$ \\
Principal B & $\begin{array}{l}\text { We try to convince and train teachers to understand that in your classroom } \\
\text { you can teach different levels. }\end{array}$ \\
Principal C & [Teachers] just need to be able to reach everybody with what they're doing. \\
& You can't teach it one way and expect everybody to get it. \\
\hline
\end{tabular}

Students working together. Although discourse on specific instructional strategies was limited, Principal A and Principal B discussed students working together as an effective method 
of instruction for students with disabilities. When asked what he believed was effective instruction for students with disabilities, Principal A discussed the importance of getting students "working together." Principal B explained how educators in his school use some of the essential components of peer tutoring strategies by placing students in "collaborative pairs." Table 26 provides a sample response from each principal that I used to develop this subtheme.

Table 26

Students Working Together

\begin{tabular}{ll}
\hline Principal & Sample Response \\
\hline Principal A & $\begin{array}{l}\text { Appropriate interactions with their peers and their instructors... Get them } \\
\text { working together }\end{array}$ \\
Principal B & $\begin{array}{l}\text { Our teachers have done a great job this year putting our kids in collaborative } \\
\text { pairs. We do a lot of group work, which is a great thing. }\end{array}$ \\
\hline
\end{tabular}

Active engagement. In addition to peer tutoring, Principal A, Principal B, and Assistant Principal B discussed that effective instruction actively engages students in the curriculum. Assistant Principal B contended that educators should engage students by making instruction "more hands on, more project-based learning." Principal B stated that when he conducts classroom observations he looks for active engagement and not just lecturing. However, Special Educator B discussed how she relies on direct instruction and repetition. She even expressed her negative attitude towards project-based learning. Principal A also discussed active engagement and believed that students with disabilities do not learn by lecture. He expressed a desire to see more "hands on stuff and real life examples." Table 27 provides a sample response from each principal that I used to develop this subtheme. 
Table 27

Active Engagement

\begin{tabular}{ll}
\hline Principal & Sample Response \\
\hline Principal A & $\begin{array}{l}\text { A lot of teachers still like to lecture and that's not the way that kids with } \\
\text { disabilities learn. They need hands on stuff and real life examples. Get them } \\
\text { working together. }\end{array}$ \\
Principal B & $\begin{array}{l}\text { We look for things like if teachers are still teaching like how Laura Ingalls } \\
\text { was talking about 100 years ago. Are the kids engaged? Is it all just lecture? }\end{array}$ \\
\hline
\end{tabular}

Reflecting on instruction. Another theme that developed regarding effective instruction

for students with disabilities focused on the need for educators to reflect on their instruction.

Principal C talked at length about the need for educators to reflect on their instruction and

determine its effectiveness. When asked to describe effective instruction for students with

disabilities, Principal C stated, "Good instruction is the feeling that the teacher has that what they

are doing is reaching the kids." The primary focus of his discourse on effective instruction was

the need for educators to reflect on what and how they are teaching. Although he did not

mention reflection as an effective instructional strategy for students with disabilities when asked

that question, Principal A alluded to the need for educators to reflect on their instruction while

discussing how he communicates his educational role. He believed that educators should reflect

on their instruction, stating, "If it fails, why did it fail? If it worked, why did it work?" Table 28

provides a sample response from each principal that I used to develop this subtheme. 
Table 28

Reflecting on Instruction

\begin{tabular}{ll}
\hline Principal & Sample Response \\
\hline Principal A & $\begin{array}{l}\text { I can't think of an instance where a teacher came to me and says "I'd really } \\
\text { like to try this" and I say no I don't think so. Because if it fails, why did it fail, } \\
\text { if it worked, why did it work? You have to look at what you're doing and } \\
\text { evaluate what you're doing and then tweak it. }\end{array}$ \\
Principal C & $\begin{array}{l}\text { The advantage of having SPED kids in the class is that you have another } \\
\text { teacher in there with you. Hopefully between the two of you you're seasoned } \\
\text { enough and savvy enough to know when you can say, "Well that didn't work. } \\
\text { Let's try something else." }\end{array}$ \\
\hline
\end{tabular}

Effective instruction is not... In addition to discussing what they believe is effective instruction for students with disabilities, the principals also discussed what is not effective. Two themes emerged from the interviews when principals discussed what they believed was not effective instruction regarding methods of delivery, teaching to the middle and reaching the last page of the textbook. These themes also address research question four.

Teaching to the middle. During the interviews with Principal A and Assistant Principal B, they expressed a belief that too many educators "teach to the middle." Although the principals expressed this belief in the context of the need to differentiate instruction, I felt it was noteworthy that two cases discussed this phenomenon with such similar language. Principal A explicitly used the phrase "teach to the middle" during his discussion about the importance of differentiating instruction. In her discourse on differentiated instruction, Assistant Principal B stated, "We're not doing it. We teach to the average learner." Both principals felt that in order for students with disabilities to be successful, educators must reach "all students." Table 29 provides a sample response from each principal that I used to develop this subtheme. 
Table 29

Teaching to the Middle

\begin{tabular}{ll}
\hline Principal & Sample Response \\
\hline Principal A & A lot of teachers just teach to the middle. That's terrible. \\
Asst. Principal B & We're not [differentiating]. We teach to the average learner. \\
\hline
\end{tabular}

Reaching the last page in the textbook. Another noteworthy theme concerning what is not effective instruction for students with disabilities is that educators believe they need to reach the last page in the textbook. Principal A and Principal C both emphasized educators' desires to "get from page one to the end of the book at the end of the year." Principal A stated that educators "think that if I don't get to page 376 it was a bad year and if I get to 390 it's awesome." Both principals expressed the idea that students with disabilities "need more than that out of a teacher." Table 30 provides a sample response from each principal that I used to develop this subtheme.

Table 30

Reaching the Last Page in the Textbook

\begin{tabular}{ll}
\hline Principal & Sample Response \\
\hline Principal A & $\begin{array}{l}\text { Teachers want to start at page } 1 \text { and get to page 376. They think that if I } \\
\text { don't get to page } 376 \text { it was a bad year and if I get to } 390 \text { it's awesome. The } \\
\text { kids need more than that out of a teacher. }\end{array}$ \\
Principal C & $\begin{array}{l}\text { To me a good teacher would take a textbook and throw it out the window. } \\
\text { The old standard of "I got to get from page } 1 \text { to the end of the book at the end } \\
\text { of the school year." No you don't. }\end{array}$ \\
\hline
\end{tabular}

Where students with disabilities are educated. In their discussion of effective instruction for students with disabilities, principals discussed what they believe is the most effective setting. Three themes emerged from their discourse on educational settings: (a) the inclusive classroom, (b) pull out classrooms, and (c) grouping students by ability. These themes 
address research question four by describing how participating West Virginia principals define effective educational settings for students with disabilities.

The inclusive classroom. All three principals stated they employed an inclusive education model for education students with disabilities. When asked where they educate students with disabilities, they unanimously replied the general education classroom. Table 31 provides a sample response from each principal that I used to develop this subtheme.

Table 31

The Inclusive Classroom

\begin{tabular}{ll}
\hline Principal & Sample Response \\
\hline Principal A & $\begin{array}{l}\text { Right now, we have two multicast inclusion teachers one in 6th grade and one } \\
\text { in 8th grade. We are operating the 7th grade like it's a multicategorical } \\
\text { inclusion program. }\end{array}$ \\
Principal B & $\begin{array}{l}\text { I routinely tell people for us in Special Education they get an inclusion } \\
\text { teacher and some of them get pull out minute. }\end{array}$ \\
Principal C & The regular education classroom. \\
\hline
\end{tabular}

Although all three principals stated that their schools used an inclusive model for educating students with disabilities, not all the principals agreed that it is always appropriate or effective. Principal A explicitly stated, "The inclusive classroom is not the solution." While Principal B and Assistant Principal B agreed that students with disabilities should be educated in the general education classroom, they cited problems with teacher attitudes and inexperience as barriers to effective instruction in the inclusive classroom.

Pull out classrooms. Along with educating students with disabilities in the general education classroom, all three principals discussed using pull out classrooms to provide additional support for students with disabilities. Principal C stated that students with disabilities typically receive 3 days of instruction in the general education classroom and two days in the 
pull out classroom. Principals A and B cited the use of pull out classes for students with disabilities in less specific terms. Table 32 provides a sample response from each principal that I used to develop this subtheme.

Table 32

Pull Out Classrooms

\begin{tabular}{ll}
\hline Principal & Sample Response \\
\hline Principal A & $\begin{array}{l}\text { We are trying to have the teacher go into inclusive classes for four periods } \\
\text { and then one pull out class, which is normally their strong suit class, Social } \\
\text { Studies, reading, etc. }\end{array}$ \\
Principal B & $\begin{array}{l}\text { I routinely tell people for us in Special Education they get an inclusion } \\
\text { teacher and some of them get pull out minute. }\end{array}$ \\
Principal C & $\begin{array}{l}\text { We do have one pullout Math class and one pullout Reading/Language Arts } \\
\text { class per grade level. }\end{array}$ \\
\hline
\end{tabular}

Grouping students by ability. In addition to discussing placement in the general education classroom, two principals also discussed what they believed was effective student grouping. Principal A explained he grouped students according to academic performance. He believed that homogenous grouping was better for addressing students' "specific needs." He also believed that homogenous grouping allowed special educators to have a "larger umbrella of influence." Principal B stated that they no longer homogeneously group students according to academic performance, stating, "They don't remember the smart class, the average class, and the low class. Like when we used to level." However, Special Educator B indicated that students with disabilities are still grouped with other low performance students. She explained how the students are grouped according to WESTEST performance to give the special educators most access to the low performing students. Table 33 provides a sample response from each principal that I used to develop this subtheme. 
Table 33

Grouping Students by Ability

\begin{tabular}{ll}
\hline Principal & Sample Response \\
\hline Principal A & $\begin{array}{l}\text { Taking kids' strengths and weaknesses and moving their schedule around so } \\
\text { you can address their needs by putting them with people that have the same } \\
\text { strengths and weaknesses. We tried to make a group of the top students, a } \\
\text { couple groups of the middle [students], and a group of the low [students]. }\end{array}$ \\
Principal B & $\begin{array}{l}\text { They don't remember the smart class, the average class, and the low class. } \\
\text { Like when we used to level. Our older teachers still remember and still want } \\
\text { leveled classes. }\end{array}$ \\
\hline
\end{tabular}

Accommodating and modifying instruction. Data from the interviews with principals

revealed two themes regarding how they accommodate and modify instruction for students with disabilities. A principal from all three cases discussed individualized accommodations and modifications and the "standard stuff." These themes address research question four by describing how participating West Virginia principals define effective accommodations and modifications for students with disabilities.

Focus on the individual student. During their discourse on accommodations and modifications, Principal A, Assistant Principal B, and Principal C highlighted the need to develop accommodations and modifications based on the individual needs of the student. Principal $\mathrm{C}$ explained in detail how he and his educators determine appropriate accommodations and modifications during SAT meetings or "informal IEP meetings." Principal A discussed the need to make accommodations meaningful and Assistant Principal B stated, "It just depends on the student." Table 34 provides a sample response from each principal that I used to develop this subtheme. 
Table 34

Focusing on the Individual Student

\begin{tabular}{ll}
\hline Principal & Sample Response \\
\hline Principal A & It's got to be for that kid. What works for him. \\
Asst. Principal B & It just depends on the student. \\
Principal C & $\begin{array}{l}\text { We have SAT meetings and we'll sit and talk for } 30 \text { minutes on one kid. We'll } \\
\text { say what does this kid need and what does this kid need in Math compared to } \\
\text { English. And right now what does this kid need. What is most important? }\end{array}$ \\
\hline
\end{tabular}

The standard stuff. When asked to describe how educators' accommodate and modify instruction for students with disabilities, Principal A, Assistant Principal B, and Principal C listed several testing and classroom accommodation and modifications. Principal A listed preferential seating, reading tests aloud, and modifying the amount of work. However, he stated, "The standard stuff, most of them are crap" and believed that good teaching should take the place of a list of accommodations and modifications. He expressed his belief about modifying the amount of work stating, "Don't just say he only has to do half of the 35 problem. Just make him show what he can do." Principal C also used the phrase "standard stuff" when describing the accommodations and modifications his educators use including extra time on tests and redirects. Like Principal A, Principal C also expressed his belief regarding the standard stuff, stating, "It looks good on paper but in reality are you just going to make him learn half his multiplication tables? Are you just going to make him only capitalize half the first words in half the sentences?" When asked about accommodations and modifications, Assistant Principal B listed the "standard stuff” Principal A referred to, including reading tests aloud, using agenda checks, extra time on tests, notes from the teachers, and allowing students to type their work. The most complete description of accommodations and modifications came from General Educator B. She was the only participant to describe how she provides specific accommodations for students with 
disabilities. Table 35 provides a sample response from each principal that I used to develop this subtheme.

Table 35

The Standard Stuff

\begin{tabular}{ll}
\hline Principal & Sample Response \\
\hline Principal A & $\begin{array}{l}\text { The standard stuff, most of them are crap. You put the kid in the front if he } \\
\text { needs it or you put him in the back if he needs that. }\end{array}$ \\
Asst. Principal B & $\begin{array}{l}\text { For IEPs, it varies from extra time and reading tests aloud. Our teachers use } \\
\text { agenda checks, notes from the teacher, and allowing students to type their } \\
\text { work }\end{array}$ \\
Principal C & $\begin{array}{l}\text { You've got your standard stuff like give more time for tests and redirects from } \\
\text { the teacher. }\end{array}$ \\
\hline
\end{tabular}

How do participating West Virginia principals ensure teachers use effective instructional strategies for students with disabilities?

WVDE Policy 5300.03 (1997) and WVDE Policy 5310 (2006) emphasized the importance of monitoring teachers' use of instructional strategies. Specifically, WVDE policymakers highlighted the importance of evaluating teachers in WVDE Policy 5300.03 (1997) stating principals will use "Personnel evaluation as a means to promote staff growth." Furthermore, the stated purpose of WVDE Policy 5310 (2006) is "To promote professional growth and development and assure quality performance in West Virginia schools." The purpose of research question five resided in understanding how principals assure quality instruction is provided to students with disabilities, assuming they have an understanding of what constitutes quality instruction. Data from this investigation converged on two themes concerning how principals create a system of standard or how they ensure educators use effective instructional strategies for students with disabilities. 
Checks and balances. Although the principals' discourse on this topic was limited, the methods they described align with their responsibilities outlined in WVDE Policy 5310 (2006). However, this was the only overarching theme at that did not have a least one subtheme with convergent data from all three cases. These themes address research question five by describing how participating West Virginia principals ensure teachers use effective instructional strategies for students with disabilities.

Observing teachers. When discussing how they ensure teachers use effective instructional strategies for students with disabilities, Principal A, Principal B, and Assistant Principal B mentioned observing teachers. Principal A stated he tries to observe classroom instruction on a "routine basis." Principal B and Assistant Principal B discussed how they conduct random "walk-throughs" of classrooms to observe teachers in addition to their mandatory observations. Special Educator B confirmed Principal B's presence in the classroom, stating "[Principal B will sometimes pop into the classrooms and observe." Although Principal C did not mention observing teachers, he did state that the assistant principal in charge of curriculum and instruction regularly attends team meetings. Table 36 provides a sample response from each principal that I used to develop this subtheme.

Table 36

Observing Teachers

\begin{tabular}{ll}
\hline Principal & Sample Response \\
\hline Principal A & $\begin{array}{l}\text { I try to be in the classroom and observe what's happening on a routine basis } \\
\text { so I know that the subjects that are being covered are educationally } \\
\text { appropriate and that we're following the CSO's for the state. }\end{array}$ \\
Principal B & $\begin{array}{l}\text { We're required to do walk-throughs. We're supposed to randomly walk } \\
\text { through classes to see what's going on. We're looking for any signs of } \\
\text { differentiation or anything besides lecturing. I can't say that we do them as } \\
\text { often as we should but we're in the halls constantly. }\end{array}$ \\
\end{tabular}


Reviewing lesson plans. In addition to observing teachers, Principal A and Principal B stated they review educators' lesson plans and provide them with written feedback. Principal A discussed how he reviews lesson plans to ensure educators are using instructional time effectively. Principal B stated that he reviews lesson plans for "any sign of differentiated instruction." Table 37 provides a sample response from each principal that I used to develop this subtheme.

Table 37

Reviewing Lesson Plans

\begin{tabular}{ll}
\hline Principal & Sample Response \\
\hline Principal A & $\begin{array}{l}\text { When the teachers turn in their lesson plans I go over them a couple times a } \\
\text { month. I'll sort through and make a checklist to see what they are doing. }\end{array}$ \\
Principal B & $\begin{array}{l}\text { I'm the one who does the lesson plan checks. I'm the one who gives them the } \\
\text { feedback and I do that every week and they get official written feedback at the } \\
\text { end of every term. }\end{array}$ \\
\hline
\end{tabular}

\section{Summary}

The purpose of this descriptive multiple case study was to provide a thick and rich description of how participating principals understand and practice instructional leadership for middle school students with disabilities. In accordance with this purpose, the results of this investigation described how principals define instructional leadership, communicate their education roles as the instructional leader, practice instructional leadership, define effective instruction for students with disabilities, and ensure teachers use effective instructional strategies. I presented the individual case results in Section 1 and the results of the cross-case synthesis in Section 2. Individual case results provided a detailed description of how the principals and assistant principals understood and practiced instructional leadership for middle school students with disabilities. The results presented did not include my subjective opinions or 
interpretations. The cross-case synthesis described the roles and responsibilities of the principals and assistant principals as well as the purpose of conducting educator observations according to the policies of the school system's Board of Education and the WVDE. Furthermore, the crosscase synthesis presented seven common themes associated with how the principals and assistant principals understood and practiced instructional leadership for middle school students with disabilities: (1) developing a school culture, (2) managing the Special Education program, (3) effective instruction is..., (4) effective instruction is not..., (5) where students with disabilities are educated, (6) accommodating and modifying instruction, and (7) checks and balances. The results of the cross-case synthesis provided the thick and rich description necessary to address the research questions. In Chapter 5, I will discuss my interpretations of the individual case results and the cross-case synthesis. 


\section{CHAPTER FIVE: Discussion}

Chapter 5 includes a summary of investigation, conclusions, and implications for field of Special Education and future research. I organized this chapter into five sections: (1) summary of the study, (2) summary of findings, (3) conclusions, (4) limitations, and (5) implications.

\section{Summary of the Study}

The purpose of this descriptive multiple case study was to in provide a thick and rich description of how participating principals understand and practice instructional leadership for middle school students with disabilities and included 3 areas of inquiry. First, I aimed to develop a better understanding of how participating principals define, communicate, and practice their role as the instructional leader for middle school students with disabilities. Second, I aimed to develop a better understanding of participating principals' perceptions of effective instructional strategies for middle school students with disabilities. Finally, I aimed to develop a better understanding of how participating principals ensure educators use evidenced-based instructional strategies for middle school students with disabilities. In accordance with this study's purpose, five research questions guided this investigation:

1. How do participating West Virginia principals define instructional leadership for students with disabilities?

2. How do participating West Virginia principals communicate their educational role as the instructional leader for students with disabilities?

3. How do participating West Virginia principals practice instructional leadership for students with disabilities?

4. How do participating West Virginia principals define effective instruction for students with disabilities? 
5. How do participating West Virginia principals ensure educators use effective instructional strategies for students with disabilities?

To address these research questions, I selected a multiple case study design with crosscase synthesis because this design allowed me to obtain in-depth information regarding instructional leadership for middle school students with disabilities in the natural setting without controlling for certain extraneous variables (e.g., instructional settings, methods of delivery, professional experience of participants, etc.). Utilizing this design, I selected an average-like (Patton, 2002) school system in West Virginia as the setting for this investigation. Each individual case focused on a middle school in the selected school system and the instructional leader of the schools. I attempted to recruit participants from all five middle schools in the school system, however, 2 principals declined to participate. Within each school, I interviewed the principal and assistant principal (when appropriate) to describe how they understood and practiced instructional leadership for middle school students with disabilities. I attempted to interview at least one special educator and one general educator from each school to confirm, refute, or elaborate on the responses provided by the principals. Despite recruitment efforts, Case B was the only case that included a general educator and a special educator. In addition to interviewing participants, I also analyzed principals' job descriptions, educator evaluation forms, and IEP documents to confirm, refute, or elaborate on principals' responses.

\section{Summary of Findings}

Results from the cross-case synthesis of the 3 case studies revealed seven overarching themes regarding how principals understood and practiced instructional leadership for middle school students with disabilities: (1) developing a school culture, (2) managing the Special Education program, (3) effective instruction is..., (4) effective instruction is not..., (5) where 
students with disabilities are educated, (6) accommodating and modifying instruction, and (7) checks and balances. In this section, I provided a brief summary of each overarching theme. I organized the themes according to the research question or questions it addressed. I discussed how the information gleaned from this investigation relates to the relevant literature in the conclusions section of this chapter.

\section{How do participating West Virginia principals define and communicate their} educational role as the instructional leader for students with disabilities? Principals defined and communicated their role as the instructional leaders for students with disabilities by discussing how they develop a school culture.

Developing a school culture. Throughout the interviews, principals explained the importance of creating a supportive learning environment for all students. Along with supporting students, they discussed the need to support educators in and out of the classroom.

Principal A, Principal B, Principal C, and Assistant Principal B also expressed the need to change educators' mindsets to create a school culture that promotes the academic achievement of all students. Finally, they described the importance of advocating for students with disabilities because, as Principal A stated, “students don't care how much you know until they know how much you care."

\section{How do participating West Virginia principals practice instructional leadership for} students with disabilities? Principals practiced instructional leadership for students with disabilities by managing the Special Education program at their school

Managing the Special Education program. When asked questions related to how they practice instructional leadership for students with disabilities, all 3 principals discussed attending IEP meetings. They also practiced instructional leadership by managing the schedule and 
creating instructional support time. Another theme that emerged regarding how principals practice instructional leadership for students with disabilities was managing discipline. Specifically, Principal B explained his unique way of using discipline referrals to promote the use of differentiated instruction by sending students with disabilities back to class if their teacher did not attempt to tailor the lesson to meet his or he needs. Principals B and C also discussed how they managed funds as part of their role as the instructional leader. Finally, Principals A and $\mathrm{C}$ discussed that they practice instructional leadership by providing educators with instructional resources such as computer labs and curriculum maps.

\section{How do participating West Virginia principals define effective instruction for}

students with disabilities? Principals defined effective instruction for students with disabilities by describing what they believed were effective and ineffective methods of delivery, effective educational settings, and effective accommodations and modifications.

Effective instruction is... When asked to define effective instruction for students with disabilities, principals discussed the importance of differentiating instruction to meet the needs of all students. Principals A, Principal B, and Assistant Principal B believed effective instruction was having students work together in "collaborative pairs." The same principals also believed that effective instruction was actively engaging students in the curriculum with "hands on" and "project-based" activities. Finally, Principals A and C explained that effective instruction is reflecting on "what worked, what didn't work, and why."

Effective instruction is not... In their discussion of effective methods of delivery for students with disabilities, two themes emerged regarding what principals believe is not effective. Principal A and Assistant Principal B believed that too many teachers "teach to the middle" and that students with disabilities are often not considered when educators plan instruction. In 
addition to teaching to the middle, Principals $\mathrm{A}$ and $\mathrm{C}$ believed that too many educators believe that effective instruction is reaching the end of the textbook. Overall, the principals believed that these instructional practices do not create a culture that supports the education of all students, especially students with disabilities.

Where students with disabilities are educated. Principals provided varying definitions of effective educational settings for students with disabilities. However, in all three middle schools, students with disabilities primarily received instruction in the general education classroom. Despite the use of an inclusive model for educating students with disabilities, Principal A expressed his belief that it is not the most appropriate setting to support academic achievement. In addition to the general education classroom, some students with disabilities also received instruction in pull out classrooms. The final theme that emerged was the use of heterogeneous or homogeneous grouping. Principal A believed that homogeneous grouping is more effective for students with disabilities. While Principal B stated he uses heterogeneous grouping, Special Educator B refuted this statement saying students are "lumped in" based on WESTEST performance.

Accommodating and modifying instruction. Principal A, Assistant Principal B, and Principal C stated effective accommodations and modifications for students with disabilities are based on the needs of individual students. They listed standard classroom and testing accommodations and modifications such as reading tests aloud, extra time on tests, and modifying the amount work. However, Principals A and C discussed the problems with the standard stuff. They believed that good teaching should replace giving a student only half the work. 


\section{How do participating West Virginia principals ensure educators use effective}

instructional strategies for students with disabilities? Principals ensure educators use of effective instructional strategies for students with disabilities by creating a system of "check and balances."

Checks and Balances. Principals created a system of checks and balances by observing classroom instruction and reviewing lesson plans. Principal B explained how he conducts random "walk throughs" of classrooms and reviews lesson plans for signs of differentiated instruction. Principal A discussed how he provides written feedback on lesson plans and monitors educators' instruction to ensure educators address all the West Virginia Content Standards and Objectives.

\section{Conclusions}

According to Leithwood et al. (2004, p. 5), "Leadership is second only to classroom instruction among all school-related factors that contribute to what students learn at school." Instructional leadership is defining and communicating the school's educational mission, managing the curriculum and instruction, supporting and supervising teachers, monitoring student's progress, and establishing high expectations for all students (DiPaola \& WaltherThomas, 2003). Perhaps no other group is in need of effective instructional leadership more than students with disabilities. National longitudinal data revealed that students with disabilities have lower post-high school outcomes than their peers without disabilities (Wagner et al., 2006). Additionally, students with disabilities continually fail to earn proficient scores on standardized tests, often causing schools to miss AYP benchmarks (Taylor et al., 2010). The need for effective instructional leadership is especially critical in West Virginia middle schools where 
pupil to administrator ratios can be twice as high as other schools and the standardized test scores of students with disabilities are amongst the lowest of all grades (WVDE, 2011a).

As the role of the principal evolved from the disciplinarian and the teachers boss to the instructional leader for all students (DiPaola \& Walther-Thomas, 2003; Searby, 2010), many believed that a disconnect between principal preparation and practice was emerging (Angelle \& Bilton, 2009; Lasky \& Karge, 2006; McHatton et al., 2010). Specifically, results from past research indicated that principals were ill prepared to serve as the instructional leader for students with disabilities because they lacked sufficient Special Education coursework (Styron Jr. \& LeMire, 2009). While previous attempts to reform principal preparation programs led to the development of national standards for principal preparation programs (Cooner et al., 2005), little changed regarding the amount of Special Education coursework included in principal preparation programs (Davis, 1980; McHatton et al., 2010). This is evident in West Virginia where a review of principal preparation programs and of the WVDE policy on principal certification revealed no requirements for principals to be educated in Special Education.

Prior to conducting this study, I believed the effects of this inadequate preparation would produce data that supported previous research, which indicated principals do not understand and practice effective instructional leadership for students with disabilities and are unable to define effective instruction for these students (Barnett \& Monday-Amaya, 1998; Garrison-Wade et al., 2007; Patterson et al., 2000). To mitigate my bias, I aimed only to describe how principals define and communicate their role as the instructional leader, how they practice that role, and how they define and ensure the use of effective instruction for students with disabilities. Results from this investigation provided a detailed description of how principals in an average-like 
school system understood and practiced instructional leadership for middle school students with disabilities.

Upon completion of the interviews with the principals, my initial feeling was that they knew more than I thought they would and I was going to refute previous research. For example, Principal C discussed how he communicates his values, beliefs, and goals to his staff to develop a school culture that supports the education of all students, which aligns with literature on effective instructional leadership (DiPaola \& Walther-Thomas, 2003). However, after further analysis, I believe that the results of this investigation support previous research, which recognized principals' limited understanding of instructional leadership for students with disabilities (Angelle \& Bilton, 2009; McHatton et al., 2010). Although Principal C described an effective instructional leadership practice for creating a supportive school culture, he was unable to identify any effective methods of delivery for students with disabilities and provided no description of how he ensures educators use effective instructional strategies.

The principals understood and practiced some aspects of effective instructional leadership (e.g., communicating values, beliefs, and goals, creating a supportive environment, and including students with disabilities in the general education classroom). However, the overall results of this investigation provided widely varying definitions and practices that did not align with the literature. Table 38 displays a matrix of my interpretations of the principals' levels of understanding of instructional leadership practices and effective instructional strategies for students with disabilities based upon existing literature and their job responsibilities outlined by the WVDE. 
Table 38

Interpretations of Principals' Level of Understanding

\begin{tabular}{|c|c|c|c|c|c|}
\hline Principal & $\begin{array}{c}\text { Definition of } \\
\text { Instructional } \\
\text { Leadership } \\
\end{array}$ & $\begin{array}{c}\text { Communicating the } \\
\text { Role of the } \\
\text { Instructional Leader }\end{array}$ & $\begin{array}{c}\text { Practice Instructional } \\
\text { Leadership }\end{array}$ & $\begin{array}{c}\text { Definition of Effective } \\
\text { Instruction }\end{array}$ & $\begin{array}{l}\text { Ensuring the Use of } \\
\text { Effective Instruction }\end{array}$ \\
\hline $\mathbf{A}$ & $\begin{array}{l}\text { MODERATE } \\
\text { Principal A discussed } \\
\text { the importance of } \\
\text { creating a supportive } \\
\text { environment for } \\
\text { students with } \\
\text { disabilities. } \\
\text { Principal A discussed } \\
\text { the importance of data } \\
\text { based decision-making. } \\
\text { Principal A defined } \\
\text { instructional leadership } \\
\text { as ensuring the use of } \\
\text { differentiated } \\
\text { instruction. }\end{array}$ & $\begin{array}{l}\text { MODERATE } \\
\text { Principal A discusses } \\
\text { effective instruction } \\
\text { with educators. } \\
\text { Principal A supports } \\
\text { the use of } \\
\text { differentiated } \\
\text { instruction. } \\
\text { Principal A } \\
\text { communicates the } \\
\text { importance of data } \\
\text { based decision-making } \\
\text { through dedicated } \\
\text { instructional time. }\end{array}$ & $\begin{array}{l}\text { MODERATE } \\
\text { Principal A practices } \\
\text { instructional leadership } \\
\text { by providing educators } \\
\text { with instructional } \\
\text { resources. } \\
\text { Principal A develops } \\
\text { the Special Education } \\
\text { program. } \\
\text { Principal A attends IEP } \\
\text { meetings. } \\
\text { Principal A manages } \\
\text { students' schedules. }\end{array}$ & $\begin{array}{l}\text { LIMITED } \\
\text { Principal A did not } \\
\text { describe any } \\
\text { evidenced-based } \\
\text { methods of delivery for } \\
\text { students with } \\
\text { disabilities. He only } \\
\text { briefly mentioned } \\
\text { active engagement and } \\
\text { peer interactions } \\
\text { Principal A believed } \\
\text { the inclusion of } \\
\text { students with } \\
\text { disabilities in the } \\
\text { general education } \\
\text { classroom and } \\
\text { heterogeneous } \\
\text { grouping was } \\
\text { ineffective. } \\
\text { Principal A provided } \\
\text { limited discourse on } \\
\text { accommodations and } \\
\text { modifications and } \\
\text { stated the "standard } \\
\text { stuff" was "crap." }\end{array}$ & $\begin{array}{l}\text { MODERATE } \\
\text { Principal A discussed } \\
\text { how he conducts } \\
\text { observes teachers and } \\
\text { reviews lesson plans. } \\
\text { However, Principal A } \\
\text { admitted that he does } \\
\text { not complete these } \\
\text { activities as often as he } \\
\text { should. }\end{array}$ \\
\hline
\end{tabular}




\begin{tabular}{cll} 
Principal & $\begin{array}{c}\text { Definition of } \\
\text { Instructional } \\
\text { Leadership }\end{array}$ & $\begin{array}{c}\text { Communicating the } \\
\text { Role of the } \\
\text { Instructional Leader }\end{array}$ \\
\hline B & LIMITED & LIMITED \\
& $\begin{array}{l}\text { Principal B defined } \\
\text { instructional leadership } \\
\text { as supporting teachers } \\
\text { and advocating for } \\
\text { students with } \\
\text { disabilities. }\end{array}$ & $\begin{array}{l}\text { Principal B discussed } \\
\text { that he communicates } \\
\text { his role as the } \\
\text { instructional leader by } \\
\text { changing educators' } \\
\text { mindsets. }\end{array}$
\end{tabular}

Principal B

communicates his role as the instructional leader by changing parents' mindsets about current instructional practices.

Educators believed Principal B had no relationship to instruction.

Principal B believed in heterogeneous grouping but educators reported homogeneous grouping.

Practice Instructional Definition of Effective Ensuring the Use of Leadership Instruction Effective Instruction

\section{LIMITED}

Principal B practices instructional leadership by managing discipline and managing funding.

Educators were unsure what his instructional leadership practices were.

\section{MODERATE}

Principal B discussion of effective instruction included group work and differentiated instruction. Although collaborative learning is considered an effective strategy, he did not discuss how it was applied in the classroom.

Principal B believed the inclusion of students with disabilities in the general education classroom is an effective educational setting. He also believed that heterogeneous grouping was effective. However, educators reported homogenous grouping.

Principal B did not discuss accom/mods

\section{MODERATE}

Principal B discussed how he conducts random walk-throughs of classrooms, observes teachers, and reviews lesson plans. However, Principal B admitted that he does not complete these activities as often as he should. 


\begin{tabular}{cll} 
Principal & $\begin{array}{c}\text { Definition of } \\
\text { Instructional } \\
\text { Leadership }\end{array}$ & $\begin{array}{c}\text { Communicating the } \\
\text { Role of the } \\
\text { Instructional Leader }\end{array}$ \\
\hline Asst. B & LIMITED & LIMITED \\
& $\begin{array}{l}\text { Assistant Principal B } \\
\text { defined instructional } \\
\text { leadership as } \\
\text { advocating for students } \\
\text { with disabilities and } \\
\text { supporting educators. }\end{array}$ & $\begin{array}{l}\text { Assistant Principal B } \\
\text { discussed how he talks } \\
\text { to educators about the } \\
\text { importance of } \\
\text { inclusion. }\end{array}$ \\
& & $\begin{array}{l}\text { Assistant Principal B } \\
\text { believed project based } \\
\text { learning was effective } \\
\text { but educators believed } \\
\text { direct instruction was } \\
\text { effective. }\end{array}$
\end{tabular}

Educators believed Assistant Principal B had no relationship to instruction.

Practice Instructional Definition of Effective Ensuring the Use of Leadership Instruction Effective Instruction

\section{LIMITED}

Assistant Principal B attends IEP meetings

Assistant Principal B develops behavior support plans.

Assistant Principal B ensures the Special

Education program complies with Federal and WVDE standards,

\section{MODERATE}

Assistant Principal B provided the best definition of evidencebased instruction for students with disabilities. She discussed the use of project-based learning and active engagement with the curriculum.

Assistant Principal B

believed that co-

teaching and including

students with

disabilities in the general education classroom was effective for students with disabilities.

Assistant Principal B

listed some assessment and classroom

accommodations and modifications used for students with disabilities that align with existing literature.

\section{LIMITED}

Assistant Principal B did not discuss any methods of how she ensures teachers use effective instructional strategies. 


\begin{tabular}{|c|c|c|c|c|c|}
\hline Principal & $\begin{array}{l}\text { Definition of } \\
\text { Instructional } \\
\text { Leadership }\end{array}$ & $\begin{array}{l}\text { Communicating the } \\
\text { Role of the } \\
\text { Instructional Leader }\end{array}$ & $\begin{array}{c}\text { Practice Instructional } \\
\text { Leadership }\end{array}$ & $\begin{array}{c}\text { Definition of Effective } \\
\text { Instruction }\end{array}$ & $\begin{array}{l}\text { Ensuring the Use of } \\
\text { Effective Instruction }\end{array}$ \\
\hline C & MODERATE & MODERATE & MODERATE & LIMITED & LIMITED \\
\hline & $\begin{array}{l}\text { Principal C defined } \\
\text { instructional leadership } \\
\text { as advocating for } \\
\text { students, creating } \\
\text { expectations for } \\
\text { educators, supporting } \\
\text { educators, and creating } \\
\text { a supportive } \\
\text { environment }\end{array}$ & $\begin{array}{l}\text { Principal C discussed } \\
\text { how he communicates } \\
\text { his values, beliefs, and } \\
\text { goals to the staff. } \\
\text { Principal C discussed } \\
\text { the importance of } \\
\text { communicating with } \\
\text { parents. } \\
\text { Principal C discussed } \\
\text { how he give educators } \\
\text { ownership in the } \\
\text { decision-making } \\
\text { process. }\end{array}$ & $\begin{array}{l}\text { Principal C practices } \\
\text { instructional leadership } \\
\text { by attending IEP } \\
\text { meetings, scheduling, } \\
\text { managing Title I funds, } \\
\text { providing } \\
\text { technology, } \\
\text { developing a positive } \\
\text { behavior support } \\
\text { system, and hiring } \\
\text { dedicated staff. } \\
\text { Although Principal C's } \\
\text { definition of } \\
\text { instructional leadership } \\
\text { included supporting } \\
\text { teachers and creating a } \\
\text { supportive learning } \\
\text { environment, he did } \\
\text { not describe how he } \\
\text { practices any of those } \\
\text { things. }\end{array}$ & $\begin{array}{l}\text { Principal C did not } \\
\text { describe any methods } \\
\text { of delivery for students } \\
\text { with disabilities only } \\
\text { the need for reflection } \\
\text { and differentiating } \\
\text { instruction. } \\
\text { Principal C believed } \\
\text { the inclusion of } \\
\text { students with } \\
\text { disabilities in the } \\
\text { general education class } \\
\text { was effective. } \\
\text { Principal C believed } \\
\text { the IEP team should } \\
\text { modify instruction for } \\
\text { a student with } \\
\text { disabilities to focus on } \\
\text { one subject at a time } \\
\text { because "There is no } \\
\text { way you can ask a kid } \\
\text { with a } 75 \text { IQ to keep up } \\
\text { in } 7 \text { classes and do } \\
\text { what everyone else is } \\
\text { doing when they have } \\
\text { a } 100 \text { IQ." This belief } \\
\text { does not align with } \\
\text { existing literature. }\end{array}$ & $\begin{array}{l}\text { Principal C did not } \\
\text { discuss any methods of } \\
\text { how he ensures } \\
\text { teachers use effective } \\
\text { instructional strategies }\end{array}$ \\
\hline
\end{tabular}




\begin{tabular}{|c|c|c|c|c|c|}
\hline Principal & $\begin{array}{c}\text { Definition of } \\
\text { Instructional } \\
\text { Leadership }\end{array}$ & $\begin{array}{c}\text { Communicating the } \\
\text { Role of the } \\
\text { Instructional Leader }\end{array}$ & $\begin{array}{c}\text { Practice Instructional } \\
\text { Leadership }\end{array}$ & $\begin{array}{c}\text { Definition of Effective } \\
\text { Instruction }\end{array}$ & $\begin{array}{l}\text { Ensuring the Use of } \\
\text { Effective Instruction }\end{array}$ \\
\hline \multirow[t]{2}{*}{ Asst. C } & LIMITED & LIMITED & LIMITED & LIMITED & LIMITED \\
\hline & $\begin{array}{l}\text { Assistant Principal C } \\
\text { did not define } \\
\text { instructional } \\
\text { leadership. He said he } \\
\text { has no role in } \\
\text { instruction. }\end{array}$ & $\begin{array}{l}\text { Assistant Principal C } \\
\text { did not discuss how he } \\
\text { communicates his role } \\
\text { as the education leader } \\
\text { because he does not } \\
\text { view it as one of his } \\
\text { roles. }\end{array}$ & $\begin{array}{l}\text { Assistant Principal C } \\
\text { stated he attends IEP } \\
\text { meetings. }\end{array}$ & $\begin{array}{l}\text { Assistant Principal C } \\
\text { did not discuss any } \\
\text { methods of delivery. } \\
\text { Assistant Principal C } \\
\text { did not discuss } \\
\text { educational settings. } \\
\text { Assistant Principal C } \\
\text { did not discuss any } \\
\text { accommodations or } \\
\text { modifications. }\end{array}$ & $\begin{array}{l}\text { Principal C did not } \\
\text { discuss how he ensures } \\
\text { teachers use effective } \\
\text { instructional strategies }\end{array}$ \\
\hline
\end{tabular}


Although it is beyond the scope of this investigation to make definitive correlations between the principals' responses and information gathered from the demographic surveys, some demographic variables may have influenced the principals' levels of understanding and are worth noting. For instance, Principal A, who had the least amount of experience but completed his certification program a decade later than Principals B and C, was the only principal to discuss the use of data based decision-making. Perhaps the more recent program emphasized data based decision-making as part of instructional leadership because of NCLB (2002). Additionally, the principals' prior experiences as a classroom teacher may have influenced their levels of understanding. Principal B and Assistant Principal B reported previous experience working with students with disabilities and expressed a moderate level of understanding of effective instructional strategies for students with disabilities. Principal $\mathrm{C}$ reported no previous experience working with students with disabilities and expressed a limited understanding. The principals' level of understanding of instructional leadership for students with disabilities may be associated with the amount of Special Education courses completed, which would support existing research (Praisner, 2003). Principal A and Principal B reported more Special Education courses than Principal $\mathrm{C}$ during their undergraduate teacher education programs. Assistant Principal B reported taking several Special Education courses unrelated to a degree or certification because she has a family member with a disability. Overall, those principals' definition of effective instructional strategies more closely aligned with existing literature than Principal C's definition. However, Principal C's discussion of how he communicates his educational role as the instructional leader for students with disabilities most closely aligned with existing literature. This may be related to the demographic characteristics of School C where over 70\% of the students were economically disadvantaged and over $14 \%$ of the students received services under 
an IEP. Perhaps, Principal C's years of experience in an "at-risk" school influenced his attitude toward the need to communicate his values, beliefs, and goals to the staff.

The remainder of this section includes my interpretations of the results as they relate to the existing literature on effective instructional leadership and effective instruction for students with disabilities. I organized this discussion by research question.

\section{How do participating West Virginia principals define instructional leadership for} students with disabilities? Overall, the principals' definitions of instructional leadership for students with disabilities were limited compared to how the literature and the WVDE defined instructional leadership. Most important, the principals placed a high value on creating a supportive environment for students with disabilities, supporting educators, and influencing educators mindsets, which research supports as a critical component of instructional leadership for students with disabilities (Billingsley, 2005; DiPaola et al., 2004; Furney et al., 2005). In fact, the principals discussed how they create a supportive culture throughout the interview and in different contexts. They defined it as a responsibility of the instructional leader, communicated it to educators, students, and parents, and practiced it through various means.

While I did not expect the principals to list all the job responsibilities defined in their job description in their definitions of instructional leadership, even as a group they did not cover the majority of what the school system and the literature says are part of their responsibilities. For instance, only one principal discussed the importance of data based decision-making, which is an essential responsibility for instructional leaders (Leithwood et al., 2004) and part of their defined role (WVDE, 2006). Furthermore, none of the principals demonstrated "knowledge of supervision to improve instruction" (WVDE, 2006, p. 14). Only Principal A's definition of instructional leadership even mentioned instruction. 
Even though the principals' beliefs about creating a supportive environment were encouraging, overall, their definitions of instructional leadership for students with disabilities lacked anything other than those beliefs. If I were to evaluate their instructional leadership performance based on what is listed on their job descriptions, Principal A would have met two of the five performance characteristics, while Principal B, Assistant Principal B, and Principal C would have only met one. Perhaps this is why the educators believed principals have no relationship to instruction.

\section{How do participating West Virginia principals communicate their educational role} as the instructional leader for students with disabilities? The principals discussed several methods they used to communicate their educational role as the instructional leader for students with disabilities including communicating values, beliefs, and goals to the staff, emailing educators, and encouraging the use of creative instructional strategies. These methods of communicating align with literature on instructional leadership, specifically the need for principals to communicate the school's educational mission (DiPaola \& Walther-Thomas, 2003; Leithwood et al., 2004). However, these practices were not reported across all three cases. Only Principal C discussed how he communicates his values, beliefs, and goals. Perhaps Principal C believed this was important because of the challenges of working in School C where 74\% of the students are economically disadvantaged and WESTEST score for students with disabilities are among the lowest in the state (WVDE, 2011a).

While Principal B provides his educators with emails regarding policy changes, there was a breakdown when it came to communicating about instruction. Principal B and Assistant Principal B did effectively communicate the importance of active engagement and project-based learning. For instance, Special Educator B stated she does not use those strategies and expressed 
her belief about project-based learning, "If you wait for them to discover something you'll be waiting a long time and they are never going to learn." Even more alarming was the belief held by General Educator B and Special Educator B that principals cannot do anything about instruction and cannot provide educators with instructional leadership. This presents a serious breakdown in communication between principals and educators as well as in the way research and policy about the principal's role is disseminated to practitioners. Despite all the research that demonstrates the importance of instructional leadership by principals, there are still educators who believe that instructional leadership is not "a role that [principals] should be stepping into."

The need for principals to communicate effectively with educators is emphasized in the literature (Billingsley, 2005) and is well defined in their job descriptions (WVDE, 2006). Despite the importance of communication, the principals shared a limited understanding of what it means to communicate and, more importantly, what they should be communicating to their educators.

\section{How do participating West Virginia principals practice instructional leadership for} students with disabilities? Principals listed several managerial practices (i.e., attending IEP meetings, managing discipline, and scheduling) for instructionally leading students with disabilities. Most of these practices align with literature regarding instructional leadership (Colvin, 2007; Portin, 2004) and the job responsibilities of principals defined by the WVDE (2006). In fact when asked about serving as the instructional leader for students with disabilities, the principals' initial discussions focused on attending IEP meetings. While these managerial practices are necessary for principals, they were the only topic of discussion regarding how they practiced instructional leadership. In their definitions of instructional leadership, principals discussed the importance of creating a supportive environment for students, supporting teachers, 
and changing educators' mindsets, including how they accomplish those tasks. However, when explicitly asked, "What is your role as the instructional leader for students with disabilities?" the principals never mentioned what they discussed in their definitions of instructional leadership. For instance, Principal B discussed how the instructional leader needs to be an advocate for students with disabilities. Yet, in his discussion of how he practices instructional leadership, he never mentioned how he advocates for students. Principal $\mathrm{C}$ also discussed the importance of advocating for students with disabilities and supporting teachers in public. However, when asked to describe his role as the instructional leader he only discussed managerial duties. Similarly, Principal A's description of how he practices instructional leadership focused on attending IEP meetings and managing schedules. He never discussed how he develops the "whole child" that he mentioned in his definition of instructional leadership.

Overall, this suggests that there may be a disconnect between what principals believe is effective instructional leadership for students with disabilities and what they do as the instructional leader. Perhaps today's principals are so overburdened with managerial responsibilities such as attendance, discipline, and budgeting that they have little time for anything else. The educators interviewed in this investigation believed their principals only performed these managerial tasks. Maybe the quote by Tucker and Codding $(2002$, p. 1) holds some truth:

Why would anyone want the job of principal? Many school principals we know have the look these days of the proverbial deer caught in the headlights. Almost overnight, it seems, they have been caught in the high beams of the burgeoning accountability movement.

However, it is worth noting that despite the emphasis found in the literature (Foley \& Nelson, 2011) and the emphasis I placed on NCLB, accountability, and AYP, none of these principals even mentioned these topics. In spite of the fact that all three schools were labeled as 
in need of improvement, not one principal referred to them in describing the role as the instructional leader. Even with the threat of corrective action from the WVDE, no one thought his job was in jeopardy because students with disabilities could not achieve mastery on WESTEST. What they did in their day-to-day jobs as principals, as instructional leaders appeared to be unaffected by NCLB and the corrective action mandates that research has emphasized as a concern for principals (Tucker \& Codding, 2002).

\section{How do participating West Virginia principals define effective instruction for} students with disabilities? Data that addressed this research question support previous research regarding how principals define and understand effective instruction for students with disabilities (Barnett \& Monda-Amaya, 1998; Rascoe, 2007). Across the three domains of effective instruction, (a) methods of delivery, (b) instructional settings, and (c) accommodations and modifications, principals demonstrated limited understanding of what represents evidence-based instructional strategies.

Definition of effective methods of delivery. When asked to define effective instruction for students with disabilities, the only method of delivery that the principals could discuss in detail was the use of differentiated instruction. While this important for the appropriate education of students with disabilities, differentiated instruction is an educational philosophy that encompasses many instructional strategies and is not considered a specific method of delivery (Hall, Strangman, \& Meyer, 2003). Although they did not define specific methods of delivery, Principal A, Principal B, and Assistant Principal B discussed the importance of "actively engaging" students with the curriculum and expressed their beliefs that "just lecturing does not work." Principal A mentioned "appropriate peer interactions" but never defined what it means as far as instruction, which is important because the phrase could be interpreted in a number of 
ways. Assistant Principal B provided the best definition of effective instruction when she briefly mentioned project-based learning. However, after interviewing Special Educator B, I learned that some educators when instructing students with disabilities do not practice this method of delivery. Principal C provided no clear definition of effective methods of delivery for students with disabilities other than to discuss the importance of educators reflecting on instruction. After I initially asked him to define effective instruction for students with disabilities, I followed up by asking him what his educators did in the classroom hoping to prompt a discussion of instructional strategies. Instead, what I got was an example of how an educator uses a Rolodex to keep track of lessons.

This represents a critical deficiency in these principals' understanding of effective instructional leadership for students with disabilities. Knowledge of evidenced-based instructional strategies is essential to ensuring their use (Praisner, 2003). If principals do not know what evidenced-based instruction is, how can they promote and ensure its use?

Definition of effective instructional settings. In their definitions of effective instructional strategies, all three principals discussed that their students with disabilities received instruction primarily in general education classrooms and occasionally in pull out classrooms. While this practice aligns with research on the most appropriate educational setting for students with disabilities (Bowers, 2009; Emery, 2009), not all the principals agreed that it is the most effective. Principal A beliefs of inclusion did not align with the findings from previous research. Speaking very passionately, Principal A stated that the general education classroom was not the most appropriate setting for students with disabilities because it did not meet the needs of individual students. This creates a unique situation in School A. Although Principal A does not believe inclusion is appropriate, his school operates under an inclusive model. This is most 
likely the result of school system mandates but it creates a dilemma. If Principal A does not believe inclusion is appropriate, what kind of message is he relaying to his educators? According to findings from previous research, whether conscious of it or not, principals affect the culture of the school and attitudes of the teachers through their own beliefs and actions (Furney et al., 2005; Murtadha-Watts \& Stoughton, 2004). Principal A defined instructional leadership as creating a supportive environment. If he does not believe that the general education classroom is appropriate for students with disabilities, perhaps he is not creating a supportive learning environment for those students. Furthermore, he discussed his disappointment that the Board of Education overturned his practice of homogeneously grouping students. Again, what message does Principal A portray by complaining about the decision to restructure his classes in a way he does not agree with?

A similar situation appeared in Case B. Although the principals believed that inclusion was most appropriate, Special Educator B did not. There was disagreement related to regarding "leveling" in Case B. The principals stated that they did not level. However, Special Educator B discussed how the low performing students are "lumped together" with the students with disabilities.

To have such divided beliefs regarding where students with disabilities receive their education presents a serious threat to the learning environment. Clearly Principal A is being forced to use a practice that he does believe is effective. Therefore, how can Principal A create a supportive learning environment for students with disabilities in the general education classroom if he does not believe it is effective? Perhaps, we, as educational researchers, are not reaching those who need our information the most. 
Definition of effective accommodations and modifications. Research has found that when students with disabilities are provided with testing accommodations their performance on standardized tests improves (Meloy et al., 2002; Schulte et al., 2001). Surprisingly, the only mention of testing accommodations came during principals' brief discussions of how the "standard stuff is crap." Instead of emphasizing the importance of providing students with disabilities appropriate testing accommodations to promote higher test scores, the principals demonstrated a limited understanding of accommodations and modifications. Even after I probed further, they never mentioned WESTEST accommodations. Again, this goes back to my previous discussion that principals do not focus on AYP like the literature suggests. Or perhaps, principals have given up trying to get students with disabilities to achieve mastery as Principal B and Assistant Principal B alluded to when Assistant Principal B stated, “They probably wouldn't [achieve mastery] anyways" and Principal B followed with, "They're not. They're not going to be above mastery or even mastery." What does that say about the current state of instructional leadership for students with disabilities if principals do not believe their students are capable of succeeding? I believe it says a lot. It is saying that they have given up hope. It is saying that despite their beliefs about creating a supportive environment for all students to learn, they expect that an entire group will still fail.

\section{How do participating West Virginia principals ensure educators use effective} instructional strategies for students with disabilities? Literature on effective instructional leadership (Leithwood et al., 2004) and the job description for principals from the WVDE (2006) emphasize the need for principals to monitor and observe educators to ensure they use effective instructional strategies. The principals in Case A and Case B discussed instructional leadership practices (e.g., reviewing lesson plans and observing instruction) that aligned with the literature 
and their job description. The educators in Case B even confirmed the practices. However, the principals admitted that they do not perform these tasks as diligently as they should. General Educator B stated that after the first three years of employment "you still see them occasionally but it's not really in the same kind of context." Principal C never mentioned reviewing lesson plans or observing teachers. All he discussed was how his assistant principal in charge of curriculum and instruction attends team meetings.

Herein lays a fundamental problem with the practice of instructional leadership. Too often educators are left to their own instructional practices, whether they are appropriate or not. How often is Special Educator B observed if she only uses repeated direct instruction, when Assistant Principal B, who is in charge of observing Special Education teachers, believes "handson" and project-based learning is more effective?

The principals all talked about the importance of providing instructional leadership by citing a number of practices that align with existing research but then they admitted that they do not monitor instruction as they should. In order to change the way educators provide instruction to students with disabilities, the instructional leader must know what is going on in the classroom. Just because a teacher writes it in a lesson plan and submits it at the end of the week does not mean it took place.

\section{Limitations}

The strength of a descriptive multiple case study design is the depth of knowledge the researcher obtains regarding a phenomenon. What the case study researcher sacrifices is the ability to make strong generalizations of the results beyond the investigation (Flick, 2009). The use of purposeful sampling also limits generalization because the researcher cannot represent, within reason, all the variability within a population (Flick, 2009). It was unreasonable to 
interview all the principals in the state. Therefore, I was unable to account for all the variables associated with research on this population.

In addition to the limitations of case study research, this investigation was limited by the absence of data from two middle schools in the selected school system. Despite recruitment efforts, which included several emails beyond the two emails originally planned and additional phone calls to the schools, principals from two of the five middle schools identified as potential cases declined to participate in this investigation. The information from these cases would have strengthened the overall results of the cross-case synthesis. Also, the lack of participation from general and special educators for Case A and Case C limited this investigation. Again, despite repeated attempts to recruit educators, which included several emails to the educators, additional emails to the principals asking them to talk to educators about participation, and modifying the interview format from face-to-face to phone, only 2 educators agreed to participate in the investigation. The lack of educator participation limits the strength of the results from the interviews with Principal A, Principal C, and Assistant Principal C because I was unable to confirm or refute their responses.

Despite these limitations, the results of this investigation provided valuable insight into how principals understand and practice instructional leadership for middle school students with disabilities because "the validity, meaningfulness, and insights generated from qualitative inquiry have more to do with the information richness of the cases selected and observational/analytical capabilities of the research than with sample size" (Patton, 2002, p. 245). While information from educators would have validated the principals' responses, the absence of their information does not diminish the richness of the data collected. Following the procedures outlined in Chapter 3, I was able to interview five principals in three schools and inquire how they define, 
communicate, and practice instructional leadership and how they define and ensure the use of effective instructional strategies for students with disabilities. Based on my systematic analysis of this information, I was able to develop seven overarching themes regarding this phenomenon and describe, in detail, how instructional leadership for middle school students with disabilities occurred in an average-like school system in West Virginia. If the results of this investigation had refuted existing literature that reported that principals have a limited understanding of instructional leadership and effective instruction for students with disabilities, data confirming the principals' responses would have been crucial. However, the results of my analysis confirm the existing literature. Like previous studies (Angelle \& Bilton, 2009; Garrison-Wade et al., 2007), results from this investigation revealed that principals have a limited understanding of instructional leadership. Even if they were only saying what they thought I wanted to hear, their responses still did not align with research on effective instructional leadership.

Furthermore, I believe the unwillingness to participate in this investigation provides meaningful insight into the phenomenon of instructional leadership for students with disabilities. Following the initial recruitment emails sent to principals, I had no one agree to participate. It was not until I sent repeated emails and made phone calls to the schools that any of the principals agreed to participate. In fact, Principal A responded to the initial email and stated that he did not think he could help me. He reconsidered after a series of emails in which I explained the purpose of the investigation and the types of questions I would be asking him. This begs the question, "Why were principals so resistant to participating in this investigation?" One principal, who declined to participate, cited time constraints, but the others offered no reason for declining my initial request. Perhaps they were intimidated by the topic of the investigation. After all, none of the middle schools in the school system met WESTEST proficiency standards for 
students with disabilities (WVDE, 2011b). Perhaps the educators at School A and School C declined to participate in this investigation for the same reason. On the other hand, educators from these schools may have been reluctant to talk about their principals at all.

Other researchers investigating instruction for students with disabilities have encountered participation problems (Heckert, 2009; Lynch, 2011; Powers, 2007). Why is it that when someone tries to investigate instruction for students with disabilities educators and administrators opt out of the conversation? I believe the reason for the lack of participation (and the overall attitude it may reflect) it is that many educational stakeholders are uncomfortable discussing instruction for students with disabilities because they are unsure of what effective instruction is. The comments of the principals and educators who participated in this investigation support this belief. Although they agreed to join the conversation, they did not demonstrate an understanding of effective instruction for students with disabilities.

\section{Implications}

Upon reviewing the results of this investigation, I have identified implications from this study regarding (a) principal preparation, (b) professional development, and (c) future research.

Implications for principal preparation. The intended audience for this research was the IHEs in West Virginia that offer principal certification and the educational policy makers of the WVDE and in the West Virginia Legislature who develop the certification guidelines for West Virginia principal preparation programs. I believe that the results of this investigation provide valuable information to this audience and have direct implications for the way West Virginia prepares future principals. Results from this investigation revealed that, although all the principals reported some Special Education coursework as part of their principal preparation programs, they showed only a limited understanding of instructional leadership for students with 
disabilities. While the principals were able to discuss some important responsibilities of the principal as the instructional leader, overall, their responses failed to address key aspects of this role. One area of understanding that was more limited than others was their knowledge of effective instruction for students with disabilities. When asked about effective instruction for students with disabilities, as a group the principals were unable to state or describe effective instructional strategies for these students other than citing the need for differentiated instruction.

Therefore, results from this investigation support the need to rethink the way we prepare principals for this important role. As more students with disabilities receive instruction in the general education setting, principals must be more knowledgeable about how to provide instruction to these students. Principal preparation programs need to cover evidenced-based instructional strategies that enhance the performance of all students, especially students with disabilities. Armed with this knowledge base, principals will be more effective instructional leaders by advocating for the use of effective instructional strategies, providing teachers with professional development opportunities on effective instruction, and knowing what to look for when observing educators in the classroom. Such topics should include the use of peer-tutoring, cognitive, and metacognitive strategies, the importance of heterogeneous grouping, and the education of students with disabilities in the general education classroom.

To accomplish this, certification policies and certification programs for principals need to adopt core competencies that focus specifically on the education of students with disabilities. Currently, the core competencies adopted by the WVDE and used by IHEs offering principal certification focus on the education of all students. The result of these competencies may be a focus on "teaching to the middle." For preparation programs to prepare principals to ensure an appropriate education for students with disabilities, the core competencies for principals must 
include Special Education language. For instance, instead of using the phrase all students, the core competencies should explicitly include the term students with disabilities.

Implications for professional development. While this research has implications for the way West Virginia prepares future principals, it also has implications for professional development efforts to enhance current principals' knowledge of Special Education. As one principal stated "I attend all the IEP meetings... but I'm not the expert." This presents a problem in West Virginia schools because the principal serves as the "district representative" and signs all IEP documents as the chairperson. If principals are expected to represent the school system and act as the legal representative responsible for Special Education compliance, they need to an expert in Special Education related the large majority of students with disabilities, which are those students who receive their education in the general education classroom. Principals like Assistant Principal $\mathrm{C}$ admitted he did not receive adequate Special Education preparation during his preparation program. Therefore, the WVDE needs to provide professional development to address the needs of principals like Assistant Principals $\mathrm{C}$ before requiring their signatures on IEP documents. Professional develop should prepare principals to be able to discuss evidencebased instructional strategies for students with disabilities. Specifically, principals should understand that effective instruction for students with disabilities includes more than direct repeated instruction. They also need to understand the benefits of including students with disabilities in the general education classroom and the importance of heterogeneous grouping. Finally, principals need to understand the importance of providing appropriate assessment accommodations to potentially increase the standardized test scores of students with disabilities.

Putting educators and principals on the same page. A surprising finding from this investigation was educators' beliefs that principals have no role as the instructional leader, nor 
should they. Both General Educator B and Special Educator B expressed this belief when asked what they thought was effective instructional leadership for students with disabilities. Despite principals' beliefs and the research that supports the importance of principals serving as the instructional leader, these teachers stated it was not the principal's job. This finding highlights the need for professional development to bridge this disconnect between educators and principals. Often in schools, principals and educators receive separate professional development. While the educators are learning about a new textbook series or new IEP forms, principals are learning about budgets and building maintenance. Is it any wonder why educators feel disconnected from principals and believe they have no relationship to instruction? To provide students with disabilities with the most appropriate education in the general education classroom, principals and educators need to learn together. By putting principals and educators on the same page regarding effective instruction for students with disabilities, educators may begin to understand the role principals can play in instruction and principals will know how their educators are supposed to be teaching.

Furthermore, research indicates that educators are more likely to implement instructional strategies through coaching rather than traditional professional development sessions (Joyce \& Showers, 2002). Therefore, effective instructional leaders need to understand the value of using coaches to communicate the importance of using evidenced-based instructional strategies. By becoming involved in the coaching process, principals may begin to illustrate their role as the instructional leaders to their educators.

Implications for future research. The purpose of this investigation was to describe how principals in an average-like school system in West Virginia understood and practiced instructional leadership for students with disabilities. This research differed from past 
investigations of principals' knowledge of Special Education because it focused specifically on instructional leadership for middle school students with disabilities. Furthermore, unlike past research, which included principals identified as exemplary instructional leaders for students with disabilities (Heckert, 2009), participants for this investigation were not selected based on such identifiers. Therefore, this study makes an important contribution to the fields of Special Education and Instructional Leadership by describing how principals in an average-like school system serves as the instructional leader for students with disabilities.

Future research on this topic should include a larger sample size of participants from additional average-like school systems and participants from a wider range of school systems. This information would strengthen the findings of this investigation and have a greater impact on policy and practice. Other research should examine if the educators' beliefs about the principal's relationship to instruction expressed in this study are common in other schools. This information would further document the need for collaborative professional development and/or the need for principals to understand the importance communicating of their educational role as the instructional leader. 


\section{References}

Acker-Hocevar, M., \& Cruz-Janzen, M. (2008). Teacher and principal preparation programs: Reforms that sustain high performance and learning in high poverty and diverse schools. International Journal of Learning, 14(10), 87-95.

Allsopp, D. H. (1997). Using classwide peer tutoring to teach beginning algebra. Remedial \& Special Education, 18(6), 367-379.

Angelle, P., \& Bilton, L. M. (2009). Confronting the unknown: Principal preparation training in issues related to Special Education. AASA Journal of Scholarship \& Practice, 5(4), 5-9.

Bakken, J. P., Mastropieri, M. A., \& Scruggs, T. E. (1997). Reading comprehension of expository science material and students with learning disabilities: A comparison of strategies. Journal of Special Education, 31(3), 300-324.

Barnett, C., \& Monda-Amaya, L. E. (1998). Principals' knowledge of and attitudes toward inclusion. Remedial and Special Education, 19(3), 181-192.

Bays, D. A., \& Crockett, J. B. (2007). Investigating instructional leadership for Special Education. Exceptionality, 15(3), 143-161.

Berkeley, S., Mastropieri, M. A., \& Scruggs, T. E. (2011). Reading comprehension strategy instruction and attribution retraining for secondary students with learning and other mild disabilities. Journal of Learning Disabilities, 44(1), 18-32.

Billingsley, B. S. (2005). Cultivating and keeping committed Special Education teachers: What principals and district leaders can do. Thousand Oaks, CA: Corwin Press.

Black, J. A. M. (1992). West virginia principals' perceptions of the importance of selected instructional leadership competencies and their desired levels of training (Doctoral dissertation). West Virginia University, Morgantown, WV. 
Bonar, R. (1937). The status of the secondary-school principal of West Virginia during the school year 1935-36 (Thesis). West Virginia University, Morgantown, WV.

Boardman, A. G., Arguelles, M. E., Vaughn, S., Hughes, M. T., \& Klingner, J. (2005). Special Education teachers' views of research-based practices. Journal of Special Education, 39(3), 168-180.

Boscardin, M. L. (2005). The administrative role in transforming secondary schools to support inclusive evidence-based practices American Secondary Education, 33, 21-32.

Bowers, C. T. (2009). Effectiveness of inclusion in an Indiana middle school (Doctoral dissertation). Walden University.

Brown, A. B., \& Clift, J. W. (2010). The unequal effect of adequate yearly progress: Evidence from school visits. American Educational Research Journal, 47(4), 774-798.

Brown, P. F. (2006). Preparing principals for today's demands. Phi Delta Kappan, 87(7), 525526.

Burns, M. K., \& Ysseldyke, J. E. (2009). Reported prevalence of evidence-based instructional practices in Special Education. Journal of Special Education, 43(1), 3-11.

Colvin, G. (2007). Seven steps for developing a proactive schoolwide discipline plan: A guide for principals and leadership teams. Thousand Oaks, CA: Corwin Press.

Cooner, D., Tochterman, S., \& Garrison-Wade, D. (2005). Preparing principals for leadership in Special Education: Applying ISLLC standards. NASSP document. Retrieved from http://www.nassp.org/Portals/0/Content/49135.pdf

Council of Chief State School Officers (2008). Educational Leadership Policy Standards: ISLLC 2008. Retrieved from http://www.ccsso.org/publications/details.cfm?PublicationID=365 
Crockett, J. B. (2002). Special Education's role in preparing responsive leaders for inclusive schools. Remedial and Special Education, 23(3), 157-168.

Crotty, M. (2003). The foundations of social research: Meaning and perspective in the research process. Thousand Oaks, CA: Sage Publications.

Cruzeiro, P. A., \& Morgan, R. L. (2006). The rural principal's role with consideration for Special Education. Education, 126(3), 569-579.

Davidson, D. N., \& Algozzine, B. (2002). Administrators' perceptions of Special Education law. Journal of Special Education Leadership, 15(2), 43-48.

Davis, W. E. (1980). An analysis of principal's formal training in Special Education. Education, 101(1), 89-94.

Delaney, E. M. (2001). The administrator's role in making inclusion work. Young Children, $56(5), 66-70$.

DeMik, S. A. (2008). Experiencing attrition of Special Education teachers through narrative inquiry. High School Journal, 92(1), 22-32.

DiPaola, M., Tschannen-Moran, M., \& Walther-Thomas, C. (2004). School principals and Special Education: Creating the context for academic success. Focus on Exceptional Children, 37(1), 1-10.

DiPaola, M., \& Walther-Thomas, C. (2003). Principals and Special Education: The critical role of school leaders (COPPSE document no. Ib-7). Gainesville, FL: University of Florida, Center on Personnel Studies in Special Education.

Emery, L. (2009). Academic achievement of middle school students with specific learning disabilities in inclusive cotaught classes (Doctoral dissertation). Walden Universtiy. 
Fletcher, J. M., Francis, D. J., Boudousquie, A., Copeland, K., Young, V., Kalinowski, S., \& Vaughn, S. (2006). Effects of accommodations on high-stakes testing for students with reading disabilities. Exceptional Children, 72(2), 136-150.

Flick, U. (2009). An introduction to qualitative research (4th ed.). Thousand Oaks, CA: Sage Publications.

Flyvbjerg, B. (2011). Case study. In N. K. Denzin \& Y. S. Lincoln (Eds.), The SAGE handbook of qualitative research (4th ed., pp. 301-316). Thousand Oaks, CA: Sage Publicaitons.

Foley, G., \& Nelson, S. (2011). The impact of Annual Yearly Progress on middle school principals job satisfaction. National Forum of Educational Administration \& Supervision Journal, 28(2), 27-50.

Furney, K. S., Aiken, J., Hasazi, S., \& Clark/Keefe, K. (2005). Meeting the needs of all students: Contributions of effective school leaders. Journal of School Leadership, 15(5), 546-570.

Garrison-Wade, D., Sobel, D., \& Fulmer, C. L. (2007). Inclusive leadership: Preparing principals for the role that awaits them. Educational Leadership \& Administration, 19, 117-132.

Gentilluci, J. L., \& Muto, C. C. (2007). Principals' influence on academic achievement: The student perspective. NASSP Bulletin, 91(3), 219-236.

Gerring, J. (2007). Case study research: Principles and practices. New York, NY: Cambridge University Press.

Guzman, N. (1997). Leadership for successful inclusive schools: A study of principal behaviours. Journal of Educational Administration, 35(5), 439-450.

Hall, T., Strangman, N., \& Meyer, A. (2003). Differentiated instruction and implications for udl implementation. Wakefield, MA: National Center on Accessing the General Curriculum. 
Heckert, J. M. (2009). A multiple case study on elementary principals' instructional leadership for students with learning disabilities (Doctoral dissertation). University of Texas at Austin, Austin, TX.

Herrington, C. D., \& Wills, B. K. (2005). Decertifying the principalship: The politics of administrator preparation in Florida. Educational Policy, 19(1), 181-200.

Hess, F. M., \& Kelly, A. P. (2007). Learning to lead: What gets taught in principal-preparation programs. Teachers College Record, 109(1), 244-274.

Irvine, A., Lupart, J., Loreman, T., \& McGhie-Richmond, D. (2010). Educational leadership to create authentic inclusive schools: The experiences of principals in a Canadian rural school district. Exceptionality Education International, 20(2), 70-88.

Johnson, B., \& Christensen, L. (2012). Educational research: Quantitative, qualitative, and mixed approaches. Thousand Oaks, CA: Sage Publications.

Joyce, B., \& Showers, B. (2002). Student achievement through staff development $\left(3^{\text {rd }} e\right.$ d.). Alexandria, VA: Association for Supervision and Curriculum Development.

Kavanaugh, A. L. (2005). Introduction to principalship. In J. Shen (Ed.), School principals (pp. 1-13). New York: Peter Lang Publishing, Inc.

Kluger, R. (1975). Simple justice: The history of Brown v. Board of Education and black America's struggle for equality. New York, NY: Vintage Books.

Lasky, B., \& Karge, B. D. (2006). Meeting the needs of students with disabilities: Experience and confidence of principals. NASSP Bulletin, 90(1) 19-36.

Leithwood, K., Louis, K. S., Anderson, S., \& Wahlstrom, K. (2004). How leadership influences student learning. New York: Wallace Foundation. 
Linn, R. L., Baker, E. L., \& Betebenner, D. W. (2002). Accountability systems: Implications of requirements of the no child left behind act of 2001. Cse technical report.

Lynch, S. D. (2011). The current state of Algebra I instruction for students with mathematical learning disabilities in West Virginia (Doctoral dissertation). West Virginia Universtiy, Morgantown, WV.

Lyons, J. E., \& Algozzine, B. (2006). Perceptions of the impact of accountability on the role of principals. Education Policy Analysis Archives, 14(16), 1-16.

Mastropieri, M. A., Scruggs, T. E., Mohler, I., Spencer, V., Book, R. T., \& Talbott, E. (2001). Can middle school students with serious reading difficulties help each other and learn anything? Learning Disabilities Research \& Practice, 16(1), 18-27.

Mastropieri, M. A., Scruggs, T. E., Norland, J. J., Berkeley, S., McDuffie, K., Tornquist, E. H., \& Connors, N. (2006). Differentiated curriculum enhancement in inclusive middle school science: Effects on classroom and high-stakes tests. Journal of Special Education, 40(3), $130-137$.

McHatton, P. A., Boyer, N. R., Shaunessy, E., \& Terry, P. M. (2010). Principals' perceptions of preparation and practice in gifted and Special Education content: Are we doing enough? Journal of Research on Leadership Education, 5(1) 1-22.

Meloy, L. L., Deville, C., \& Frisbie, D. A. (2002). The effect of a read aloud accommodation on test scores of students with and without a learning disability in reading. Remedial \& Special Education, 23(4), 248-255.

Melton, J. (1971). Role perceptions of the elementary school principalship. The National Elementary Principal, 50(4) 40-43. 
Merriam-Webster. (2011). Evolution, Retrieved from http://www.merriamwebster.com/dictionary/evolution.

Mertens, D. M. (2009). Research and evaluation in education and psychology: Integrating diversity with quantitative, qualitative, and mixed methods. Thousand Oaks, CA: Sage Publications.

Mills, B. D. (1974). A survey of the elementary school principalship in West Virginia (Doctoral dissertation). West Virginia University, Morgantown, WV.

Murtadha-Watts, K., \& Stoughton, E. (2004). Critical cultural knowledge in Special Education: Reshaping the responsiveness of school leaders. Focus on Exceptional Children, 37(2), 18.

Neuendorf, K. A. (2002). The content analysis guidebook. Thousand Oaks, CA: Sage Publications.

No Child Left Behind Act of 2001, Pub. L. No. 107-110, 115 Stat. 1425 (2002).

Patterson, J., Marshall, C., \& Bowling, D. (2000). Are principals prepared to manage Special Education dilemmas? NASSP Bulletin, 84(613), 9-20.

Patton, M. Q. (2002). Qualitative research and evaluation methods. Thousand Oaks, CA: Sage Publications.

Popper, K. (1959). The logic of scientific discovery. New York: Basic Books.

Portin, B. (2004). The roles that principals play. Educational Leadership, 61(7), 14-18.

Praisner, C. L. (2003). Attitudes of elementary school principals toward the inclusion of students with sisabilities. Exceptional Children, 69(2), 135-145.

Quinn, D. M. (2002). The impact of principal leadership behaviors on instructional practice and student engagement. Journal of Educational Administration, 40(5), 447-467. 
Rascoe, P. A. (2007). An analysis of Virginia's high school principals educational background, knowledge and perceptions related to Special Education (Doctoral dissertation). Virginia Polytechnic Institute and State University, Blacksburg, VA.

Rea, P. J., McLaughlin, V. L., \& Walther-Thomas, C. (2002). Outcomes for students with learning disabilities in inclusive and pullout programs. Exceptional Children, 68(2), 203222.

Reeves, C. (2003). Implementing the No Child Left Behind Act: Implications for rural schools and districts. Naperville, Illinois: North Central Regional Educational Laboratory.

Rosenthal, G. (2004). Biographical research. In C. Seale, G. Gobo, J. F. Gubrium \& D. Silverman (Eds.), Qualitative research practice (pp. 48-64). Thousand Oaks, CA: Sage Publications.

Scholz, R. W., \& Tietje, O. (2002). Embedded case study methods: Integrating quantitative and qualitative knowledge. Thousand Oaks, CA: Sage Publications.

Schulte, A. A. G., Elliott, S. N., \& Kratochwill, T. R. (2001). Effects of testing accommodations on standardized mathematics test scores: An experimental analysis of the performances of students with and without disabilities. School Psychology Review, 30(4), 527-547.

Searby, L. J. (2010). Preparing future principals: Facilitating the development of a mentoring mindset through graduate coursework. Mentoring \& Tutoring: Partnership in Learning, $18(1), 5-22$.

Stake, R. E. (2006). Multiple case study analysis. New York, NY: Guilford Press.

Stoner, J. B. (2010). Qualitative research in education: Other methods of seeking knowledge. In F. E. Obiakor, J. P. Bakken \& A. F. Rotatori (Eds.), Current issues and trends in Special 
Education: Research, technology, and teacher preparaion (pp. 19-39). Bingley, UK: Emerald Group Publishing Limited.

Styron Jr., R. A., \& LeMire, S. D. (2009). Principal preparation programs: Perceptions of high school principals. Journal of College Teaching \& Learning, 6(6), 51-62.

Supovitz, J., Sirinides, P., \& May, H. (2010). How principals and peers influence teaching and learning. Educational Administration Quarterly, 46(1), 31-56.

Swanborn, P. (2010). Case study research: What, why and how? Thousand Oaks, CA: Sage Publications.

Taylor, J., Stecher, B., O'Day, J., Naftel, S., \& Le Floch, K. C. (2010). State and local implementation of the "No Child Left Behind Act". Volume IX--accountability under "NCLB": Final report. Washington, DC: US Department of Education.

Thurlow, M., Christenson, S., Sinclair, M., Evelo, D., \& Thronton, H. (1995). Staying in school: Strategies for middle school students with learning \& emotional disabilities. Washington, DC: U.S. Office of Special Education Programs.

Tucker, M. S., \& Codding, J. B. (Eds.). (2002). The principal challenge: Leading and managing schools in an era of accountability. San Fransico, CA: Jossey-Bass.

Urban, W. J., \& Wagoner, J. L. (2009). American education: A history (4th ed.). New York: Routledge.

U.S. Census Bureau (2012). State \& County QuickFacts. Retrieved from http://quickfacts.census.gov/qfd/states/54/54107.html

U.S. Department of Education, Institute of Education Sciences, National Center for Education Statistics (2010). West Virginia State Snapshot, Retrieved May 25, 2011, Retrieved from http://www.eddataexpress.ed.gov/state-report.cfm?state=WV 
U.S. Department of Education, Institute of Education Sciences, National Center for Education Statistics (2011a). The Nation's Report Card: Mathematics 2011. Washington, D.C.: U.S. Department of Education

U.S. Department of Education, Institute of Education Sciences, National Center for Education Statistics (2011b). The Nation's Report Card: Reading 2011. Washington, D.C.: U.S. Department of Education

Wagner, M., Newman, L., Cameto, R., and Levine, P. (2006). The Academic Achievement and Functional Performance of Youth With Disabilities. A Report of Findings from the National Longitudinal Transition Study-2 (NLTS2). Menlo Park, CA: SRI International. Retrieved from http://www.nlts2.org/reports/2006_07/nlts2_report_2006_07_complete.pdf.

Wakeman, S. Y., Browder, D. M., Flowers, C., \& Ahlgrim-Delzell, L. (2006). Principals' knowledge of fundamental and current issues in Special Education. NASSP Bulletin, $90(2), 153-174$.

Warner, R. J. (2009). A comparison of teaching models that promote academic achievement in an inclusive secondary classroom (Doctoral dissertation). Tarleton State University, Stephenville, TX.

Waters, T., Marzano, R. J., \& McNulty, B. (2003). Balanced leadership: What 30 years of research tells us about the effect of leadership on student achievement. Aurora, CO: MidContinent Research for Education and Learning.

Weidenthal, C., \& Kochhar-Bryant, C. (2007). An investigation of transition practices for middle school youth. Career Development for Exceptional Individuals, 30(3), 147-157. 
Welch, D. T. (2009). Leaders who succeed. A case study of leaders' decisions that encourage achievement with Special Education students (Doctoral dissertation). Loyola University Chicago, Chicago, IL.

West Virginia Department of Education (2011a). 2009-2010 NCLB Report Card: West Virginia, Retrieved from http://wveis.k12.wv.us/nclb/pub/rpt0910/rptcardS\%5Ctest2.cfm?sy=10

West Virginia Department of Education (2011b). 2009-2010 NCLB Report Card: Wood County, Retrieved from http:// http://wveis.k12.wv.us/nclb/pub/rpt0910/rptcardC/test2.cfm?sy=10\&cn=096

West Virginia Department of Education Policy 2320: A process for improving education: Performance based accreditation system, § 126-13 (2007).

West Virginia Department of Education Policy 2419: Regulations for the education of students with exceptionalities, § 126-16 (2010).

West Virginia Department of Education Policy 5100: Approval of educational personnel preparation programs, $§ 126-114$ (2009).

Wes Virginia Department of Education Policy 5310: Performance evaluation of school personnel, § 126-142(2006).

West Virginia Department of Education Policy 5500.03: Qualities, proficiencies, and leadership skills for principals, § 126-147 (1997).

Wigle, S. E., \& Wilcox, D. J. (1999). The Special Education competencies of general education administrators. Reading Improvement, 36(1), 4-15.

Witzel, B. S. (2005). Using CRA to teach algebra to students with math difficulties in inclusive settings. Learning Disabilities, 3(2), 49-60. 
Yin, R. K. (2009). Cast study research: Design and methods (4th ed.). Thousand Oaks, CA: Sage Publications.

Yin, R. K. (2012). Applications of case study research (3rd ed.). Thousand Oaks, CA: Sage Publications.

Zaretsky, L., Moreau, L., \& Faircloth, S. (2008). Voices from the field: School leadership in Special Education. Alberta Journal of Educational Research, 54(2), 161-177. 


\section{Appendix A}

\section{LEA Recruiting Cover Letter}

Dear Dr. Patrick Law,

This letter is a request for permission to conduct a research project to describe principals' roles and responsibilities as the instructional leader for students with disabilities. This project is being conducted by Jeremy Lynch, MA in the department of Special Education at WVU under the supervision of Barbara Ludlow, Ed.D., at the College of Human Resources and Education, as a requirement for the degree of doctor of education. Your permission to conduct this research in Wood County Schools in this project is greatly appreciated. The research will include sending a brief (10-minute) questionnaire to all middle school principals in your system. Each principal will be asked to participate in a private, face-to-face interview (approximately 30 minutes) to be scheduled at his or her convenience. Following the interview with the principal, I will ask a Special Education teacher and general education teaching in the same building to participate in a similar private, face-to-face interview (approximately 30 minutes) to be scheduled at his or her convenience. I would like to audio record the interview with their permission. I will be the only person with access to the audio recordings and all recordings will be destroyed once the interview is transcribed.

Involvement in this project will be kept as confidential as legally possible. All data will be reported in the aggregate. I will not ask or report any information that should lead back to you or any participants being identified as a participant. Participation is completely voluntary. West Virginia University's Institutional Review Board acknowledgement of this project is on file. If you agree to allow me to conduct this research in (Name) County Schools please print and sign the attached letter on county letterhead and mail it to:

Jeremy Lynch

RR 4 Box 102

Ridgeley, WV 26753

I hope that you will participate in this research project, as it could be beneficial in understanding how principals serve as instructional leaders for students with disabilities. Thank you very much for your time. Should you have any questions about this letter or the research project, please feel free to contact Jeremy Lynch at (724) 504-6074 or by e-mail at jlynch18@ mix.wvu.edu. You may also contact Dr. Barabara Ludlow at (304) 293- 3835 or by email at barabar.ludlow@mail.wvu.edu.

Thank you for your time and help with this research.

Sincerely,

Jeremy Lynch 


\section{Appendix B}

Superintendent Permission Form

To Whom It May Concern:

As superintendent of Wood County Schools, I am writing to give permission for Jeremy Lynch to conduct his research in Wood County Schools. I understand this study will investigate the principal's role as the instructional leader for students with disabilities and will include interviews with principals and special and general education teachers. I also understand that this study is part of Jeremy's dissertation research for the degree of Educational Doctorate at West Virginia University.

Sincerely,

Superintendent 


\section{Appendix C}

Principal Cover Letter

Dear (Name),

This letter is a request for you to take part in a research project to describe how principals serve as the instructional leader for students with learning disabilities. This project is being conducted by Jeremy Lynch, M.A. in the Department of Special Education at West Virginia University under the supervision of Barbara Ludlow, Ed.D., Professor and Chair of the Department of Special Education at West Virginia University, as a requirement for the degree of doctor of education. Your participation in this project is greatly appreciated. It will take approximately 10 minutes to fill out the attached questionnaire and approximately 30 minutes to participate in a private, face-to-face interview to be scheduled at your convenience. I would like to audio record the interview with your permission. I will be the only person with access to the recording, which will be destroyed after the interview is transcribed.

Your participation is completely voluntary. You may skip any question that you do not wish to answer and you may discontinue at any time. Your job status will not be affected if you decide either not to participate or to withdraw. Your involvement in this project will be kept as confidential as legally possible. I will not ask any information that should lead back to your identity as a participant and all data will be reported in the aggregate. You must be 18 years of age or older to participate. West Virginia University's Institutional Review Board acknowledgement of this project is on file. Your completion and return of the attached questionnaire is considered to reflect your consent to participate in this study. By participating in this study, you will be entered for a chance to win one of three $\$ 50$ gift cards from Amazon.com.

I hope that you will participate in this research project, as it could be beneficial in understanding how principals serve as instructional leaders for students with disabilities. Thank you very much for your time. Should you have any questions about this letter or the research project, please feel free to contact Jeremy Lynch at (724) 504-6074 or by e-mail at jlynch18@ mix.wvu.edu. You may also contact my advisor, Dr. Barbara Ludlow, at (304) 293-3835 or via email at barbara.ludlow@mail.wvu.edu.

Thank you for your time and help with this research.

Sincerely, Jeremy Lynch 


\section{Appendix D}

Principal questionnaire

1. Are you currently certified as a principal in the state of West Virginia? Yes No

2. From what college or university did you receive your principal certification?

3. When did you receive your principal certification?

4. How long have you been working as a principal? How long have you been principal at your current school?

5. What content areas are you certified to teach?

6. What content areas did you teach before transferring to administration?

7. How long did you teach before transferring to administration?

8. Did you have any experience instructing students with learning disabilities? If so, in what context (e.g. co-teaching, self contained, consultative).

9. How many Special Education courses (graduate and undergraduate) have you taken?

10. How many of those Special Education courses were required as part of your undergraduate teacher preparation program?

11. How many of those Special Education courses were required as part of your principal preparation program?

12. How many Special Education courses have you taken on your own (unrelated to a degree or certification)?

13. Are you willing to participate in a private, face-to-face interview? Yes No

14. May I interview educators from your school who work with students with LD in order to gain more information on instructional leadership for students with LD? Yes No

Please email your completed questionnaire to:

Jeremy Lynch at jlynch18@ mix.wvu.edu

I will be in contact with you if you indicated that you would be willing to participate in the interview. If you have any questions, please feel free to contact me at the above email address or by phone at (724) 504-6074. You may also contact my advisor, Dr. Barbara Ludlow, at (304) 293-3835 or via email at barbara.ludlow@mail.wvu.edu

Thank you for your time and consideration.

Sincerely,

Jeremy Lynch 


\section{Appendix E}

Follow up Email

Dear (Principals name),

This email is a reminder that if you wish to participate in a research project about instructional leadership for students with disabilities, please complete and return the attached demographic questionnaire. I have also attached another copy of the cover letter explaining this research. If you have any questions, please feel free to contact at me at this email address of by phone at (724) 504-6074.

Thank you for your time and I hope you will consider participating in this research.

Sincerely,

Jeremy Lynch 


\section{Appendix F}

Interview selection email

Dear (Principals name),

Thank you for agreeing to participate in this research project and completing the principal

questionnaire. You have agreed to an interview to further investigate how principals serve as the instructional leader for students with learning disabilities. The next step in this process is the completion of a face-to-face interview to be scheduled at your convenience. The interview will be in your office and will last approximately 30 minutes.

Please provide me with a list of dates and times you are available within the next two weeks.

Thank you in advance for your participation.

Sincerely,

Jeremy Lynch 


\section{Appendix G}

Educator Cover Letter

Dear (Name),

This letter is a request for you to take part in a research project to describe how principals serve as the instructional leader for students with learning disabilities. This project is being conducted by Jeremy Lynch, M.A. in the Department of Special Education at West Virginia University under the supervision of Barbara Ludlow, Ed.D., Professor and Chair of the Department of Special Education at West Virginia University, as a requirement for the degree of doctor of education. Your participation in this project is greatly appreciated. It will take approximately 10 minutes to fill out the attached questionnaire and approximately 30 minutes to participate in a private, face-to-face interview to be scheduled at your convenience. I would like to audio record the interview with your permission. I will be the only person with access to the recording, which will be destroyed after the interview is transcribed.

Your participation is completely voluntary. You may skip any question that you do not wish to answer and you may discontinue at any time. Your job status will not be affected if you decide either not to participate or to withdraw. Your involvement in this research will be kept as confidential as legally possible. I will not ask any information that should lead back to your identity as a participant and all data will be reported in the aggregate. You must be 18 years of age or older to participate. West Virginia University's Institutional Review Board acknowledgement of this project is on file. Your completion and return of the attached questionnaire is considered to reflect your consent to participate in this study. By participating in this study, you will be entered for a chance to win one of three $\$ 50$ gift cards from Amazon.com.

I hope that you will participate in this research project, as it could be beneficial in understanding how principals serve as instructional leaders for students with disabilities. Thank you very much for your time. Should you have any questions about this letter or the research project, please feel free to contact Jeremy Lynch at (724) 504-6074 or by e-mail at jlynch18@ mix.wvu.edu. You may also contact my advisor, Dr. Barbara Ludlow, at (304) 293-3835 or via email at barbara.ludlow@mail.wvu.edu.

Thank you for your time and help with this research.

Sincerely, Jeremy Lynch 


\section{Appendix $\mathrm{H}$}

Educator Questionnaire

1. Are you currently certified as an educator in WV? Yes No

2. From what college or university did you receive your teaching certification?

3. When did you receive your teaching certification?

4. How many Special Education courses (graduate and undergraduate) have you taken?

5. How many of those Special Education courses were required as part of your undergraduate teacher preparation program?

6. How many Special Education courses have you taken on your own (unrelated to a degree or certification)?

7. How long have you been working as an educator? How long have you been at your current school?

8. Do you work with students with learning disabilities? If so, how many students and in what content areas?

9. Where do you educate students with learning disabilities (e.g. general ed classroom, self-contained, etc.)?

10. What content areas are you certified to teach?

11. Are you willing to participate in a private, face-to-face interview? Yes No

Please mail the completed questionnaire to:

Jeremy Lynch at jlynch18@mix.wvu.edu

I will be in contact with you if you indicated that you would be willing to participate in the interview. If you have any questions, please feel free to contact me at the above email address or by phone at (724) 504-6074. You may also contact my advisor, Dr. Barbara Ludlow, at (304) 293-3835 or via email at barbara.ludlow@mail.wvu.edu

Thank you for your time and consideration.

Sincerely,

Jeremy Lynch 


\section{Appendix I}

Educator follow up email

Dear (Name),

This email is a reminder that if you wish to participate in a research project about instructional leadership for students with learning disabilities, please complete and return the attached demographic questionnaire. I have also attached another copy of the cover letter explaining this research. If you have any questions, please feel free to contact at me at this email address of by phone at (724) 504-6074.

Thank you for your time and I hope you will consider participating in this research.

Sincerely,

Jeremy Lynch 


\section{Appendix J}

Educator interview selection email

Dear (Educators name),

Thank you for agreeing to participate in this research project and completing the principal

questionnaire. You have agreed to an interview to further investigate how principals serve as the instructional leader for students with learning disabilities. The next step in this process is the completion of a face-to-face interview to be scheduled at your convenience. The interview will be in your office and will last approximately 30 minutes.

Please provide me with a list of dates and times you are available within the next two weeks.

Thank you in advance for your participation.

Sincerely,

Jeremy Lynch 


\section{Appendix K}

Principal Interview Protocol

1. Please describe your role as a principal.

a. You mentioned (instruction, etc.) can you tell me more about that? or

b. Tell me about your relationship to instruction.

c. What about your relationship to instruction for students with LD?

2. What is instructional leadership?

3. What is effective instructional leadership for students with LD?

a. What is your role as the instructional leader for students with LD?

b. How do you put that role into practice? What would I see or hear?

4. Tell me how you think we should create supportive learning environments for students with LD.

a. What would I see, hear, or feel in your school?

5. Describe what you think is effective instruction for students with LD.

6. Tell me what your teachers do here. How do your teachers provide instruction for students with LD?

a. I've heard you talk about X. What about how she/he teaches in the classroom. What teaching strategies are used?

b. How do you ensure and monitor the use of those strategies?

7. Where are your students with LD educated?

a. How do you ensure and monitor where the students are educated?

8. How do your teachers accommodate and modify instruction for students with LD?

a. How do you ensure and monitor these accommodations and modifications?

9. What didn't I ask you that I should have asked you? 


\section{Appendix L}

\section{Educator Interview Protocol}

1. Please describe what your principal does in your school.

a. You mentioned (instruction, etc.). Can you tell me more about that? or

b. Tell me about his/her relationship to instruction.

c. What about his/her relationship to instruction for students with LD?

2. What is effective instructional leadership for students with LD?

a. What is your principal's role as the instructional leader for students with LD?

b. How does he/she put that role into practice? What would I see or hear?

3. Tell me how you think we should create supportive learning environments for students with LD.

a. What would I see, hear, or feel in your school?

4. Describe what you think is effective instruction for students with LD.

5. Tell me what you do here. How do you provide instruction for students with LD?

a. I've heard you talk about X. What about how you teach in the classroom. What teaching strategies do you use?

6. Where are your students with LD educated?

7. How do you accommodate and modify instruction for students with LD?

8. What didn't I ask you that I should have asked you? 


\section{Appendix M}

Principal A Word Table

\begin{tabular}{|l|}
\hline DIL- Creating a supportive environment \\
\hline DIL- Differentiated instruction \\
\hline DIL- "whole child" \\
\hline DIL- Data driven decision making \\
\hline CER- Challenging traditional instruction/thinking \\
\hline CER- Creating instructional time \\
\hline CER- Supporting teachers \\
\hline PIL- Attending IEP meetings \\
\hline PIL- Managing Special Education program \\
\hline PIL- Student schedules \\
\hline PIL- Providing teachers with resources \\
\hline MD- Peer interactions \\
\hline MD- Active engagement \\
\hline S- Inclusion \\
\hline S- General education classes \\
\hline S- Pull out \\
\hline S- Inclusion flawed \\
\hline S- Leveling \\
\hline S- SPED teachers with access to students \\
\hline A/M- Individual needs of the student \\
\hline A/M- Meaningful \\
\hline A/M- Problem with standard accom/mod \\
\hline A/M- Half the work \\
\hline A/M- Read tests aloud \\
\hline EEI- Observing teachers \\
\hline EEI- Review lesson plans \\
\hline EEI- Written feedback on lesson plans \\
\hline
\end{tabular}

Note. DIL= Defines Instructional Leadership; $\mathrm{CER}=$ Communicates Educational Role; $\mathrm{PIL}=$ Practice Instructional Leadership;

$\mathrm{MD}=$ Method of Delivery; $\mathrm{S}=$ Setting; $\mathrm{A} / \mathrm{M}=$ Accommodations and Modifications; EEI= Ensures Effective Instruction. 


\section{Appendix N}

Principal B Word Table

\begin{tabular}{|l|}
\hline DIL- Supporting teachers \\
\hline DIL- Advocating for students \\
\hline CER- Changing educators' mindsets \\
\hline CER- Supportive environment for students w/ LD \\
\hline CER- Talks to educators about differentiated instruction \\
\hline CER- Emails to educators \\
\hline PIL- Attending IEP meetings \\
\hline PIL- Managing discipline \\
\hline PIL- Managing Special Education program \\
\hline PIL- Special Education compliance \\
\hline MD- Project-based learning \\
\hline MD- Differentiated instruction \\
\hline MD- Collaborative pairs \\
\hline S- Inclusion \\
\hline S- Pull out \\
\hline S- No leveling \\
\hline A/M- Based on individual needs of the student \\
\hline A/M- Extra time on tests \\
\hline A/M- Read tests aloud \\
\hline A/M- Agenda checks \\
\hline A/M- Notes from teacher \\
\hline A/M- Typed work \\
\hline EEI- Observing teachers \\
\hline EEI- Reviewing lesson plans \\
\hline EEI- Providing written feedback on lesson plans \\
\hline
\end{tabular}

Note. DIL= Defines Instructional Leadership; CER= Communicates Educational Role; PIL= Practice Instructional Leadership; $\mathrm{MD}=$ Method of Delivery; $\mathrm{S}=$ Setting; $\mathrm{A} / \mathrm{M}=$ Accommodations and Modifications; EEI= Ensures Effective Instruction. 


\section{Appendix O}

Principal C Word Table

\begin{tabular}{|l|}
\hline DIL- Active involvement/Modeling \\
\hline DIL- Advocating for students \\
\hline DIL- Setting expectations for teachers \\
\hline DIL- Supporting teachers \\
\hline DIL- Creating a supportive learning environment \\
\hline CER- Communicating with parents \\
\hline CER- Communicating values, beliefs, and goals \\
\hline CER- Ownership in decision making \\
\hline PIL- Attending IEP meetings \\
\hline PIL- Scheduling \\
\hline PIL- Managing Title I funds \\
\hline PIL- Providing technology \\
\hline PIL- Developing a positive behavior supportive system \\
\hline PIL- Hiring dedicated staff \\
\hline MD- Reflecting on instruction \\
\hline MD- Differentiated instruction \\
\hline MD- Willingness to try/Unafraid to fail \\
\hline S- Inclusion \\
\hline S- Pull out \\
\hline A/M- Tailoring instruction to individual students \\
\hline A/M- Collaborative decision making with all stakeholders \\
\hline A/M- "Standard" accommodations/modifications \\
\hline A/M- Problem with "standard" accom/mod \\
\hline A/M- Extra time on tests \\
\hline A/M- Redirects from teacher \\
\hline A/M- Half the work \\
\hline A/M- Positive relationships \\
\hline EEI- AP attends team meetings \\
\hline
\end{tabular}

Note. DIL= Defines Instructional Leadership; CER= Communicates Educational Role; PIL= Practice Instructional Leadership; $\mathrm{MD}=$ Method of Delivery; $\mathrm{S}=$ Setting; $\mathrm{A} / \mathrm{M}=$ Accommodations and Modifications; EEI= Ensures Effective Instruction. 
Appendix P

Development of Themes

Themes and Overarching Themes

Developing a school culture

Creating a learning environment

Supporting their educators

Changing educators' mindsets

Being an advocate

Managing the Special Education program

Attending IEP meetings

Scheduling

Creating instructional support time

Managing discipline

Managing Funds

Providing resources

Effective instruction is...

Differentiated instruction

Students working together

Active engagement

Reflecting on instruction

Effective instruction is not...

Teaching to the middle

Reaching the last page in the textbook

Where students with disabilities are educated

The inclusive classroom

Pull out classrooms

Heterogeneous or Homogeneous Grouping?

\section{Accommodating and modifying instruction}

Focus on the individual student

The standard stuff

\section{Checks and balances}

Observing teachers

Reviewing lesson plans
Case A

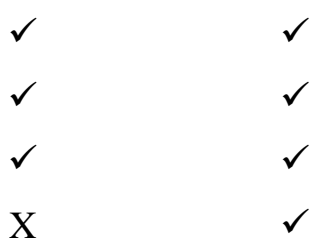

Case B

Case C

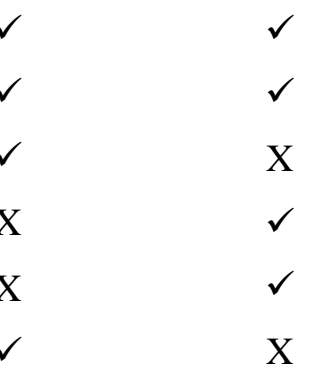

$\begin{array}{ll}\checkmark & \checkmark \\ \checkmark & \checkmark \\ \checkmark & \checkmark \\ \checkmark & \mathrm{X}\end{array}$

X

X

$\checkmark$

$\begin{array}{ll}\checkmark & \checkmark \\ \checkmark & \mathrm{X}\end{array}$

X
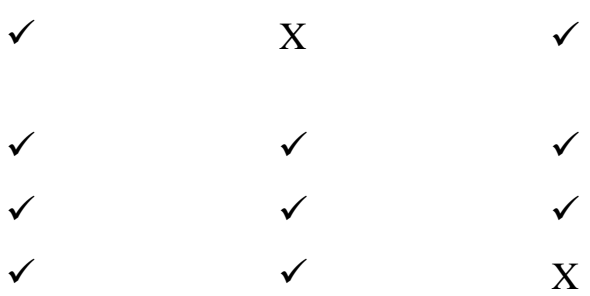

$\checkmark$

X
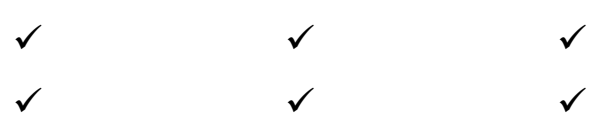

X

X

Note. $\checkmark$ means at least one principal from that case provided a response that contributed to the subtheme; X means that no principal from that case provided a response that contributed to the subtheme; AsstPrin $=$ Assistant Principal. 